Portland State University

PDXScholar

Civil and Environmental Engineering Master's

Project Reports

Summer 2018

\title{
Non-Linear Deformation Analysis of an Embankment Dam
}

Silas T. Sanderson

Portland State University

Follow this and additional works at: https://pdxscholar.library.pdx.edu/cengin_gradprojects

Part of the Structural Engineering Commons

Let us know how access to this document benefits you.

\section{Recommended Citation}

Sanderson, Silas T., "Non-Linear Deformation Analysis of an Embankment Dam" (2018). Civil and Environmental Engineering Master's Project Reports. 41.

https://doi.org/10.15760/CCEMP.40

This Project is brought to you for free and open access. It has been accepted for inclusion in Civil and Environmental Engineering Master's Project Reports by an authorized administrator of PDXScholar. Please contact us if we can make this document more accessible: pdxscholar@pdx.edu. 


\section{MASTER OF SCIENCE \\ IN \\ CIVIL AND ENVIRONMENTAL ENGINEERING}

Project Advisor:

Dr. Arash Khosravifar, Ph.D., P.E.

Portland State University

(C)2018 


\section{ACKNOWLEDGMENTS}

First and foremost, I would like to thank Dr. Arash Khosravifar for his guidance, expertise, and commitment in my pursuit of this project. I could not have completed this project without him and I am grateful for all the support he has given me over the years. I would also like to thank the PSU Civil Engineering staff including Dr. Diane Moug and Megan Falcone for their time and assistance navigating the technical and administrative challenges while I was pursuing my degree.

To the U.S. Army Corps of Engineers - Portland District for their support in pursuit of this project and my degree. I would especially like to thank Dr. Jeremy Britton for making the commitment to my professional development and for giving me the opportunity to realize my vision.

To my family, friends, and colleagues for their encouragement, advice, and timely distractions from the grind. And to Deanna Dsouza for having the confidence in me to complete this degree and for her intangible support throughout the years. 


\begin{abstract}
Non-linear deformation analysis (NDA) of embankment dams is becoming more common as geotechnical engineers seek to better understand how critical infrastructure will perform under high seismic loading. In order to perform this type of analysis, site specific ground motions and engineering properties of the embankment dam are required. The NDA modeling effort consists of a static and seepage analysis to establish an initial stress state followed by a dynamic analysis to simulate the embankment response to ground motions. Using this approach, a two dimensional NDA was performed on an embankment dam using the NDA program FLAC. This report discusses the input parameters, modeling efforts, and results of the analysis.
\end{abstract}




\section{TABLE OF CONTENTS}

$1.0 \quad$ INTRODUCTION .................................................................................................................................

$1.1 \quad$ PURPOSE AND SCOPE ...................................................................................................................

$2.0 \quad$ GROUND MOTIONS DEVELOPMENT .............................................................................................

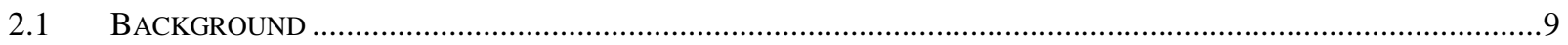

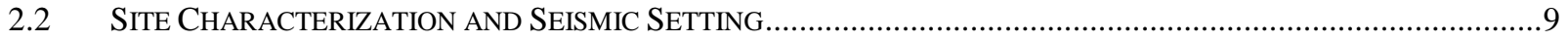

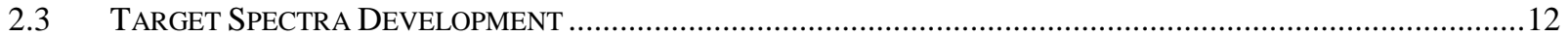

2.4 GROUND MOTION SELECTION AND SCALING...................................................................................13

STATIC AND DYNAMIC EMBANKMENT PARAMETERS ........................................................26

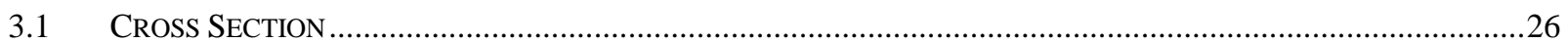

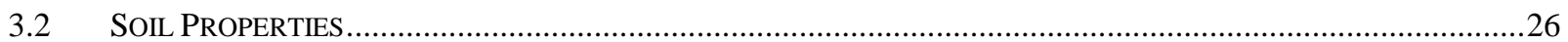

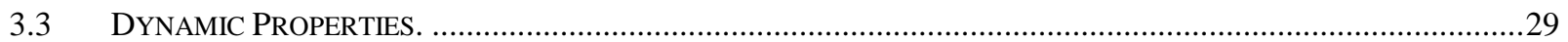

4.0 NON-LINEAR DEFORMATION ANALYSIS ................................................................................35

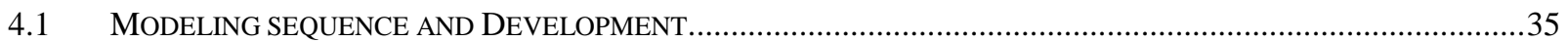

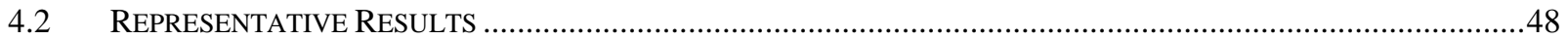

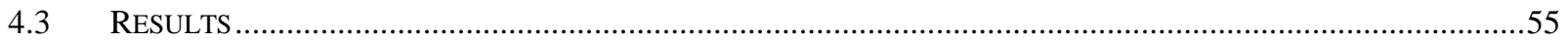

5.0 CONCLUSIONS AND OBSERVATIONS.......................................................................................60

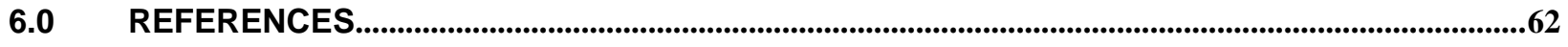

7.0 APPENDIX - FLAC CODE...........................................................................................................64 


\section{LIST OF TABLES}

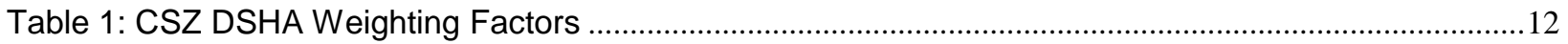

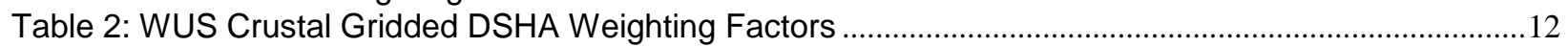

Table 3: Deaggregation of Seismic Hazard at Project Site (USGS 2008) ….............................................14

Table 4: Source Characteristics, Summary of Selected Ground Motion Records, and Scaling Factors .....14

Table 5: Deterministic Hazard Spectra, Site Class C/D (5\% Damping) ...........................................................15

Table 6: Static Strength Soil Parameters - Design and Field Records ........................................................28

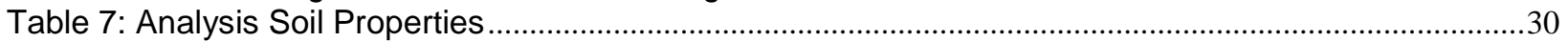

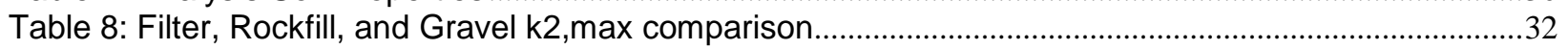

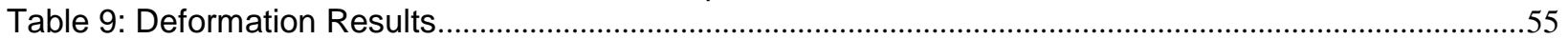

Table 10: Input and Crest PGAs, and Amplification Factors ...................................................................... 


\section{LIST OF FIGURES}

Figure 1: Embankment Foundation Geology, Sta. 10+50 to 21+00 …................................................. 16

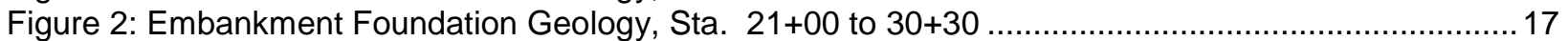

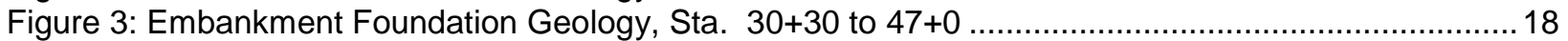

Figure 4: Mean Hazard Curves for PGA (USGS 2008 and 2014), and CSZ (median $+\sigma$ ) and WUS Crustal

Gridded (median $+\sigma)$ Deterministic PGA for Site Class B/C (Vs=760 m/s), 5\% Damping......... 19

Figure 5: CSZ (median $+\sigma$ ) and WUS Crustal Gridded (median $+\sigma$ ) Deterministic Target Spectra for Site Class B/C (Vs=760 m/s), 5\% Damping (50\% in 100 Years and 10\% in 100 Years Uniform Hazard Spectra (USGS 2008 and 2014) provided for comparison)........................................20

Figure 6: Deaggregation of Hazard by Magnitude and Distance at PGA 50\% in 100 Years (144-Year Return Period)

Deaggregation of Hazard by Magnitude and Distance at PGA 10\% in 100 Years (949-Year

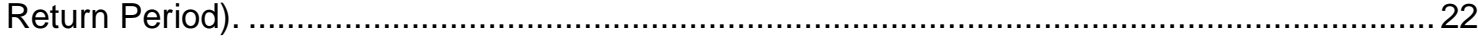

Figure 7: Deaggregation 21

Figure 8: Deaggregation of Hazard by Magnitude and Distance at PGA 2\% in 50 Years (2475-Year Return Period) 23

Figure 9: Comparison of Selected Ground Motions Records (Scaled) and geomean with the Deterministic Target CSZ (median $+\sigma$ ) Spectrum, 5\% Damping. 24

Figure 10: Comparison of Selected Ground Motions Record (Scaled) with the Deterministic Target WUS

Crustal Gridded (median $+\sigma$ ) Spectrum, 5\% Damping …................................................ 25

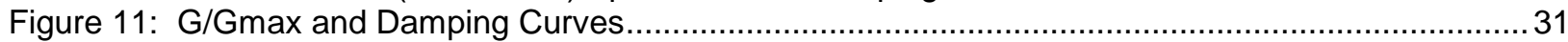

Figure 12: Gravel, Rockfill, and Filter Shear wave velocity profile - k2,max comparison ................................. 33

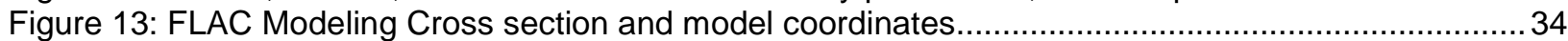

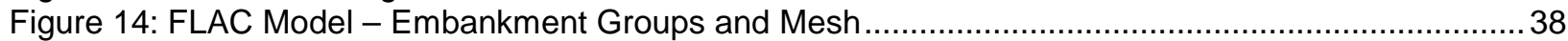

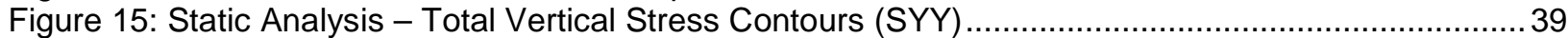

Figure 16: Static Analysis - Total Horizontal Stress Contours (SXX) .............................................. 40

Figure 17: Seepage Analysis - Phreatic Surface (blue line) and Pore Pressure Contours ......................41

Figure 18: Seepage Analysis - Effective Vertical Stress Contours (ESYY) .........................................4 42

Figure 19: Seepage Analysis - Effective Horizontal Stress Contours (ESXX) .................................... 43

Figure 20: Maximum Shear Strain Increment pre Dynamic Loading (SSI) ........................................ 44

Figure 21: Mean Effective Stress Dependent Gmax .................................................................... 45

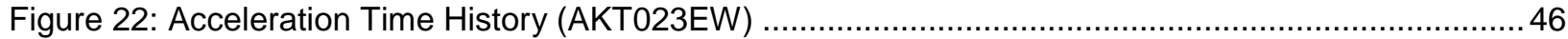

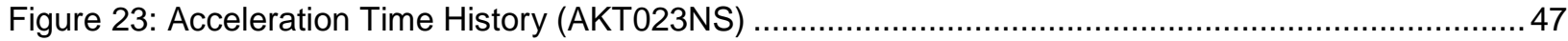

Figure 22: Dynamic Analysis - Vertical Displacement Contours (AKT023EW) ....................................49

Figure 23: Dynamic Analysis - Horizontal Displacement Contours (AKT023EW) .....................................50

Figure 24: Dynamic Analysis - Displacement Contours (AKT023EW) …...........................................51

Figure 25: Dynamic Analysis - Maximum Shear Strain Increment at end of Dynamic Loading (SSI)

(AKT023EW) .52

Figure 26: Dynamic Analysis - Crest and Top of Bedrock Vertical Displacement History (AKT023EW)... 53

Figure 27: Dynamic Analysis - Exaggerated Deformed Mesh (AKT023EW) .......................................5 54

Figure 30: Relative Horizontal Crest Displacement (ft) versus Time (s) for AKT023EW and AKT023NW 56

Figure 31: Vertical Crest Displacement (ft) versus Time (s) for AKT023EW and AKT023NW..................56

Figure 32: Vertical Crest Deformation Comparison - Swaisgood (2014) and FLAC vs PGA (g) ..............57

Figure 33: PGA vs Amplification Factor at Crest - Yu et al. 2012 and FLAC results ..............................58

Figure 34: Crustal Source Response Spectra - Input Outcrop Motion (dashed) and Top of Crest (solid) 58

Figure 35: Crustal Source Amplification Factors - Input Outcrop Motion relative to Top of Crest .............59 


\subsection{INTRODUCTION}

\subsection{Purpose and Scope}

The effects of strong ground motions from earthquakes on embankment dams has varied from little visible damage to failure. In the context of seismic performance of embankment dams, failure in this report is defined as breach of the embankment and loss of the reservoir either due to internal erosion or deformations at the crest that exceeds the available freeboard. Generally, embankment dams have performed well during seismic events (Foster et. al, 2000). The recent Tohoku earthquake (Mw 9, 2011) further affirmed this assertion. Over 400 dams experienced "severe" ground motions and only one irrigation dam failed (Matsumoto et. al, 2011). In the United States., a notable dam safety incident occurred at the Lower San Fernando Dam in 1971. Strong ground motions from a magnitude 6.5 earthquake caused the embankment to significantly deform. While the embankment did not breach, only a small remnant of it remained to retain the pool. Arguably, this incident served as a catalyst to the geotechnical engineering community to better understand and predict the effects of strong ground motions from earthquakes on embankment dams.

Many dams in the Pacific Northwest were built during an era that did not fully recognize the seismic hazard presented by the Cascadia Subduction Zone (CSZ) or crustal sources. Overtime, the understanding of the seismic hazards in the region has changed. Fortunately, the analysis methods and techniques used to better understand embankment behavior from seismic loading have evolved and improved. These include empirical correlations (Swaisgood, 2003, 2014), pseudo-static analysis (HynesGriffin and Franklin, 1984), Newmark sliding block analysis (Newmark, 1965, Makdisi and Seed 1978, and Bray, Macedo, and Travasarou, 2018), 2-D equivalent linear analyses (ELA) (QUAD4), and more advanced non-linear deformation analysis (NDA) methods using programs such as FLAC (Itasca, 2008). These more advanced methods are becoming more common as engineers seek to better understand how critical infrastructure will perform under high seismic loading. Programs such as Fast Lagrangian Analysis of Continua (FLAC) use finite difference techniques to numerically model complex soil behaviors experienced by an embankment during seismic loading. The embankment is modeled with elements and each element is assigned its own properties and a constitutive model to define its stress/strain behavior. While this method is more complicated, the biggest advantage is that an estimate of the deformation 
magnitude and patterns of movement can be obtained, and a more realistic (non-linear) soil behavior can be modeled.

The purpose of this study was to conduct a non-linear deformation analysis of an embankment dam subject to seismic loading using the program FLAC and to document the steps required to perform a NDA so that others may use this report as a roadmap. The objective of the analysis is to estimate the maximum relative crest movements and to observe the patterns of deformation. Below are the general steps required to perform a NDA on an embankment dam and the section of the report where they are discussed.

\begin{tabular}{|c|c|}
\hline Task & Objective \\
\hline \multicolumn{2}{|r|}{ Section 2 - Development of Ground Motions } \\
\hline Design Earthquakes & $\begin{array}{l}\text { Determine design or analysis criteria for target ground motions (e.g. OBE, } \\
\text { MCE, MDE). }\end{array}$ \\
\hline $\begin{array}{l}\text { Site Characterization and } \\
\text { Seismic Setting }\end{array}$ & $\begin{array}{l}\text { Describe seismic setting of the project site, examine foundation conditions } \\
\text { and determine site class. }\end{array}$ \\
\hline $\begin{array}{l}\text { Seismic Hazard } \\
\text { Evaluation }\end{array}$ & $\begin{array}{l}\text { Conduct seismic hazard deaggregation to determine dominant seismic } \\
\text { sources and characteristics. }\end{array}$ \\
\hline $\begin{array}{l}\text { Target Spectra } \\
\text { Development }\end{array}$ & $\begin{array}{l}\text { Develop design or analysis target spectra using a deterministic seismic } \\
\text { hazard analysis (DSHA) or probabilistic seismic hazard analysis (PSHA) in } \\
\text { accordance with the design or analysis criteria. }\end{array}$ \\
\hline $\begin{array}{l}\text { Ground Motion Selection } \\
\text { and Scaling }\end{array}$ & $\begin{array}{l}\text { Select representative ground motions. Scale or match ground motions to } \\
\text { target spectra. }\end{array}$ \\
\hline \multicolumn{2}{|c|}{ Section 3 - Static and Dynamic Embankment } \\
\hline Analysis Cross Section & $\begin{array}{l}\text { Select analysis cross section and determine embankment zones requiring } \\
\text { soil parameters }\end{array}$ \\
\hline Soil Properties & $\begin{array}{l}\text { Select constitutive model(s) and determine required soil properties for each } \\
\text { embankment zone including, but not exclusively, unit weight (saturated and } \\
\text { dry), permeability, strength parameters, small strain shear modulus } \\
\text { (Gmax), Poisson's ratio, G/Gmax damping curves. }\end{array}$ \\
\hline \multicolumn{2}{|r|}{ Section 4 - Non-linear Deformation Analysis } \\
\hline Grid Generation & $\begin{array}{l}\text { Select appropriate element height and generate an efficient and } \\
\text { representative grid for model based on the selected analysis cross section. }\end{array}$ \\
\hline Initial Stress State & $\begin{array}{l}\text { Establish initial stress state for dynamic loading by incrementally "building" } \\
\text { the embankment and conducting a seepage analysis to establish pore } \\
\text { pressure distribution. }\end{array}$ \\
\hline Dynamic Analysis & $\begin{array}{l}\text { Run selected scaled or matched time histories through model, tracking } \\
\text { important parameters or response through time. }\end{array}$ \\
\hline Results & $\begin{array}{l}\text { Document and validate results of analysis, parametric studies, and } \\
\text { constitutive model calibration. }\end{array}$ \\
\hline
\end{tabular}




\subsection{GROUND MOTIONS DEVELOPMENT}

\subsection{Background}

The project site for this study is located in the Western Cascade subprovince of the Cascade Range. The embankment at the project site is a 347-foot-high zoned, rockfill embankment structure with a gated spillway.

\section{Design Earthquakes and Ground Motions}

The design and evaluation of civil works structures consists of the Operating Basis Earthquake (OBE), the Maximum Design Earthquake (MDE), and the Maximum Credible Earthquake (MCE). The OBE is an earthquake that can be reasonably expected to occur within the service life of the project and is defined as having a $50 \%$ chance of occurrence in a 100 year return period. It is evaluated using a probabilistic seismic hazard assessment (PSHA). The performance requirement is that the project function with little or no damage and without interruption of function. The MCE is the largest earthquake that can be expected at the site and is evaluated using a deterministic seismic hazard analysis (DSHA) taken at the median plus one standard deviation (84 $4^{\text {th }}$ percentile) level. A PSHA informs the return period of the MCE. The MDE is the maximum earthquake for which the structure is evaluated. For critical, high hazard potential structures, the MDE is equivalent to the MCE and the performance objective is that the structure does not lead to catastrophic failure. Given the low $(<0.1 \mathrm{~g})$ anticipated ground motions at the OBE, only the MCE will be analyzed.

\subsection{Site Characterization and Seismic Setting}

The dam is within the area influenced by the Cascadia Subduction Zone (CSZ) of the Pacific Northwest and the highly active area of Cape Mendocino, California. The Cascadia Subduction Zone is part of the worldwide system of active faults that subdivides the earth's crust into large moving plates. The Cape Mendocino area is a triple junction of three seismically active components (Cascadia Subduction zone, San Andreas Fault, and Mendocino Transform Fault). The CSZ is an 800 mile long fault extending from Cape Mendocino, California north to Vancouver Island, Canada. It defines the area where the offshore oceanic plate (Juan De Fuca Plate) is diving down (subducting) beneath the North American Continental Plate. Within the zone, three types of earthquake sources dominate the seismic 
hazard at this site. The first source area is along the interface between the subducting oceanic plate and the overriding continental plate. In this area, mega-thrust earthquakes with a magnitude $(\mathrm{Mw})$ between 8.5 and 9.2 are believed to have occurred about once every 450 to 550 years. The second source zone results from the downward moving ocean crustal slab bending and breaking up generating Mw 5 to about 7.5 earthquakes. These earthquakes are generally quite deep with focal depths of 25 miles or more. Deep intraplate earthquakes are smaller in size but occur more frequently than the mega-thrust events. The third source zone is the typical shallow crustal earthquakes magnitudes $<1$ to about 7 .

\section{Site Geology and Foundation:}

Rock units in the area of the reservoir fall into two main groups, the Western Cascades and the High Cascades. Overburden in the dam site area consists of alluvium, slopewash, and pumice deposits. Most of the overburden, under the main embankment, was removed and the dam foundation consists of basalt flows and tuffs of the Little Butte Volcanic Series. All of the right abutment area was stripped to rock except for a gravel zone that is similar to the pit run gravel embankment and was left in place between Stations $A 24+50$ to $A 26+75$. Between Stations $A 13+50$ to $A 14+90$ and $A 15+75$ to $A 17+00$, $a$ trench for the impervious core and minus 3-inch gravel zones were excavated approximately 15 feet into a soft to moderately hard tuff. Originally, the left embankment intracanyon basalt flow, or caprock, was to be left in place and used as the foundation. However, deficiencies in the caprock exposed during cleanup of the foundation necessitated its removal from the dam foundation. The caprock is underlaid by a buried terrace of fluvioglacial gravels. This older alluvial interbed consists of poorly graded sandy gravel, cobbles and boulders with minor silt, and is 100 feet thick in a former buried channel near the present channel and averages about 60 feet in depth. A cutoff trench was excavated through the gravel unit, down to bedrock, so that the impermeable zone could extend down to bedrock through the gravel.

\section{Site Classification:}

There is no geophysical or in-situ data (SPT, Vs30, etc) available to determine a site class. The main dam is founded on Basalt Flows and Tuffs (Figure 1 through Figure 3). A site class was inferred by comparing the geologic conditions of the site to a database of published reference sites. The database contains shallow seismic site characterization data, including Vs data and associated geologic conditions, 
from 25 reference sites in Washington and Oregon. Where Tuff or Basalt was noted as likely underlying the references sites, the Vs profiles were examined. At the depths where bedrock was likely encountered, Vs values ranged from 640 to $1600 \mathrm{~m} / \mathrm{s}$. Therefore, Site Class B/C (Vs30 $=760 \mathrm{~m} / \mathrm{s})$ was selected for the site.

\section{Seismic Hazard Evaluation:}

An initial evaluation of the seismic hazard utilized the 2008 and 2014 U.S. Geologic Survey (USGS) PSHA data. The PSHA provides spectral acceleration estimates at a bedrock site (Site Class $\mathrm{B} / \mathrm{C} ; \mathrm{Vs} 30=760 \mathrm{~m} / \mathrm{s}$ ) for varying return periods. At this site, the 2008 and 2014 PGA data are nearly identical and are plotted in Figure 4.

\section{Deaggregation:}

Graphical deaggregation of the hazard at the 144, 950, and 2475 Year Return periods are shown in Figure 6 through Figure 8 for the PGA. Table 3 illustrates the relative contributions, Mw, distance, and $\varepsilon$ values of seismic sources for four return periods (144, 950, 2,475 and 9,950 Years). Cumulative Cascadia is the dominant source at all design criteria levels followed by random WUS Crustal Gridded. As the table indicates, $84^{\text {th }}$ percentile CSZ ground motions have a return period between 2,500 and 10,000 years.

\section{Source Characteristics:}

Sources characteristics were developed from the deaggregation data. For the CSZ ground motions, a 9.0 magnitude (Mw) was assumed at a distance of $105 \mathrm{~km}$. The PSHA data (USGS 2008) was used to estimate the return period of a median plus one standard deviation (84 $4^{\text {th }}$ percentile) CSZ earthquake and was determined to be slightly less frequent than a 2475 Return Period (Figure 4). Therefore, a rupture distance that was slightly closer than the 2475 Return Period deaggregation was selected. The focal or hypo-central depth was estimated to be $25 \mathrm{~km}$ based on the data presented in Juan de Fuca slab geometry and its relation to Wadati-Benioff zone seismicity (McCrory, 2012). The WUS Crustal Gridded source characteristics were assumed to be equal to the maximum Mw and minimum distance found in deaggregation data. This resulted in a $6.31 \mathrm{Mw}$ at a distance of $13.2 \mathrm{~km}$. 


\subsection{Target Spectra Development}

For the purposes of this project, only the MCE target spectra was developed. The MCE was developed using a DSHA taken at the median plus one standard deviation (84 $4^{\text {th }}$ percentile) level. Target spectra were developed for the domination seismic sources, CSZ and WUS Crustal Gridded. The MCE design spectra for a CSZ Interface Event was develop using four established Ground Motion Prediction Equations (GMPEs) and were weighted as shown in Table 1. These weights are the same as was used in the USGS2014 source model.

Table 1: CSZ DSHA Weighting Factors

\begin{tabular}{|c|c|}
\hline GMPE & Weight \\
\hline Atkinson and Boore, 2003 & 0.1 \\
\hline Zhao, 2006 & 0.3 \\
\hline BC Hydro, 2016 & 0.3 \\
\hline Atkinson and Macias, 2009 & 0.3 \\
\hline
\end{tabular}

Target spectra for the less dominant, WUS Crustal gridded source was developed using the PEER Weighted Average of 2014 NGA West-2 GMPE spreadsheet. The GMPEs were weighted as shown in Table 2.

Table 2: WUS Crustal Gridded DSHA Weighting Factors

\begin{tabular}{|c|c|}
\hline GMPE & Weight \\
\hline ASK14 & 0.22 \\
\hline BSSA14 & 0.22 \\
\hline CB14 & 0.22 \\
\hline CY14 & 0.22 \\
\hline I14 & 0.12 \\
\hline
\end{tabular}

The target spectra for each dominant seismic source are shown in Table 5. 


\subsection{Ground Motion Selection and Scaling}

A total of 5 ground motions records, 4 for the CSZ and 1 for the WUS Crustal Gridded ground motions, were selected for matching and scaling. Selection criteria considered rupture distance, Vs of the site, and spectral shape relative the target spectrum. The ground motion records selected for the target spectra are shown in Table 4. The selected ground motions were then scaled to match the target spectra with a priority given to matching the PGA, and the periods from 0.5 to 1.5 seconds, which is the estimated range of natural period of the embankment. The target spectra, scaled ground motions, and geomean of scaled ground motions are shown in Figure 9 and Figure 10. 
Table 3: Deaggregation of Seismic Hazard at Project Site (USGS 2008)

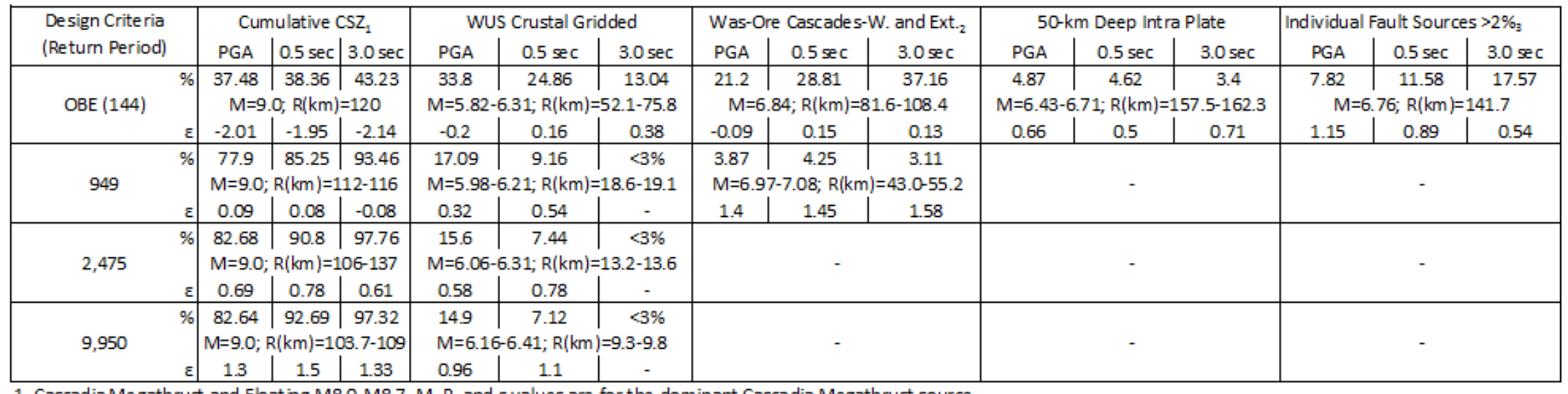

1. Cascadia Megathrust and Floating M8.0-M8.7. M, R, and $\varepsilon$ values are for the dominant Cascadia Megathrust source

2. Wash-Oreg Cascades-West and Extensional Faults. M, R, and $\varepsilon$ values are for the dominant Cascades-West source

3. Klam ath Graben, Sky Lakem Whaleshead, and Cape Blanco Anticline. M, R, and $\varepsilon$ values are for the dominant Whaleshead source

4. MCE Design Level estimated return pe riod between 2500 and 10000 Years.

Table 4: Source Characteristics, Summary of Selected Ground Motion Records, and Scaling Factors

\begin{tabular}{|c|c|c|c|c|c|c|c|c|c|c|}
\hline \multicolumn{2}{|c|}{ Source to Match } & Earthquake & Year & $\mathrm{Mw}$ & Station & Component & Fault Mechanism & Epi. Distance, km & $\mathrm{Vs} 30, \mathrm{~m} / \mathrm{s}$ & Scale Factor \\
\hline \multicolumn{2}{|r|}{$\overline{c \text { CSZ }}$} & Tohoku & 2011 & 9 & TAJIRI-MYGH06 & 90 & Subduction - Interface & 117.2 & 593 & 1.1 \\
\hline M & 9 & Tohoku & 2011 & 9 & SHIZUGAWA-MYGH12 & 360 & Subduction - Interface & 88.3 & 748 & 0.75 \\
\hline \multirow[t]{2}{*}{$\mathrm{R}, \mathrm{km}$} & 105 & Maule & 2010 & 8.8 & HUALANE-HUA & $\mathrm{T}$ & Subduction - Interface & 136 & 528 & 0.7 \\
\hline & & Maule & 2010 & 8.8 & CURICO-CUR & NS & Subduction - Interface & 170.5 & $592-710$ & 0.9 \\
\hline \multicolumn{2}{|c|}{ WUS Crustal Gridded } & \multirow{2}{*}{ Iwate - Japan } & \multirow{2}{*}{2008} & \multirow{2}{*}{6.9} & \multirow{2}{*}{ АКT023 } & EW & \multirow{2}{*}{ Reverse } & \multirow{2}{*}{11.68} & \multirow{2}{*}{556} & 0.78 \\
\hline $\mathrm{M}$ & $\begin{array}{lll}6.31 & \mathrm{R}, \mathrm{km} & 13.2\end{array}$ & & & & & NS & & & & 0.78 \\
\hline
\end{tabular}


Table 5: Deterministic Hazard Spectra, Site Class C/D (5\% Damping)

\begin{tabular}{|c|c|c|}
\hline $\mathbf{T}(\mathrm{s})$ & $\begin{array}{c}\text { CSZ (med +o) } \\
\text { Sa (g) }\end{array}$ & $\begin{array}{c}\text { Gridded }(\text { med }+\sigma) \\
\mathrm{Sa}(\mathrm{g})\end{array}$ \\
\hline 0.01 & 0.329 & 0.299 \\
\hline 0.02 & 0.346 & 0.306 \\
\hline 0.03 & 0.362 & 0.341 \\
\hline 0.05 & 0.384 & 0.439 \\
\hline 0.075 & 0.492 & 0.574 \\
\hline 0.1 & 0.592 & 0.660 \\
\hline 0.15 & 0.666 & 0.737 \\
\hline 0.2 & 0.668 & 0.710 \\
\hline 0.25 & 0.642 & 0.639 \\
\hline 0.3 & 0.620 & 0.572 \\
\hline 0.4 & 0.589 & 0.465 \\
\hline 0.5 & 0.538 & 0.385 \\
\hline 0.75 & 0.449 & 0.255 \\
\hline 1 & 0.391 & 0.183 \\
\hline 1.5 & 0.305 & 0.106 \\
\hline 2 & 0.245 & 0.071 \\
\hline 3 & 0.173 & 0.039 \\
\hline 4 & 0.130 & 0.025 \\
\hline 5 & 0.104 & 0.017 \\
\hline 7.5 & 0.069 & 0.008 \\
\hline 10 & 0.052 & 0.005 \\
\hline
\end{tabular}




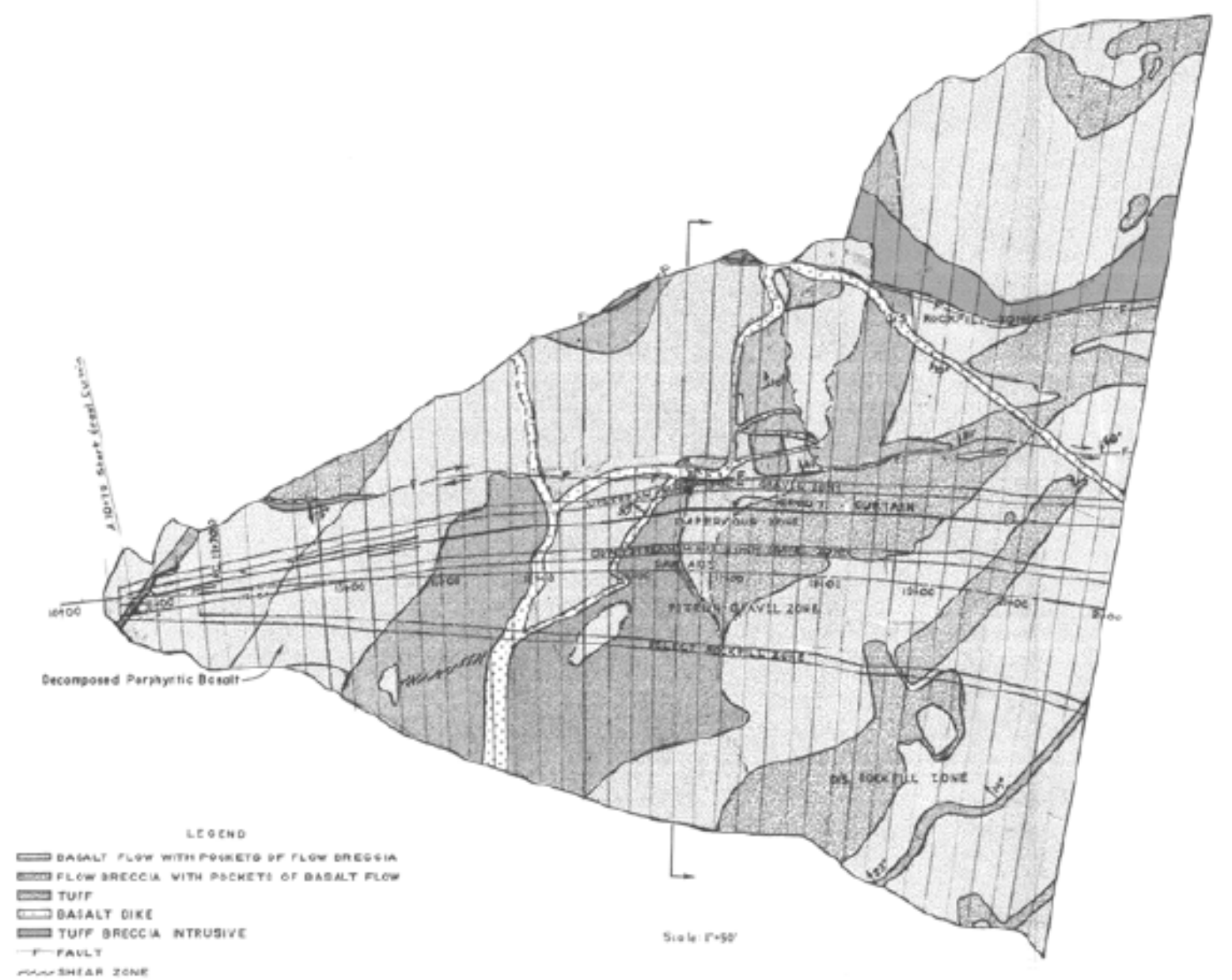

Figure 1: Embankment Foundation Geology, Sta. 10+50 to 21+00 


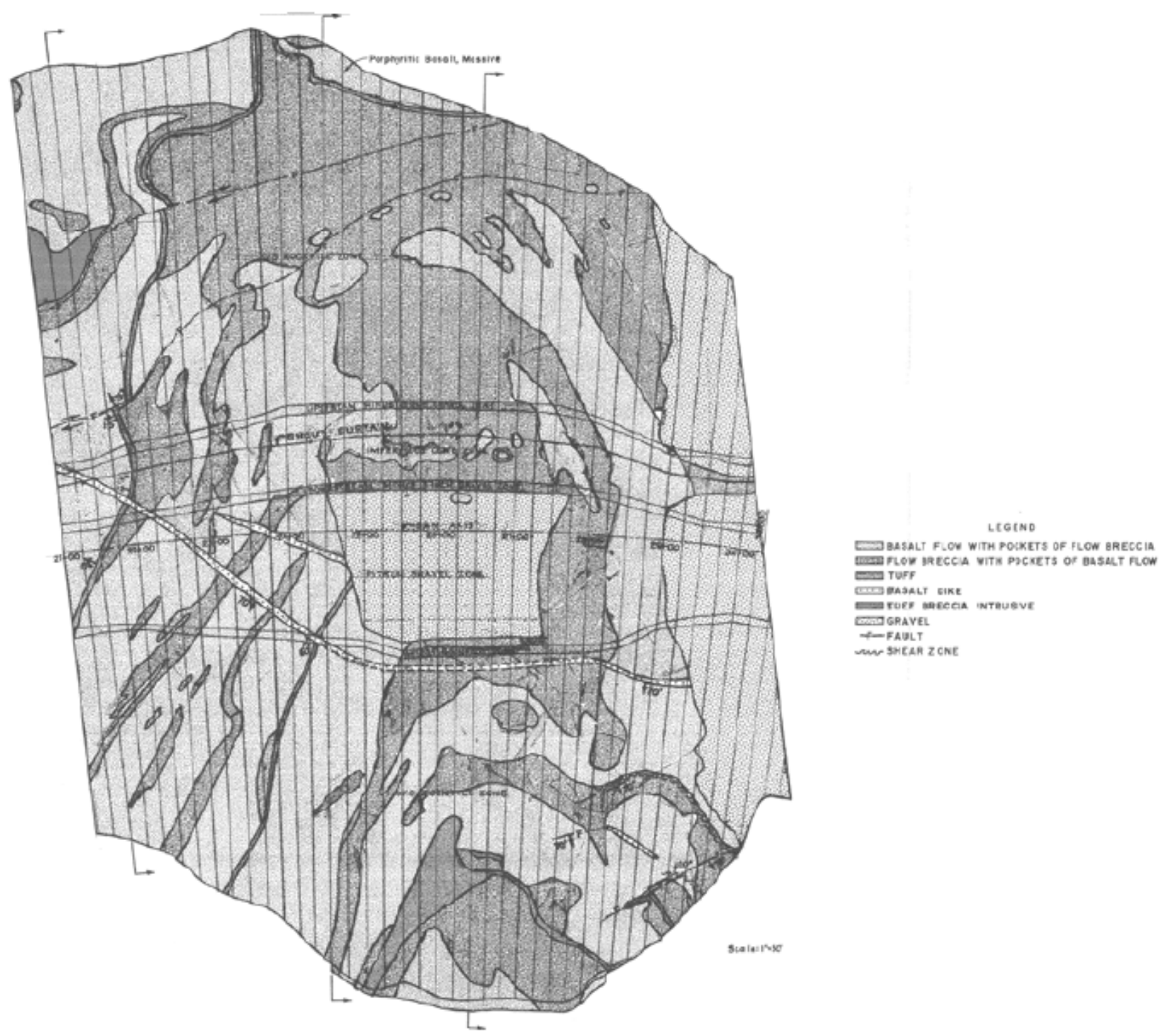

Figure 2: Embankment Foundation Geology, Sta. $21+00$ to $30+30$ 


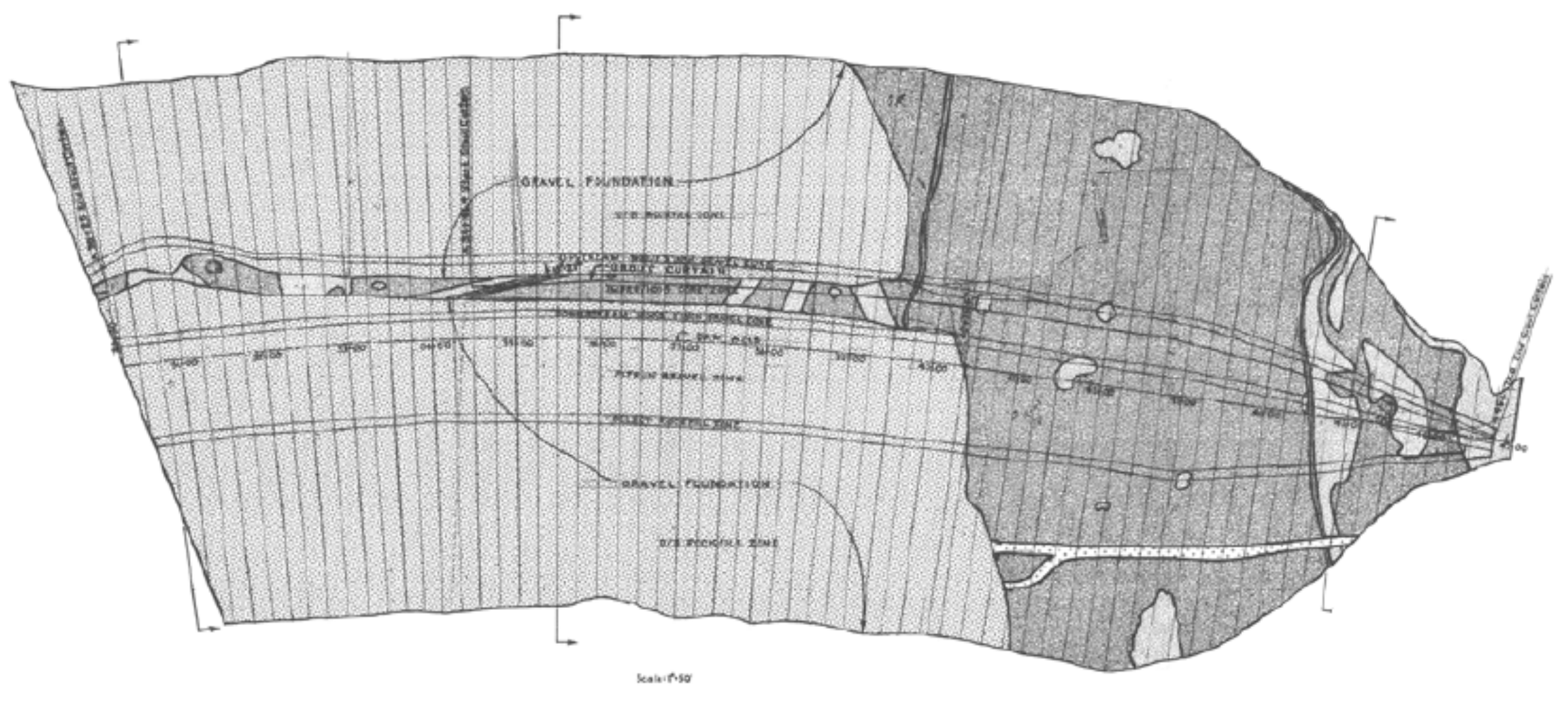

Leotho

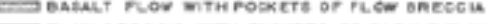

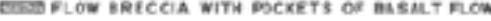

DII TUFF

EOS BRAVEL

Figure 3: Embankment Foundation Geology, Sta. $30+30$ to $47+0$ 


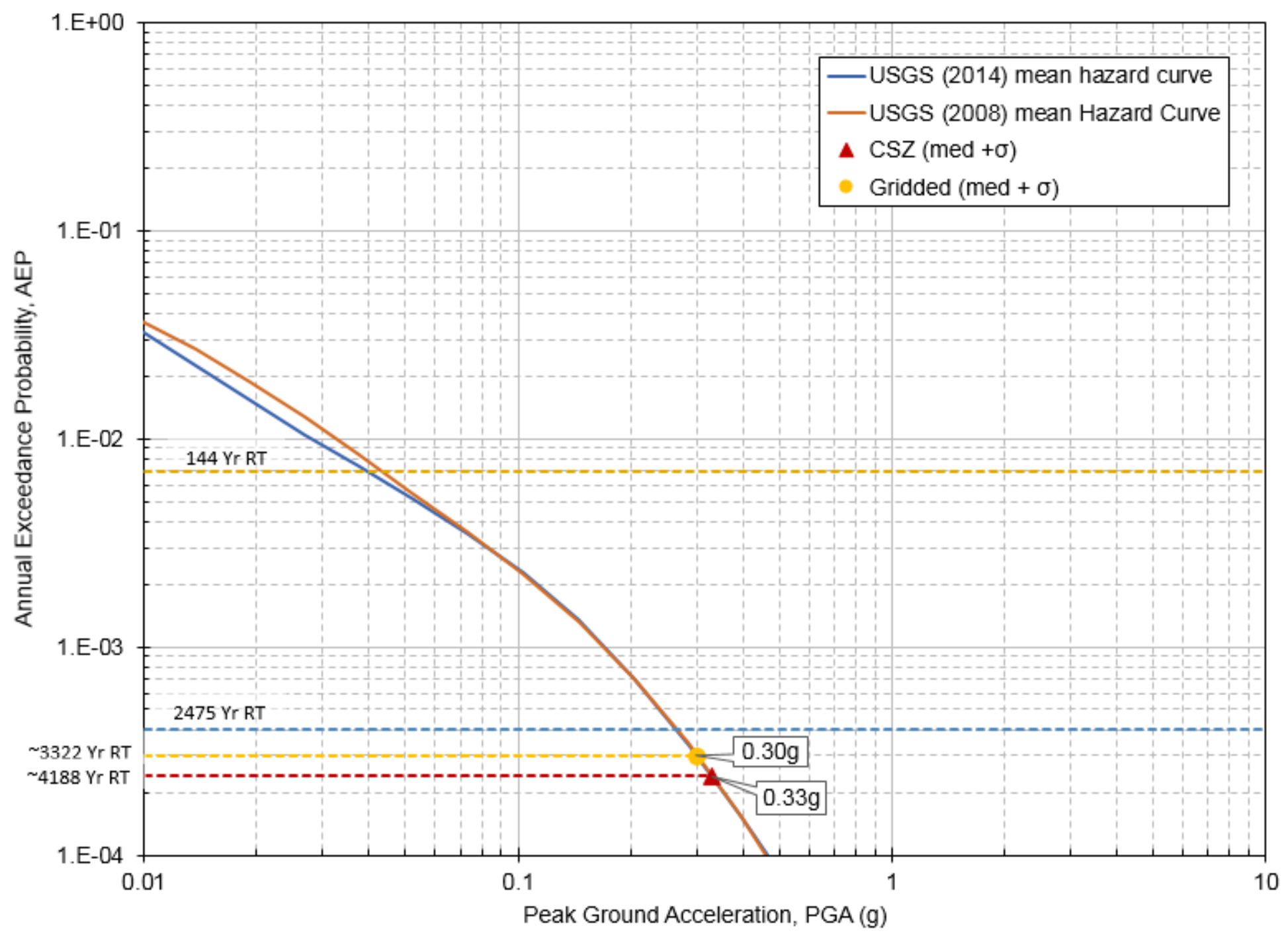

Figure 4: Mean Hazard Curves for PGA (USGS 2008 and 2014), and CSZ (median $+\sigma$ ) and WUS Crustal Gridded (median $+\sigma$ ) Deterministic PGA for Site Class B/C (Vs=760 m/s), 5\% Damping. 


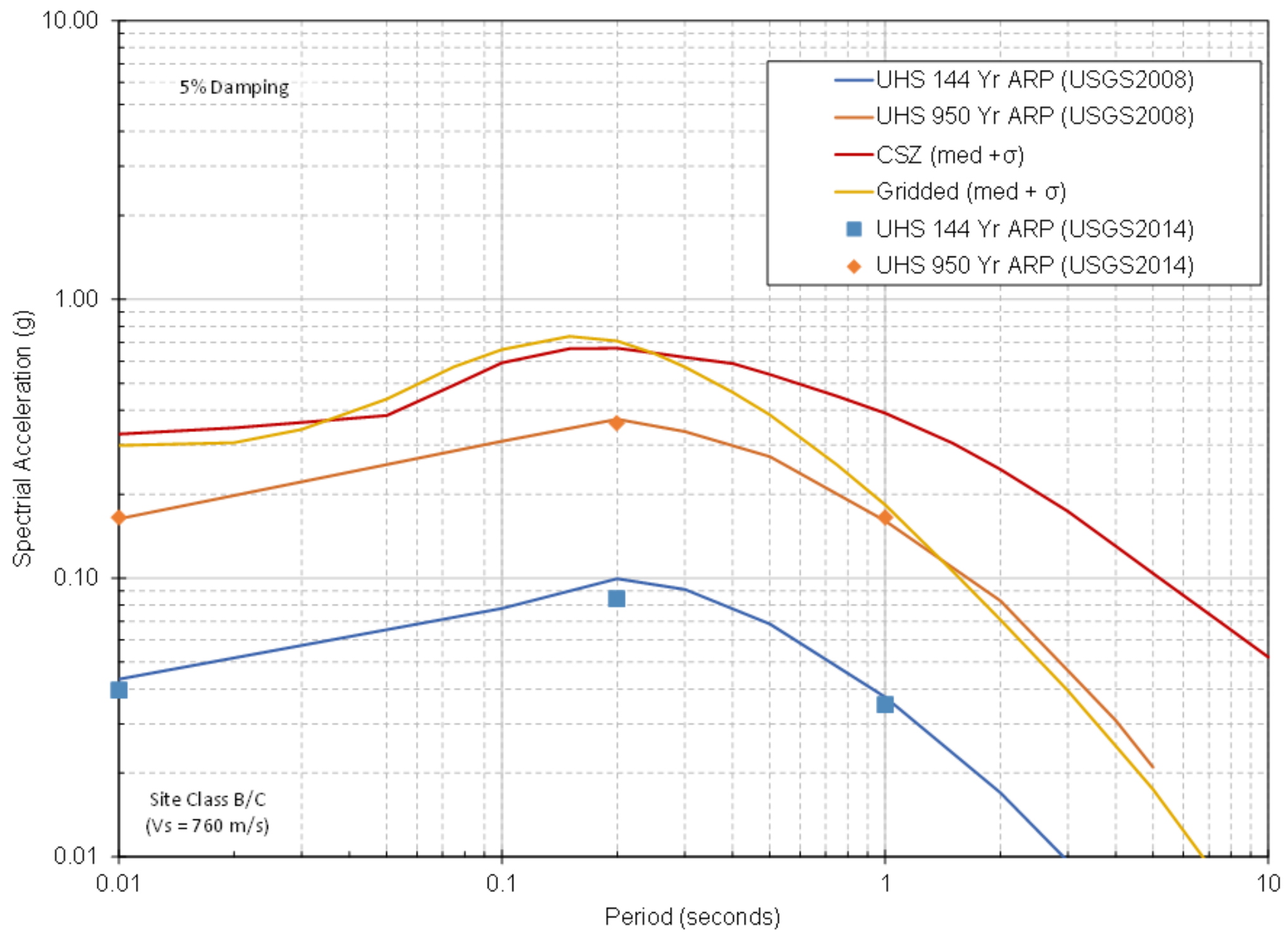

Figure 5: CSZ (median $+\sigma)$ and WUS Crustal Gridded (median $+\sigma$ ) Deterministic Target Spectra for Site Class B/C $(\mathrm{Vs}=760 \mathrm{~m} / \mathrm{s}), 5 \%$ Damping (50\% in 100 Years and 10\% in 100 Years Uniform Hazard Spectra (USGS 2008 and 2014) provided for comparison). 
PSH Deaggregation on NEHRP BC rock

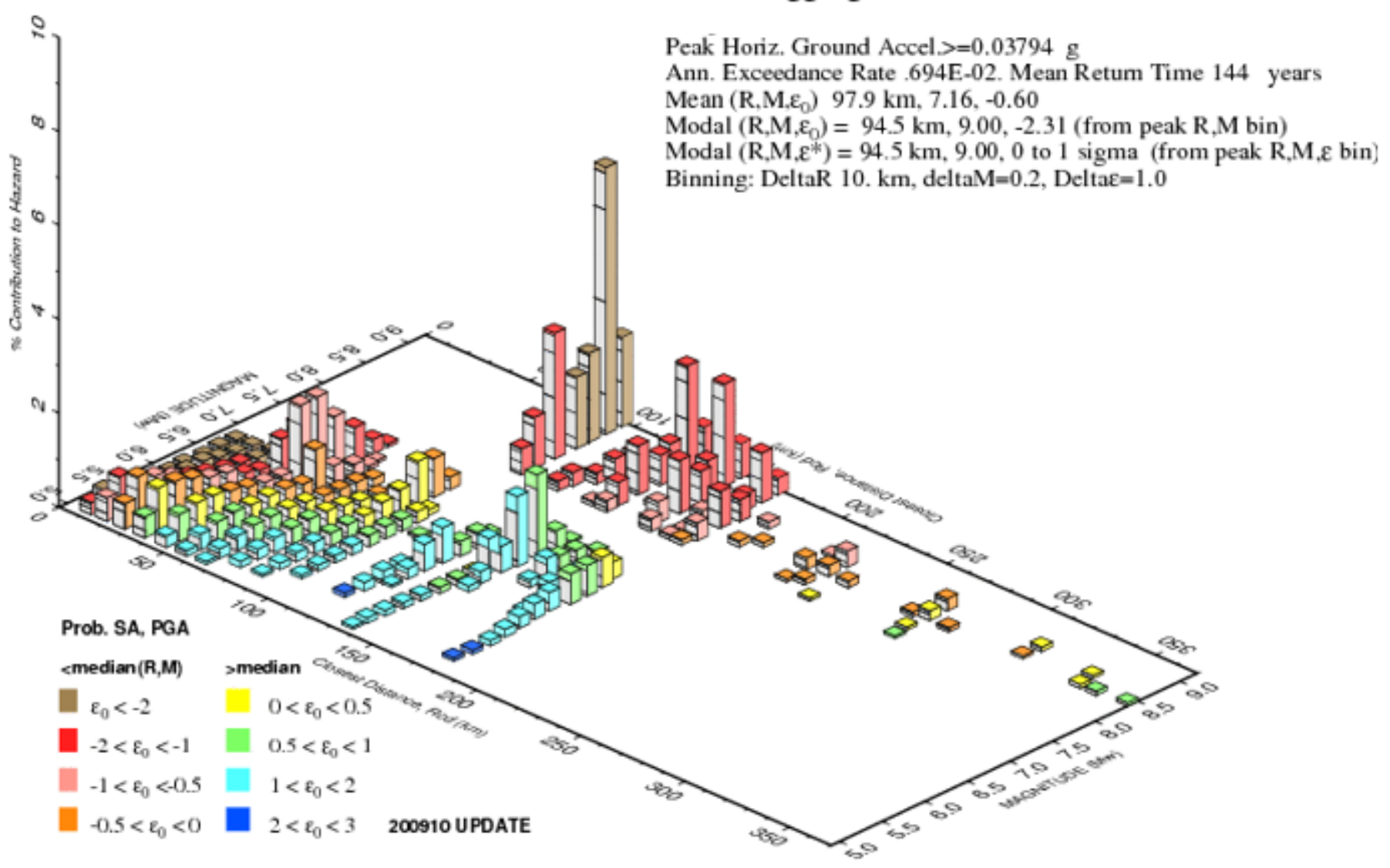

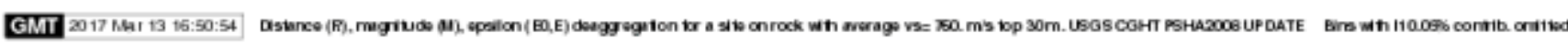

Figure 6: Deaggregation of Hazard by Magnitude and Distance at PGA 50\% in 100 Years (144-Year Return Period). 
PSH Deaggregation on NEHRP BC rock

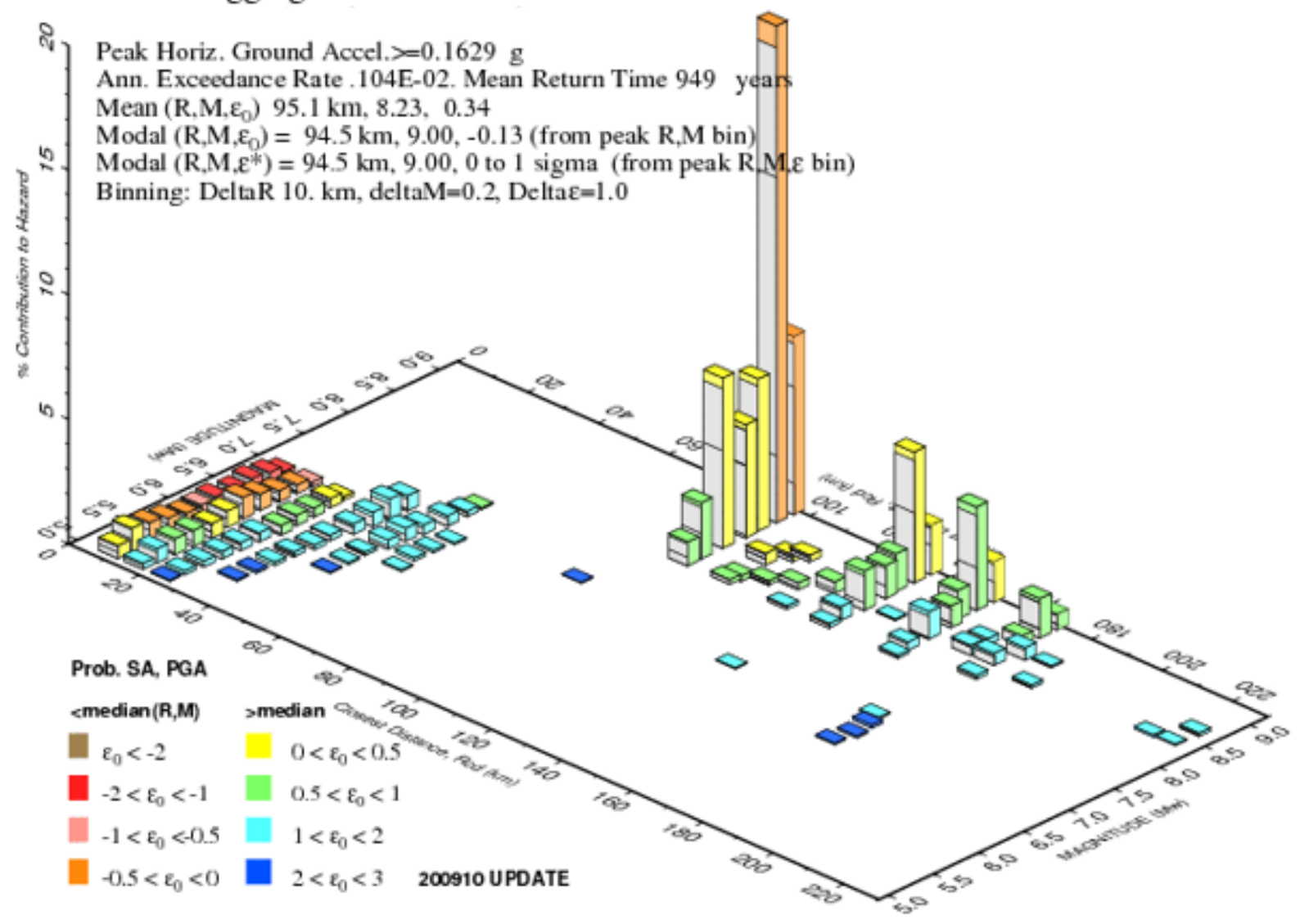

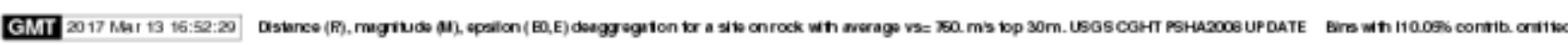

Figure 7: Deaggregation of Hazard by Magnitude and Distance at PGA $10 \%$ in 100 Years (949-Year Return Period). 
PSH Deaggregation on NEHRP BC rock

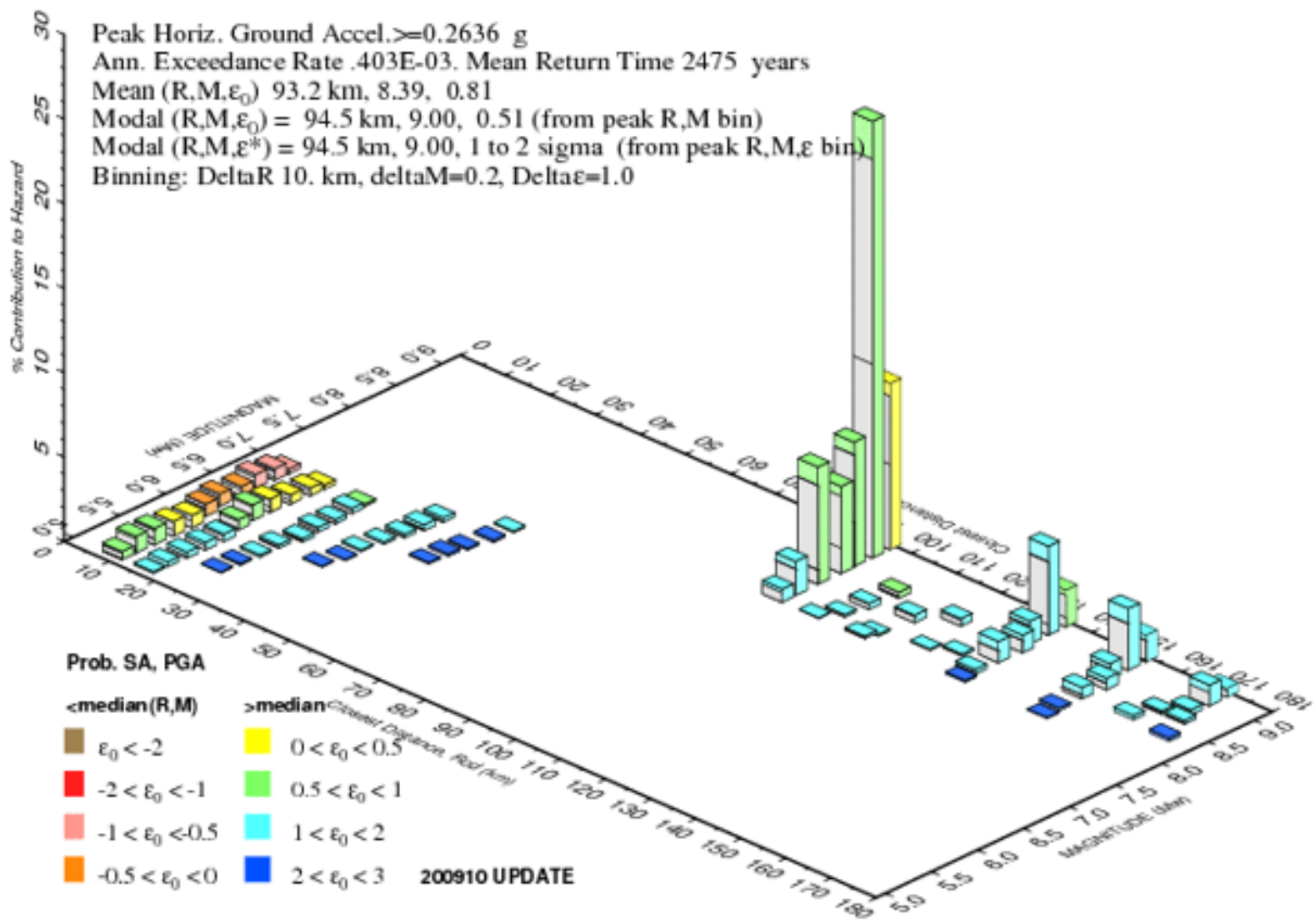

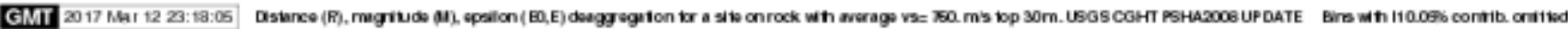

Figure 8: Deaggregation of Hazard by Magnitude and Distance at PGA 2\% in 50 Years (2475-Year Return Period). 


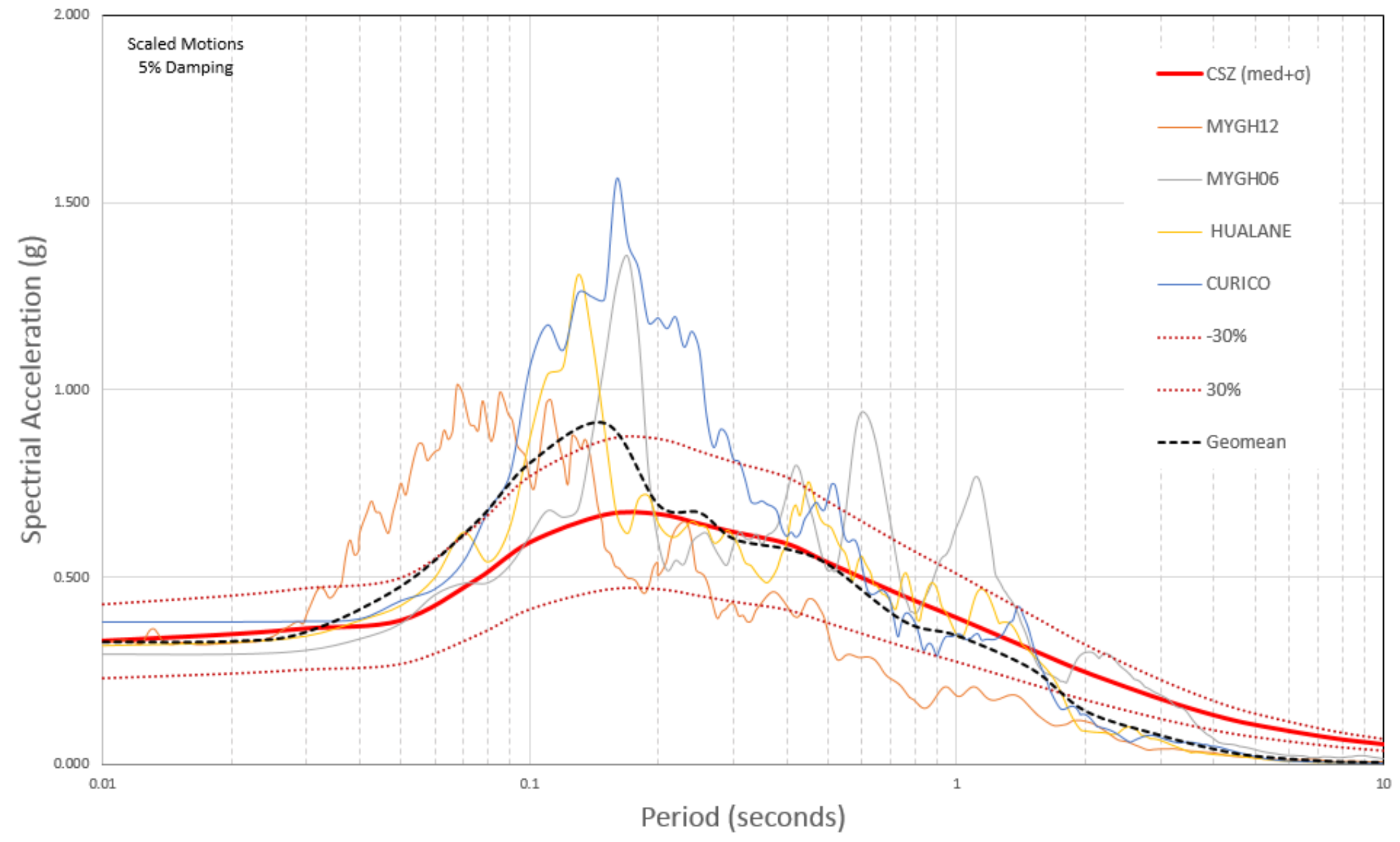

Figure 9: Comparison of Selected Ground Motions Records (Scaled) and geomean with the Deterministic Target CSZ (median $+\sigma$ ) Spectrum, 5\% Damping. 


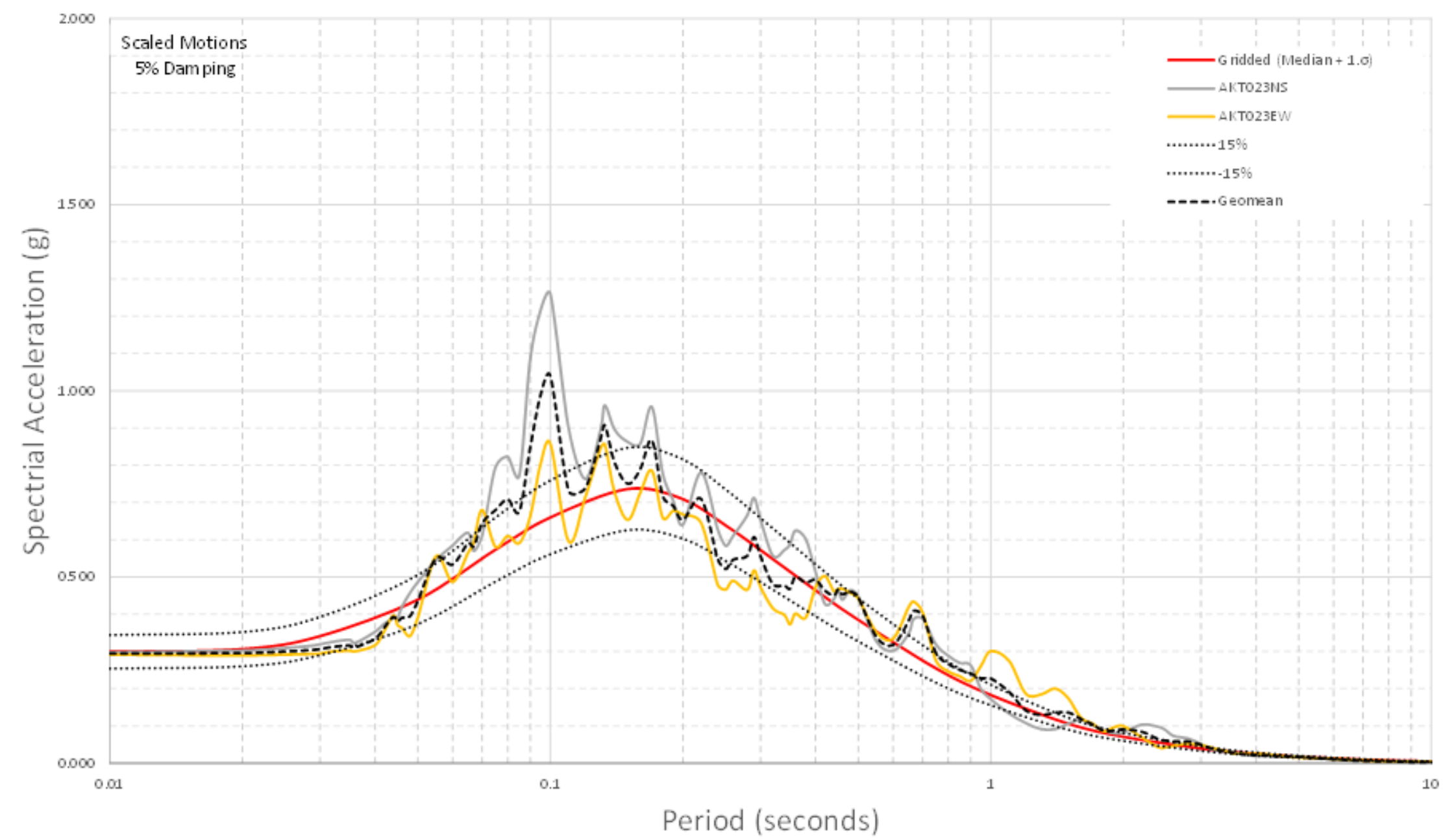

Figure 10: Comparison of Selected Ground Motions Record (Scaled) with the Deterministic Target WUS Crustal Gridded (median $+\sigma$ ) Spectrum, 5\% Damping 


\subsection{STATIC AND DYNAMIC EMBANKMENT PARAMETERS}

\subsection{Cross Section}

The embankment dam analyzed is approximately 347 feet tall and 3600 feet long. The maximum section is located at Sta. $26+00$ and was used in the analysis. The bedrock dip at the project site is relatively minor, therefore a flat bedrock profile was assumed. The embankment cross section generally consists of a slightly inclined, central impervious core with upstream and downstream rockfill shells. The impervious core is protected by upstream and downstream 10 foot filter zones. A sizeable pit run gravel section exists just downstream of the impervious core and filter. A 10 foot wide select rockfill zone transitions the pit run zone to the outer rockfill shell. The upstream slope is inclined at $1.85 \mathrm{H}: 1 \mathrm{~V}$ while the downstream slope is inclined at $1.75 \mathrm{H}: 1 \mathrm{~V}$.

\subsection{Soil Properties}

Key embankment materials required for the deformation analysis include unit weights, permeability, and static strength parameters. The assigned properties for each embankment zone are discussed below.

\section{Unit Weights}

The impervious core material was sourced from necessary excavations, left abutment and terrace excavations, and approved upstream borrow sources. The core material can generally be classified as Clay $(\mathrm{CL})$ with some silt $(\mathrm{ML})$ and minor amounts of plastic silt $(\mathrm{MH})$ and clay $(\mathrm{CH})$. The Plasticity Index ranges from 10 to 32 with an average of 22 . Construction specifications required the core material to be compacted in 1 foot layers with a maximum particle size of 6 inches. Compaction was achieved with a minimum of four passes of a rubber tire roller. In place field density and moisture data indicates that the embankment was compacted to between 75 and 106 pounds per cubic foot (pcf) with an average of 95 pcf. Field dry density ranged from 88 to 107 percent of Standard Proctor optimum dry density. Moisture content ranged from 19.7 to 37 percent with an average of 27 percent which corresponds to no more than 
3 percent above optimum and no less than 1 percent below optimum. The average field saturated unit weight was 123 pcf.

Upstream and downstream filter zones consist of 3-inch minus materials processed from gravel and concrete borrow. The maximum particle size is 3 inches with no more than 5\% passing a No. 200 sieve. Compaction was achieved in 1 foot lifts with a minimum of 2 passes of a vibratory roller. The average field dry density was 132 pcf with a range of 112 to 140 pcf. The average saturated unit weight was 147 pcf and the average moist unit weight was 130 pcf.

The pit run gravel was sourced from foundation excavation and designated upstream borrow sources. The maximum particle size was 15 inches with no more than 5\% passing the No. 200 sieve and no more than $60 \%$ passing the No. 4 . Compaction was achieved in 1.5 foot lifts with no less than 2 passes of a vibratory roller. The average field density was recorded as $142.5 \mathrm{pcf}$ with a range of 136 to 149 pcf. This is was significantly higher than the design density of 117 pcf. The average moist and saturated units weights were recorded as 147 pcf and 153 pcf, respectively.

Rockfill and select rockfill was obtained from sound fragments of basalt from quarry operations or required excavations. Oversize cobbles from 3-inch minus processing were also used. The maximum rock size was not to exceed 2 feet, the average D50 was 3.5 inches, and no more than $12 \%$ was allowed to pass the No. 4 sieve. Compaction was achieved in 2 foot lifts for the rockfill and 1 foot lifts for the select rockfill. Both the rockfill and select rockfill were compacted with no less than 4 passes of a vibratory roller. The field dry density was recorded to be 127 pcf which was greater than the design dry density of 116 pcf. The average moist and saturated units weights for both the rockfill and select rockfill were recorded as 127 pcf and 141 pcf, respectively.

The main dam is founded on Basalt Flows and Tuffs. According to project design records and sampling, the average dry density and saturated density are 127 pcf and 141 pcf, respectively.

\section{Permeability}

Design documentation used a permeability of $1.97 \times 10-8 \mathrm{ft} / \mathrm{min}(1 \times 10-8 \mathrm{~cm} / \mathrm{s})$ for the impervious core. This value is reasonable and will be used in the analysis. There is no design documentation for the permeability of filter zones. The filter zones were specified to have less than 5\% passing the No. 200 . This material can be described as a well graded mixture of sand and gravel which given the limited fines 
content should be free draining. Therefore, a permeability of $1 \times 10-3 \mathrm{~cm} / \mathrm{s}$ was selected. There is no design permeability data for the pit run gravel. The sand content of the pit run gravel ranges from 0 to $45 \%$ and there are limited ( $<5 \%$ fines). Therefore it is reasonable to assume that this zone would be an order of magnitude more pervious than the filter zone and will be assumed to be $1 \times 10-2 \mathrm{~cm} / \mathrm{s}$. The rockfill and select rockfill consists of mostly cobbles and gravels with 0 to $12 \%$ sand. This can be considered to be a fairly clean, gravel with high permeability. Therefore it is reasonable to assume a permeability of $1 \times 10-1 \mathrm{~cm} / \mathrm{s}$. Based on design documentation, the permeability of bedrock is $1.7 \times 10-4 \mathrm{ft} / \mathrm{min}(8.64 \times 10-5$ $\mathrm{cm} / \mathrm{s})$.

\section{Static Strength Parameters}

The project design and field strength data was available for the impervious core material. Only design strength data was available for all other zones. Design and field strength data are presented in Table 6. For the purposes of this study the Design values (R strength) were used for the impervious core since they are fairly similar to the field data and they are conservative when compared to the $S$ strength data. The remaining embankment materials were reviewed and the S strength (Consolidated-Drained) values were used for the analysis.

Table 6: Static Strength Soil Parameters - Design and Field Records

\begin{tabular}{|l|c|c|c|c|}
\hline Material & & Test & $\Phi\left(^{\circ}\right)$ & $\begin{array}{c}\mathrm{C} \\
(\mathrm{ksf})\end{array}$ \\
\hline \multirow{2}{*}{ Impervious Core } & Design & $\mathrm{R}$ & 13.5 & 0.6 \\
\cline { 3 - 5 } & & $\mathrm{S}$ & 25 & 0 \\
\cline { 3 - 5 } & Field Data & $\mathrm{R}$ & $9.9-15.8$ & 1.08 \\
\cline { 3 - 5 } & & $\mathrm{S}$ & $23.6-$ & 0 \\
& & & 34.2 & \\
\hline Minus 3 Inch Filter & \multirow{2}{*}{ Design } & $\mathrm{R}$ & 39 & 0 \\
\cline { 3 - 5 } & & $\mathrm{S}$ & 42.5 & 0 \\
\hline Pitrun Gravel & Design & $\mathrm{R}$ & 39 & 0 \\
\cline { 3 - 5 } & & $\mathrm{S}$ & 42.5 & 0 \\
\hline Rockfill and Select Rockfill & Design & & 45 & 0 \\
\hline
\end{tabular}

The soil parameters used in the analysis are presented in Table 7. 


\subsection{Dynamic Properties}

In order to perform the analysis, several dynamic soil properties are required. The dynamic properties required include maximum shear modulus (Gmax) and the G/Gmax and damping ratio curves. Site specific data was not available. However, a nearby project with similar materials and in place densities has site specific shear wave velocity data available that was used to inform the values, where appropriate, listed below. The constitutive model for all embankment materials is a Mohr-Coulomb with sigmoidal-3 function used to approximate the G/Gmax curves.

\section{$\underline{G m a x}$}

Gmax values were determined using the following relationships.

Impervious Core: As stated above, the average PI of the core material is 22 . Given the relatively short height of the embankment and the compaction equipment used, the over consolidation ratio (OCR) is likely between 2 and 3 . Therefore the following relationship will be used:

$$
\text { Gmax/Su = } 600-\text { Kramer (1996) }
$$

Pit Run Gravel, Rockfill, and Filters: $\mathrm{Gmax}=1000\left(\sigma^{\prime} \mathrm{m}\right)^{0.5} \mathrm{k}_{2, \max }-\mathrm{k}_{2, \max }=120$. In order select an appropriate $k_{2, \max }$ value, a comparison was made between a $k_{2, \max }$ values of 80 and 120 . Shear wave velocities were then calculated and compared to the nearby reference site with similar embankment construction. The $\mathrm{k}_{2, \max }$ value of 120 was chosen because it most closely compared to the site specific shear wave data collected at the reference site.

\section{G/Gmax and Damping Curves}

Impervious Core: Curves by Vucetic and Dobry (1991) for $\mathrm{PI}=15$. Avg. $\mathrm{PI}=22$ (10-32 range) Filters and Pit Run Gravels: Curves by EPRI (1993) for depths $=50-120$ feet.

Rockfill: Gazetas and Dakoulas (1992). 


\section{Table 7: Analysis Soil Properties}

Soil Properties

\begin{tabular}{|c|c|c|c|c|c|c|c|c|}
\hline Unit & Description & Gmax (psf) & $\gamma_{\text {Moist }}(p c f)$ & $\gamma_{\text {Sat }}(p c f)$ & c or Su (ksf) & $\phi$ & G/Gmax & Vertical Perm. K $(\mathrm{cm} / \mathrm{s})$ \\
\hline Impervious Core & $\begin{array}{l}\text { CL and ML; } \mathrm{Pl}_{\mathrm{AVG}}=22 ; \text { Compaction: } 1 \\
\text { foot lifts; } 4 \text { passes rubber tire roller; }+3 / \\
1 \% \text { opt. }\end{array}$ & Su(600) - Kramer (1996) & 121 & 123 & 0.6 & 13.5 & Vucetic and Dobry (1991) & $1 x-10-8$ \\
\hline Minus 3 Inch Filter & $\begin{array}{l}\mathrm{U} / \mathrm{S} \text { and } \mathrm{D} / \mathrm{S} \text { filters; Max. size } 3 \text { inches; } \\
\text { Compaction: } 1 \text { foot lifts; } 2 \text { passes } \\
\text { vibratory roller }\end{array}$ & $1000\left(\sigma^{\prime} m\right)^{0.5} k_{2, \text { max }}-k 2$, max $=120$ & 130 & 147 & - & 42.5 & EPRI (1993) - $50-120 \mathrm{ft}$ & $1 \times 10-3$ \\
\hline Pitrun Gravel & $\begin{array}{l}\text { Max. size } 15 \text { inches; Compaction: } 1.5 \\
\text { foot lifts; } 2 \text { passes vibratory roller }\end{array}$ & $1000\left(\sigma^{\prime} m\right)^{0.5} k_{2, \text { max }}-k 2, \max =120$ & 147 & 153 & - & 42.5 & EPRI (1993) - $50-120 \mathrm{ft}$ & $1 \times 10-2$ \\
\hline Rockfill and Select Rockfill & $\begin{array}{l}\text { Max. size } 24 \text { inches; } \mathrm{d} 50=3.5 \text { inches; } \\
\text { Compaction: } 2 \text { foot lifts }(1 \mathrm{ft} \text { select); } 4 \\
\text { passes vibratory roller }\end{array}$ & $1000\left(\sigma^{\prime} m\right)^{0.5} k_{2, \text { max }}-k 2$, max $=120$ & 127 & 141 & - & 45 & Gazetas and Dakoulas (1992) & $1 \times 10-1$ \\
\hline Bedrock & Basalt Flows and Tuffs & & 127 & 141 & - & - & & $8.64 \times 10-5$ \\
\hline
\end{tabular}




\section{G/Gmax and Damping Curves}

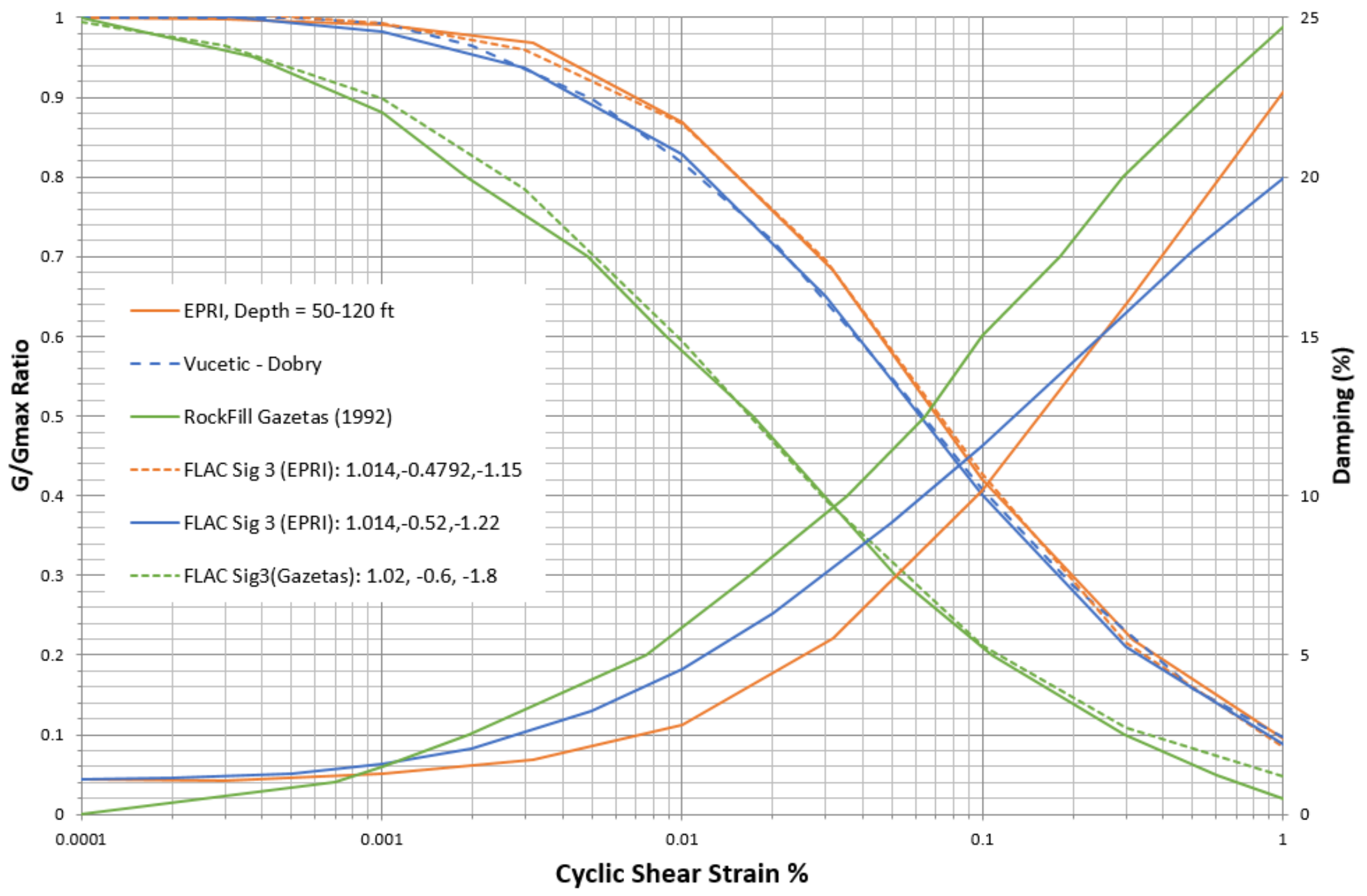

Figure 11: G/Gmax and Damping Curves 
Table 8: Filter, Rockfill, and Gravel k2,max comparison

Filter, Rockfill, and Gravel

\begin{tabular}{|c|c|c|c|c|c|}
\hline \multirow[b]{3}{*}{$\sigma^{\prime}(\mathrm{ksf})$} & \multirow[b]{3}{*}{$\sigma^{\prime} m$ (ksf) } & \multicolumn{2}{|c|}{$\mathrm{k} 2$, $\max$} & \multicolumn{2}{|c|}{$\mathrm{k} 2$, $\max$} \\
\hline & & 80 & 120 & 80 & 120 \\
\hline & & \multicolumn{2}{|c|}{ Gmax (psf) } & \multicolumn{2}{|c|}{$V s(\mathrm{ft} / \mathrm{s})$} \\
\hline 0.0 & 0.0 & $0.0 \mathrm{E}+00$ & $0.0 \mathrm{E}+00$ & 0 & 0 \\
\hline 0.4 & 0.2 & $1.2 \mathrm{E}+06$ & $1.8 \mathrm{E}+06$ & 510 & 624 \\
\hline 0.8 & 0.4 & 1.7E+06 & $2.5 E+06$ & 606 & 742 \\
\hline 1.2 & 0.7 & $2.1 \mathrm{E}+06$ & $3.1 \mathrm{E}+06$ & 671 & 822 \\
\hline 1.6 & 0.9 & $2.4 \mathrm{E}+06$ & $3.6 \mathrm{E}+06$ & 721 & 883 \\
\hline 2.0 & 1.1 & $2.7 \mathrm{E}+06$ & $4.0 \mathrm{E}+06$ & 762 & 934 \\
\hline 2.4 & 1.3 & $2.9 \mathrm{E}+06$ & $4.4 \mathrm{E}+06$ & 798 & 977 \\
\hline 2.8 & 1.5 & $3.1 \mathrm{E}+06$ & $4.7 \mathrm{E}+06$ & 829 & 1015 \\
\hline 3.2 & 1.8 & $3.4 \mathrm{E}+06$ & $5.0 \mathrm{E}+06$ & 857 & 1050 \\
\hline 3.6 & 2.0 & $3.6 \mathrm{E}+06$ & $5.3 \mathrm{E}+06$ & 883 & 1081 \\
\hline 4.0 & 2.2 & $3.8 \mathrm{E}+06$ & $5.6 \mathrm{E}+06$ & 906 & 1110 \\
\hline 4.4 & 2.4 & $3.9 \mathrm{E}+06$ & $5.9 \mathrm{E}+06$ & 928 & 1137 \\
\hline 4.8 & 2.6 & $4.1 \mathrm{E}+06$ & $6.2 \mathrm{E}+06$ & 949 & 1162 \\
\hline 5.2 & 2.9 & $4.3 E+06$ & $6.4 \mathrm{E}+06$ & 968 & 1185 \\
\hline 5.6 & 3.1 & $4.4 \mathrm{E}+06$ & $6.7 \mathrm{E}+06$ & 986 & 1208 \\
\hline 6.0 & 3.3 & $4.6 \mathrm{E}+06$ & $6.9 \mathrm{E}+06$ & 1003 & 1229 \\
\hline 6.4 & 3.5 & $4.7 \mathrm{E}+06$ & $7.1 \mathrm{E}+06$ & 1019 & 1249 \\
\hline 6.8 & 3.7 & $4.9 \mathrm{E}+06$ & $7.3 \mathrm{E}+06$ & 1035 & 1268 \\
\hline 7.2 & 4.0 & $5.0 \mathrm{E}+06$ & $7.5 E+06$ & 1050 & 1286 \\
\hline 7.6 & 4.2 & $5.2 \mathrm{E}+06$ & $7.8 \mathrm{E}+06$ & 1064 & 1303 \\
\hline 8.0 & 4.4 & $5.3 E+06$ & $8.0 \mathrm{E}+06$ & 1078 & 1320 \\
\hline 8.4 & 4.6 & $5.4 \mathrm{E}+06$ & $8.2 E+06$ & 1091 & 1336 \\
\hline 8.8 & 4.8 & $5.6 \mathrm{E}+06$ & $8.3 E+06$ & 1104 & 1352 \\
\hline 9.2 & 5.1 & $5.7 \mathrm{E}+06$ & $8.5 E+06$ & 1116 & 1367 \\
\hline 9.6 & 5.3 & $5.8 \mathrm{E}+06$ & 8.7E+06 & 1128 & 1382 \\
\hline 10.0 & 5.5 & $5.9 \mathrm{E}+06$ & $8.9 E+06$ & 1140 & 1396 \\
\hline 10.4 & 5.7 & $6.0 \mathrm{E}+06$ & $9.1 \mathrm{E}+06$ & 1151 & 1410 \\
\hline 10.8 & 5.9 & $6.2 \mathrm{E}+06$ & $9.2 \mathrm{E}+06$ & 1162 & 1423 \\
\hline 11.2 & 6.2 & $6.3 \mathrm{E}+06$ & $9.4 \mathrm{E}+06$ & 1173 & 1436 \\
\hline 11.6 & 6.4 & $6.4 \mathrm{E}+06$ & $9.6 \mathrm{E}+06$ & 1183 & 1449 \\
\hline 12.0 & 6.6 & $6.5 E+06$ & 9.7E+06 & 1193 & 1461 \\
\hline 12.4 & 6.8 & $6.6 \mathrm{E}+06$ & $9.9 \mathrm{E}+06$ & 1203 & 1473 \\
\hline 12.8 & 7.0 & $6.7 E+06$ & $1.0 \mathrm{E}+07$ & 1212 & 1485 \\
\hline 13.2 & 7.3 & $6.8 \mathrm{E}+06$ & $1.0 \mathrm{E}+07$ & 1222 & 1496 \\
\hline 13.6 & 7.5 & $6.9 E+06$ & $1.0 \mathrm{E}+07$ & 1231 & 1508 \\
\hline 14.0 & 7.7 & $7.0 \mathrm{E}+06$ & $1.1 \mathrm{E}+07$ & 1240 & 1518 \\
\hline 14.4 & 7.9 & $7.1 \mathrm{E}+06$ & $1.1 \mathrm{E}+07$ & 1249 & 1529 \\
\hline 14.8 & 8.1 & $7.2 \mathrm{E}+06$ & $1.1 \mathrm{E}+07$ & 1257 & 1540 \\
\hline 15.2 & 8.4 & $7.3 E+06$ & $1.1 \mathrm{E}+07$ & 1266 & 1550 \\
\hline 15.6 & 8.6 & $7.4 \mathrm{E}+06$ & $1.1 \mathrm{E}+07$ & 1274 & 1560 \\
\hline 16.0 & 8.8 & $7.5 \mathrm{E}+06$ & $1.1 \mathrm{E}+07$ & 1282 & 1570 \\
\hline 16.4 & 9.0 & $7.6 \mathrm{E}+06$ & $1.1 \mathrm{E}+07$ & 1290 & 1580 \\
\hline 16.8 & 9.2 & $7.7 \mathrm{E}+06$ & $1.2 \mathrm{E}+07$ & 1298 & 1589 \\
\hline 17.2 & 9.5 & $7.8 \mathrm{E}+06$ & $1.2 \mathrm{E}+07$ & 1305 & 1599 \\
\hline 17.6 & 9.7 & $7.9 E+06$ & $1.2 \mathrm{E}+07$ & 1313 & 1608 \\
\hline 18.0 & 9.9 & $8.0 E+06$ & $1.2 \mathrm{E}+07$ & 1320 & 1617 \\
\hline 18.4 & 10.1 & $8.0 E+06$ & $1.2 E+07$ & 1327 & 1626 \\
\hline 18.8 & 10.3 & $8.1 \mathrm{E}+06$ & $1.2 \mathrm{E}+07$ & 1335 & 1635 \\
\hline 19.2 & 10.6 & $8.2 \mathrm{E}+06$ & 1. $2 \mathrm{E}+07$ & 1342 & 1643 \\
\hline 19.6 & 10.8 & $8.3 E+06$ & $1.2 \mathrm{E}+07$ & 1349 & 1652 \\
\hline 20.0 & 11.0 & $8.4 \mathrm{E}+06$ & $1.3 E+07$ & 1355 & 1660 \\
\hline
\end{tabular}

1. $\sigma^{\prime} m=\left(\sigma^{\prime}+2 \sigma^{\prime} k_{0}\right) / 3-k_{0}=0.32$

2. Gmax $=1000\left(\sigma^{\prime} m\right)^{0.5} k_{2, \max }$

3. $V s=\left((G \max )(\mathrm{g}) / Y_{\text {sat }}\right)^{0.5}-\gamma \mathrm{sat}=147 \mathrm{pcf}$ 


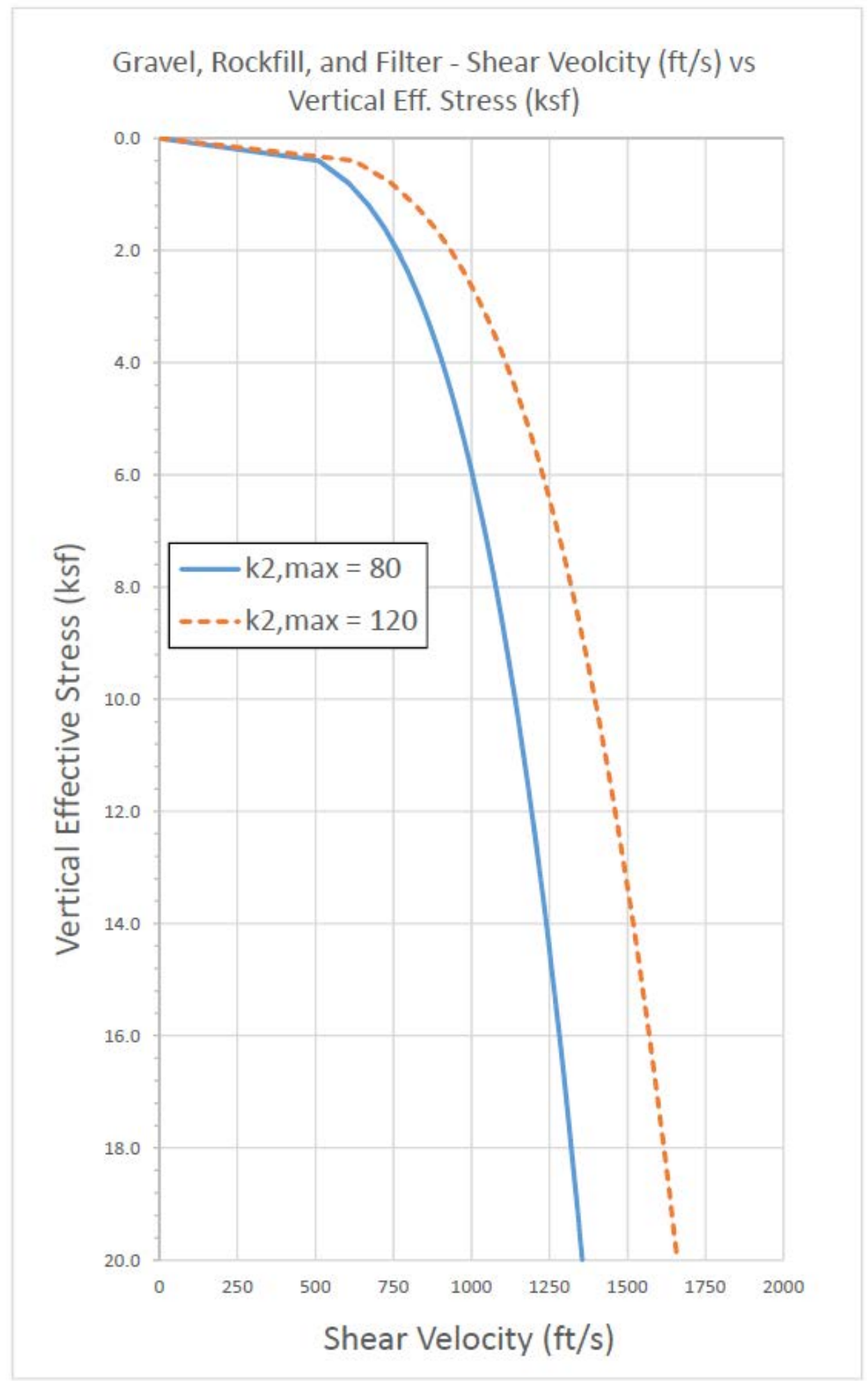

Figure 12: Gravel, Rockfill, and Filter Shear wave velocity profile - k2,max comparison 


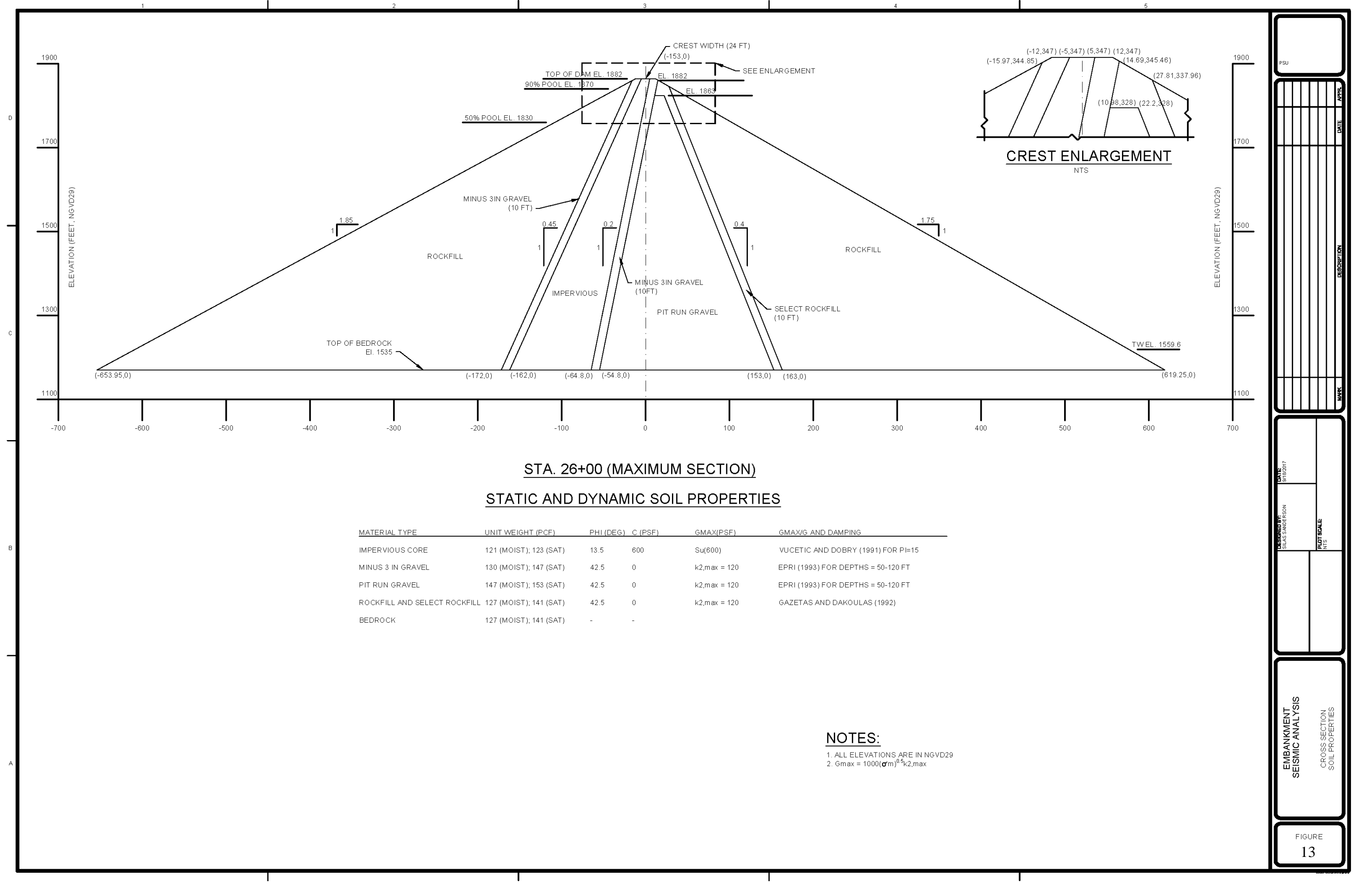

Figure 13: FLAC Modeling Cross section and model coordinates. 


\subsection{NON-LINEAR DEFORMATION ANALYSIS}

\section{Dynamic Analysis}

The two-dimensional (2-D), non-linear embankment response was calculated using FLAC-2D. FLAC-2D is a two-dimensional numerical modeling software that uses the finite difference method to model complex soil behavior, such as problems involving large displacement or strains, and non-linear behavior (Itasca, 2016). Soil is represented by elements or zones arranged in a grid and each element responds to applied forces with respect to its assigned linear or non-linear stress/strain constitutive model. The elements yield and plastically flow, and the grid can deform and move upon loading. Input parameters for the FLAC analysis include acceleration time histories and engineering properties of the embankment materials.

\subsection{Modeling sequence and Development}

The embankment modeling consists of three steps outlined below.

1) Static analysis at the end of dam construction (built in 10 increments) to establish initial total stress state

2) Effective stress analysis to simulate pore and mechanical pressures from reservoir loading 3) Dynamic analysis to simulate response to ground motions. It should be noted that pore pressures are not generated in the Mohr-Coulomb constitutive model.

\section{Model Setup:}

The FLAC model geometry was based on the as-constructed conditions. The $\mathrm{x}$ and $\mathrm{y}$ coordinates used in the model were shown on Figure 13. The bedrock in the model was extended to a depth of $225 \mathrm{ft}$ below the embankment and extended approximately 1,200 $\mathrm{ft}$ upstream and downstream of the embankment toes. The origin coordinate of the model $(0,0)$ is located at the top of bedrock at the centerline of the embankment. The section analyzed is the maximum embankment section at Sta. $26+00$.

In order to maintain computational accuracy of the dynamic response analysis, the element height should be less than one-eighth of a $20 \mathrm{~Hz}$ maximum wavelength. Assuming a bedrock shear wave velocity of 2,493 ft/s this corresponds to a maximum element size of approximately $15 \mathrm{ft}$. For the embankment, the shear wave velocity was estimated to range from $600 \mathrm{ft} / \mathrm{s}$ to $1,600 \mathrm{ft} / \mathrm{s}$ as determined 
from the Gmax distribution. Based on this range of shear wave velocities, the maximum element sizes should range from 3.9 to $10.4 \mathrm{ft}$. The final selected grid size for the model was 400 by 110 with a maximum bedrock element height of $15 \mathrm{ft}$ and embankment element height of $3.65 \mathrm{ft}$ (Figure 14).

\section{Boundary Conditions:}

The boundary conditions used for the static and effective stress analysis were fixed in the $\mathrm{x}$ and $\mathrm{y}$ directions along the base and fixed in the $x$ direction only along the sides of the model to allow for vertical movement in the model during loading. For the dynamic analysis, free field boundaries were assigned to the upstream and downstream bedrock edges of the model and a compliant boundary was assigned to the base using a quiet boundary in FLAC. The free field boundary is used to simulate the behavior of the extended bedrock.

\section{Time histories:}

Discussion of the time histories used in the analysis can be found in Section 2.0 Development of Seismic Design Response Spectra. The maximum duration of the selected time histories was 300 seconds. During much of the duration, the acceleration are minimal $(<+/-0.05 \mathrm{~g})$. In order to speed the computational time, the records were trimmed to the duration corresponding to acceleration greater than $+/-0.05 \mathrm{~g}$. Plots illustrating the original and trimmed accelerations time histories are shown in Figure 22 and Figure 23.

Time history records are applied to the model through a shear stress applied along the base of the model. The magnitude of the shear stress is calculated through the following relationship:

$$
\operatorname{Sxy}(\mathrm{t})=-\mathrm{Vs} \rho
$$

Where: $V s=$ bedrock shear wave velocity

$$
\rho=\text { bedrock density }(\gamma / g)
$$

\section{Static Analysis:}

The initial static analysis consisted of incrementally building the embankment in 10 segments to the full height of $347 \mathrm{ft}$. The analysis was solved after each increment and any deformations set to zero before applying the next increment. This initial stress state was used in the effective stress analysis. Initial static stress states are shown on Figure 15 and Figure 16. 


\section{Seepage Analysis:}

The embankment was analyzed under normal full pool conditions. A phreatic surface was estimated and applied to model in order to determine the pore pressure distribution through the model (Figure 17). After the model came to equilibrium, displacements and velocities were set to zero and the mechanical pressure of the reservoir was applied embankment and model was brought to equilibrium. This state represents the initial stress state prior to dynamic loading. The final stress and strain states prior to dynamic loading are shown in Figure 18 through Figure 20.

\section{Dynamic Analysis:}

Prior to dynamic loading, the shear modulus properties were updated to account for mean effective stress (Figure 21). The time history from the crustal source was used in the analysis. Frequency dependent Raleigh damping of one percent was added to the model to match closely to assumed natural frequency of the embankment. 


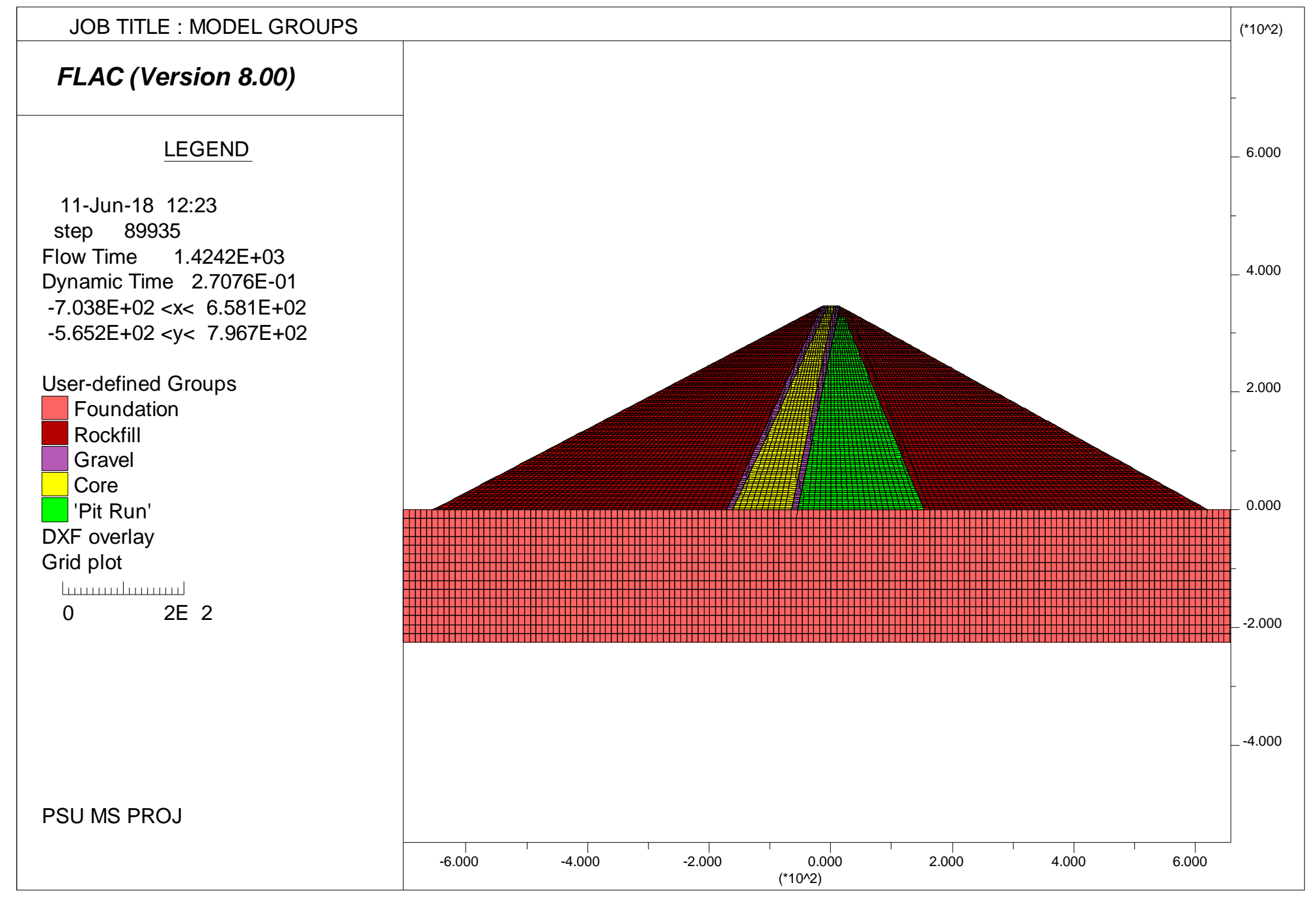

Figure 14: FLAC Model - Embankment Groups and Mesh 


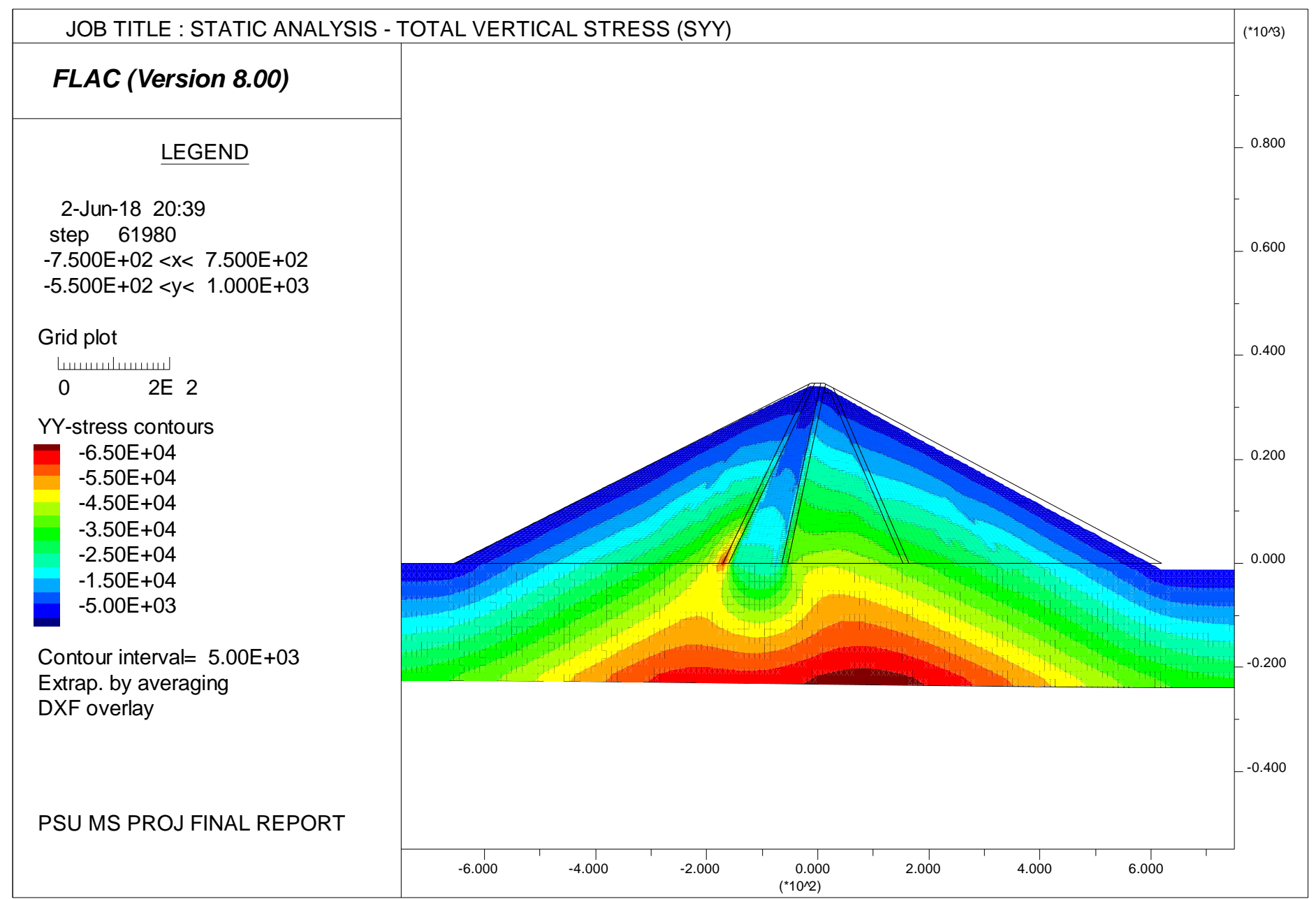

Figure 15: Static Analysis - Total Vertical Stress Contours (SYY) 


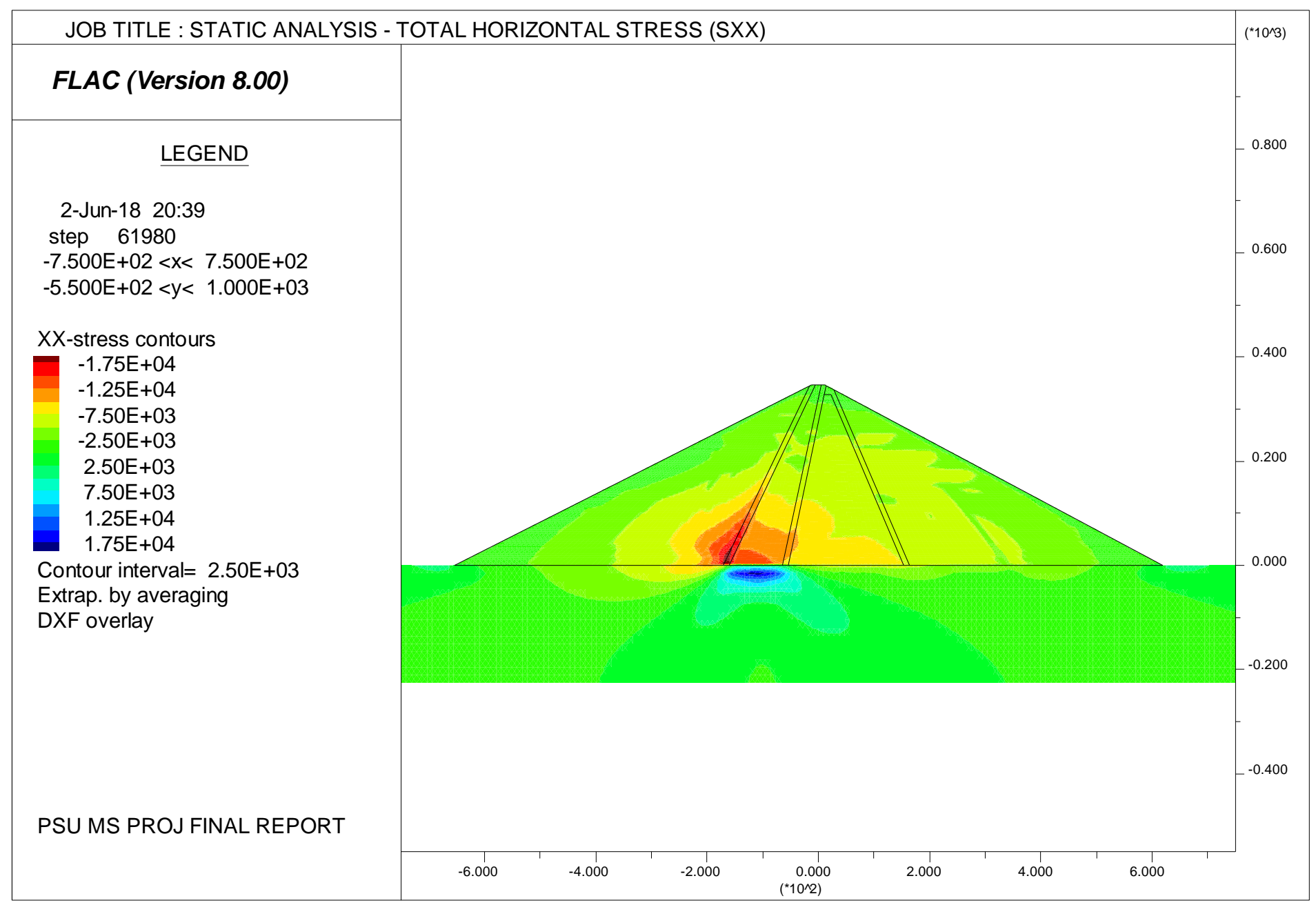

Figure 16: Static Analysis - Total Horizontal Stress Contours (SXX) 


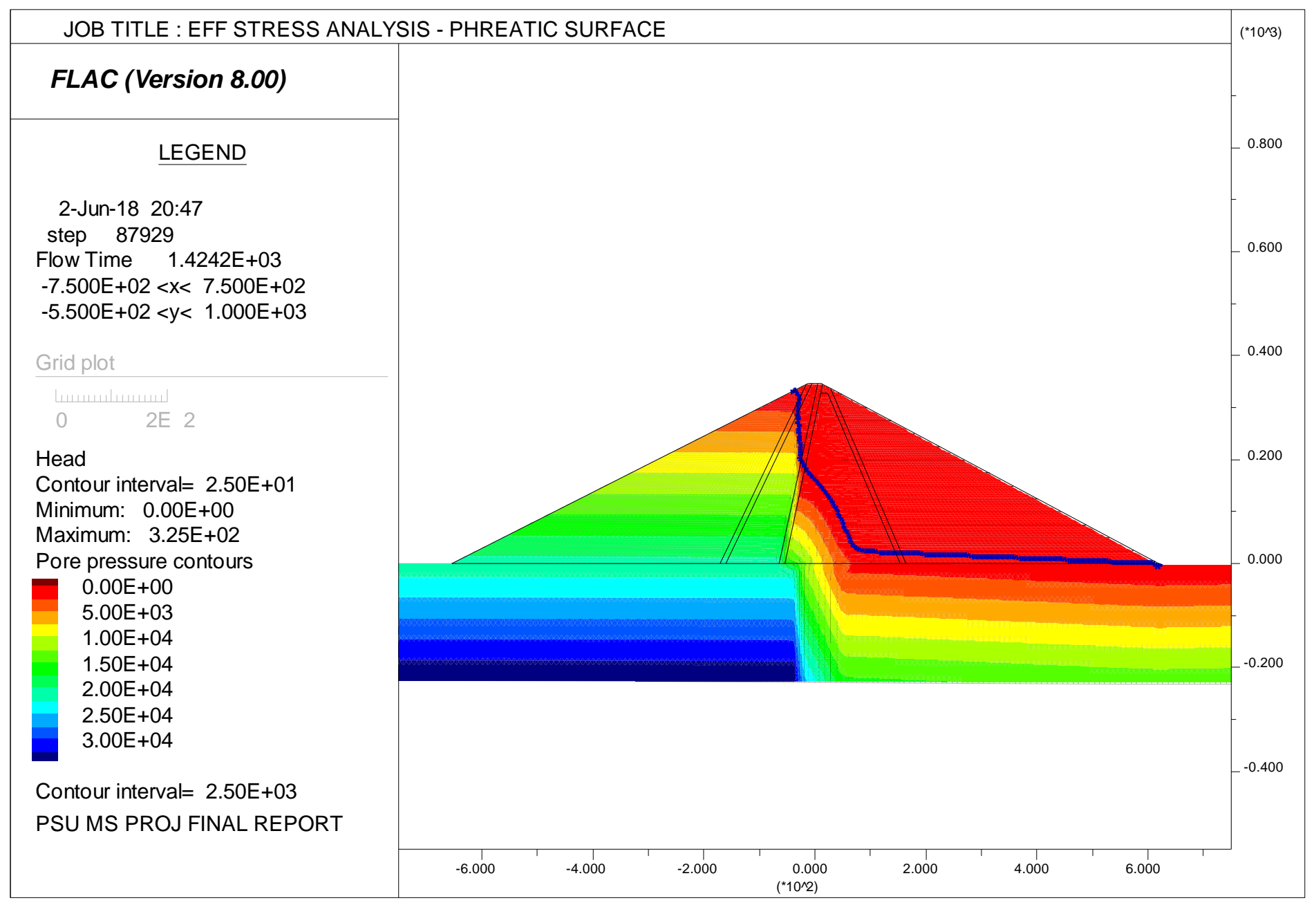

Figure 17: Seepage Analysis - Phreatic Surface (blue line) and Pore Pressure Contours 


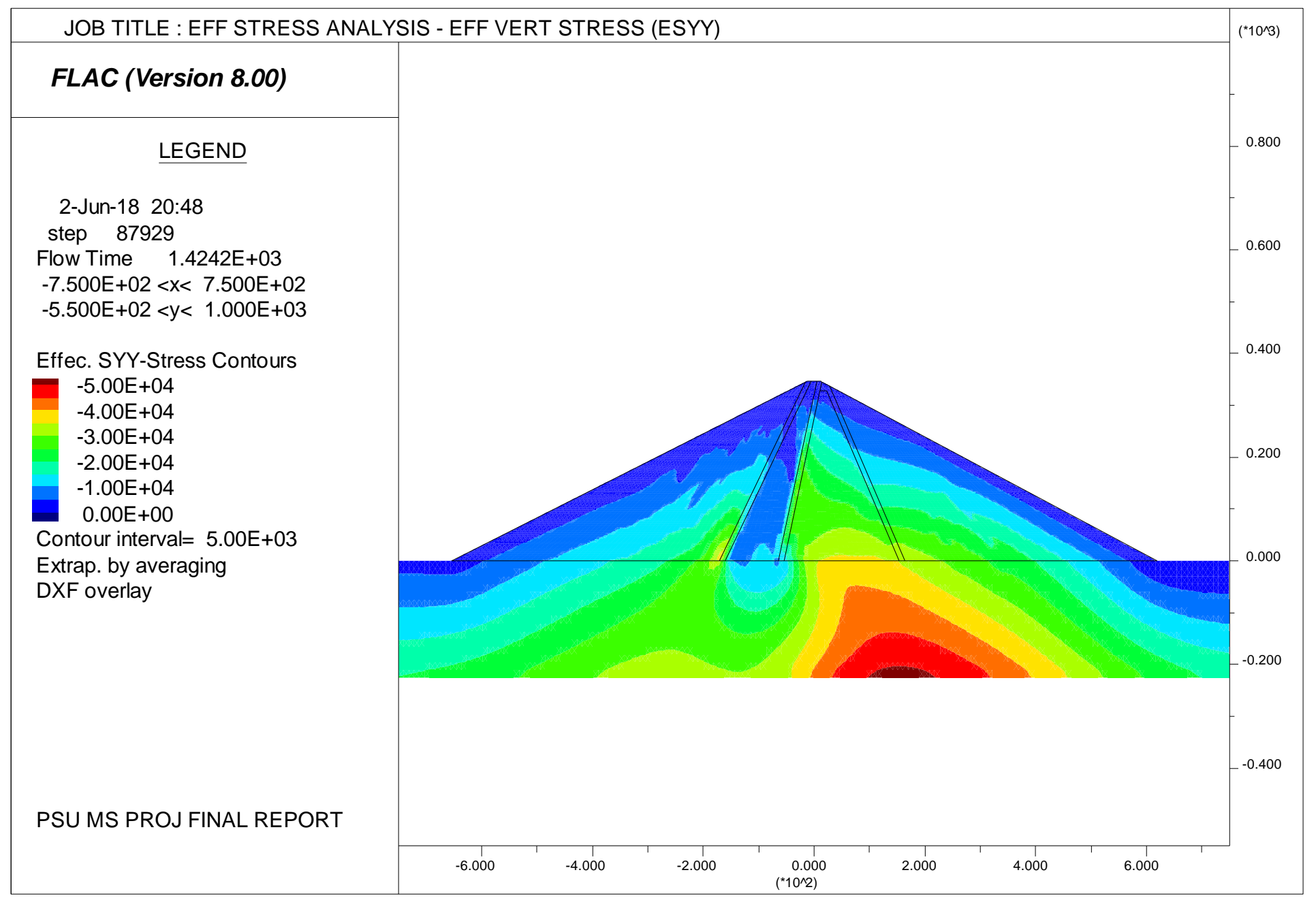

Figure 18: Seepage Analysis - Effective Vertical Stress Contours (ESYY) 


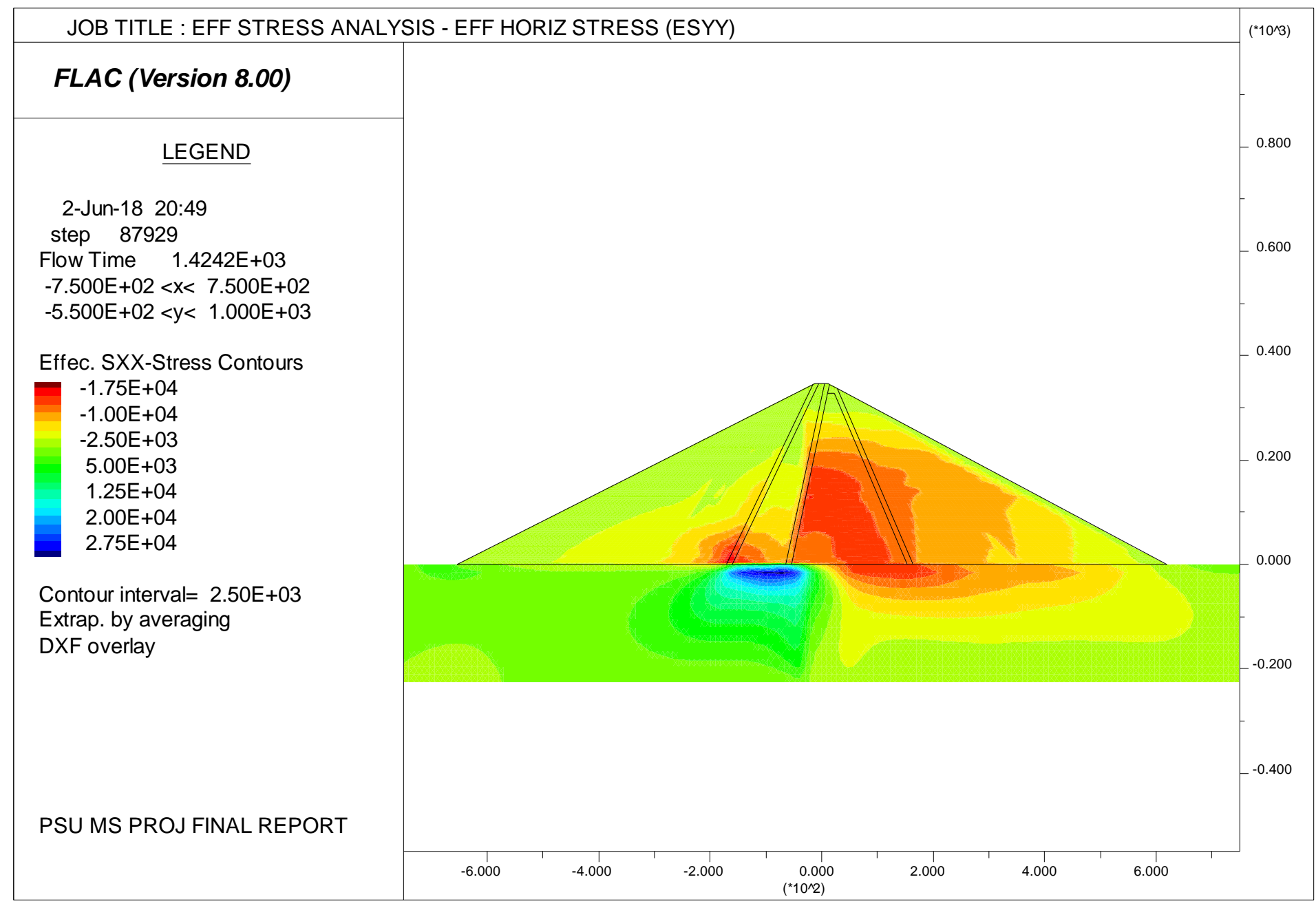

Figure 19: Seepage Analysis - Effective Horizontal Stress Contours (ESXX) 


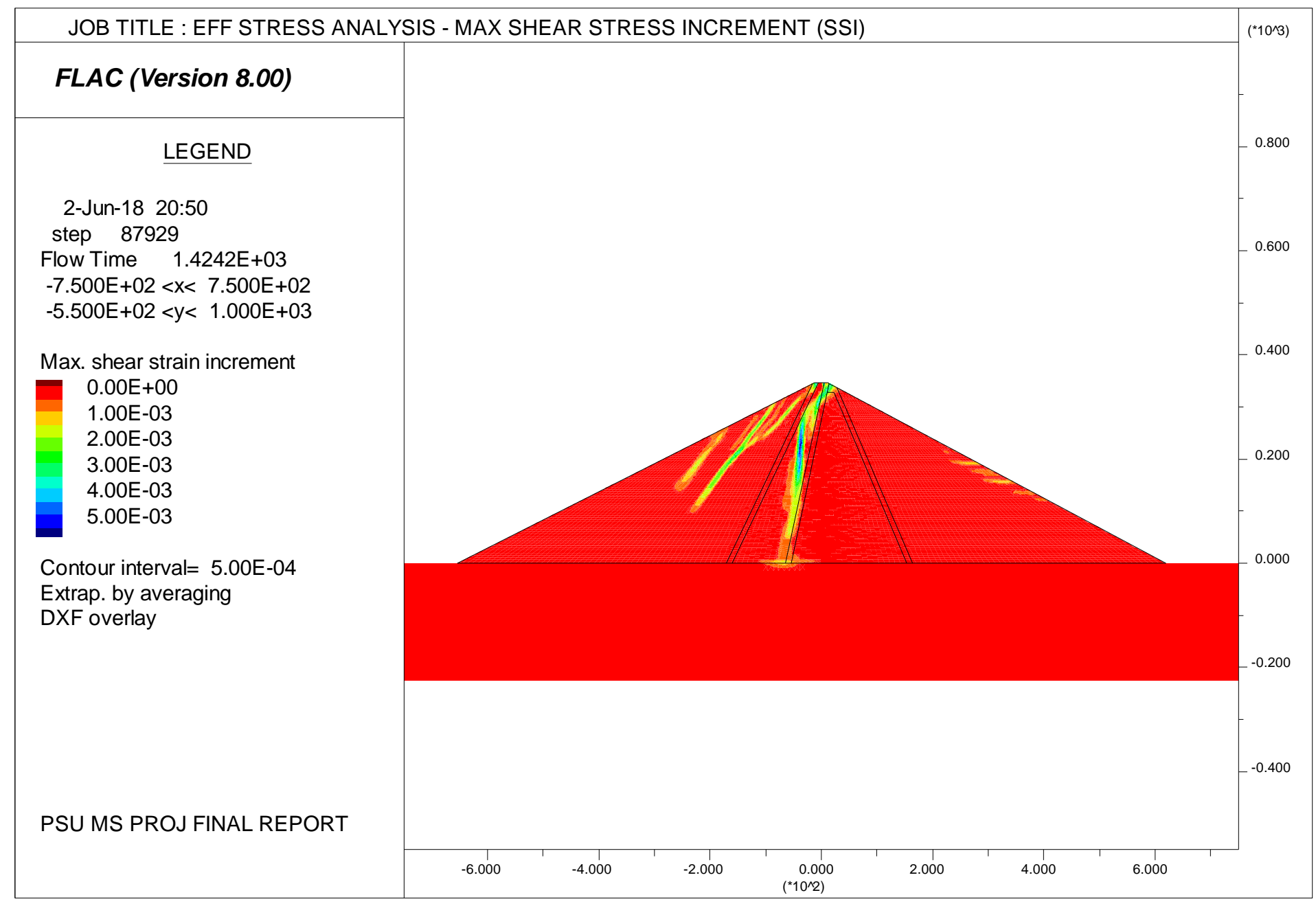

Figure 20: Maximum Shear Strain Increment pre Dynamic Loading (SSI) 


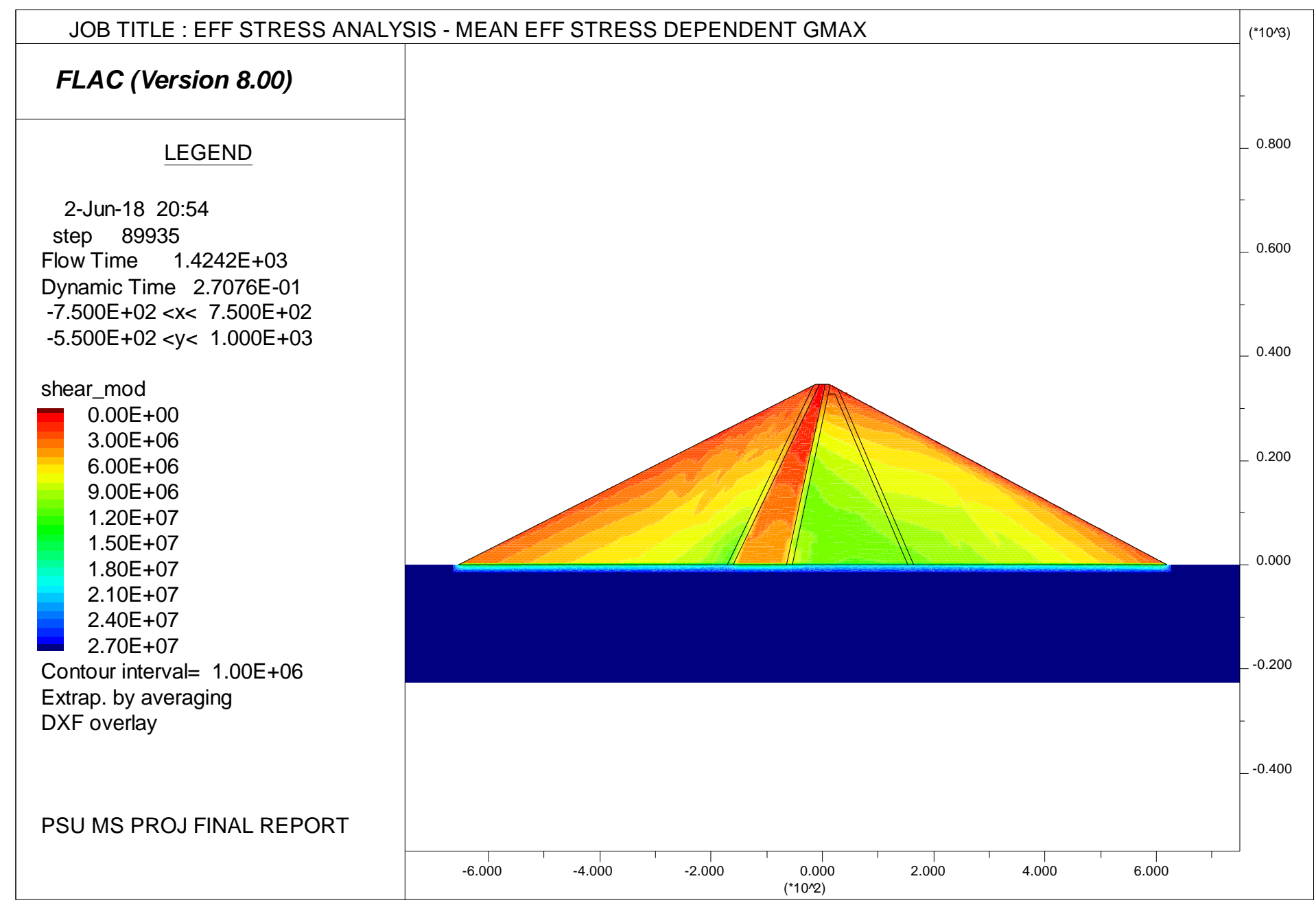

Figure 21: Mean Effective Stress Dependent Gmax 


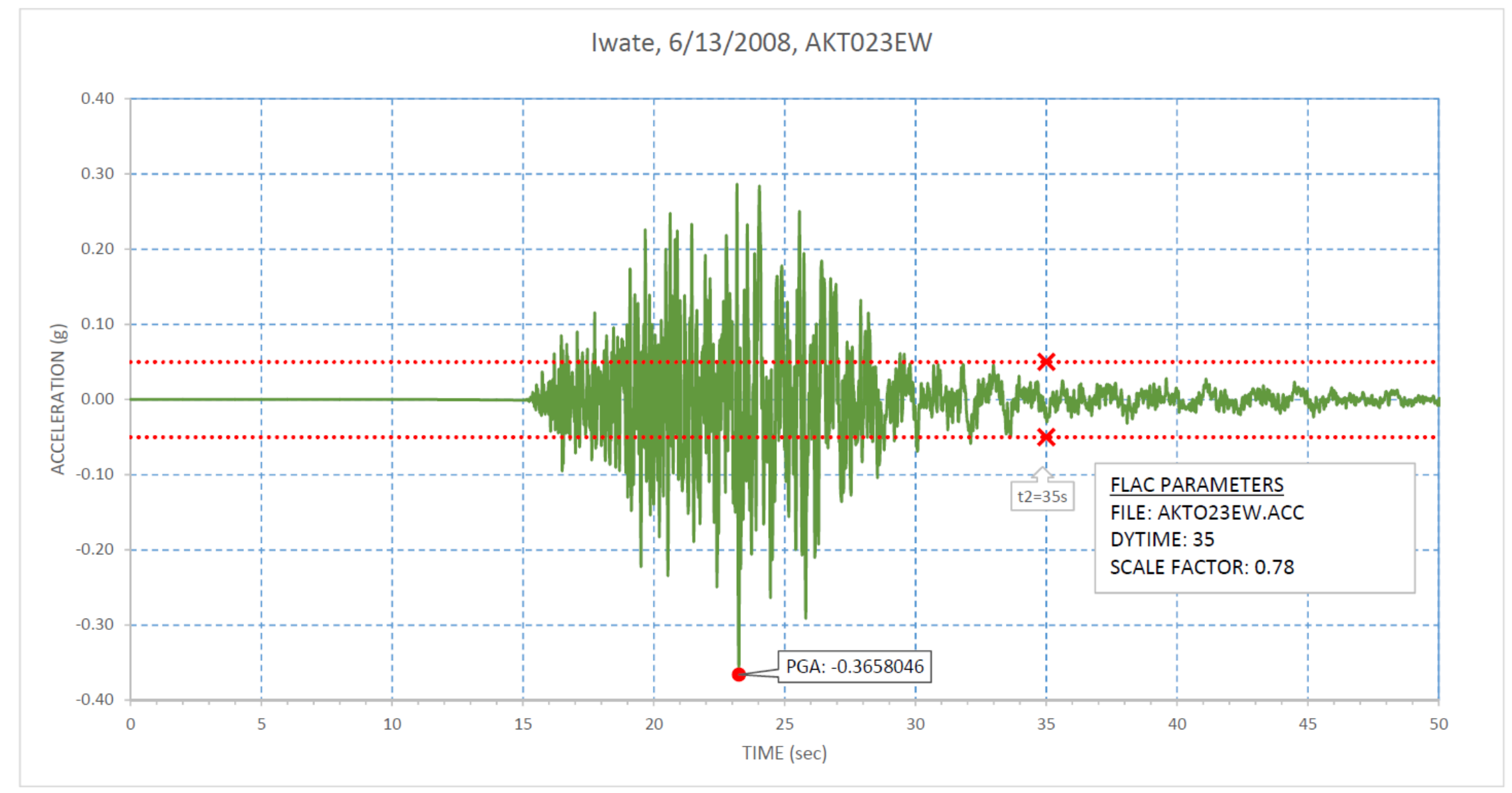

Figure 22: Acceleration Time History (AKT023EW) 


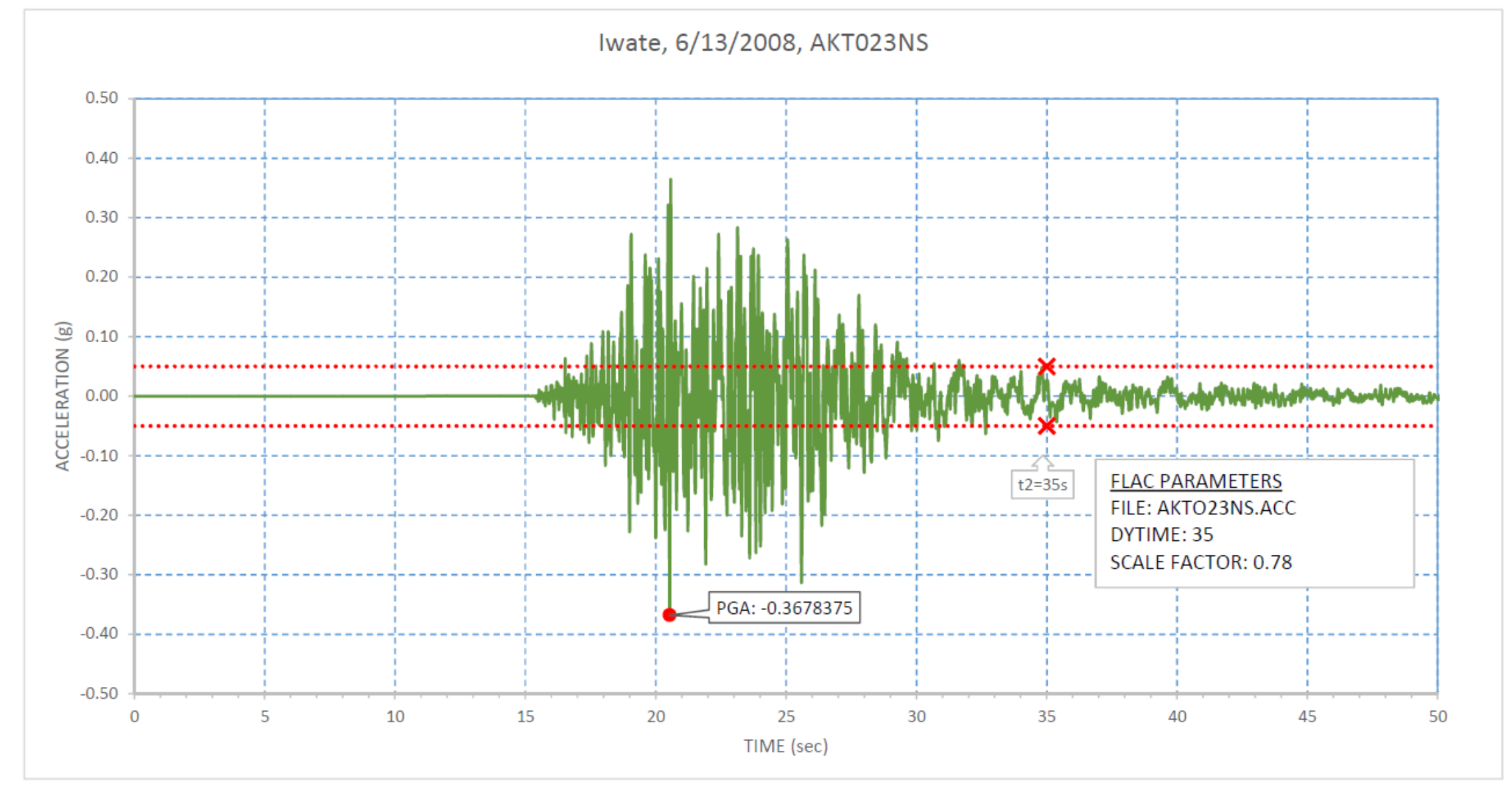

Figure 23: Acceleration Time History (AKT023NS) 


\subsection{Representative Results}

For the purposes of this project, only the crustal source with two horizontal components (AKT023EW and AKT023NS) were applied to the model. Representative FLAC output plots for record AKT023EW are shown below. Vertical, horizontal, and overall displacement contours are shown on Figure 24 through Figure 26. Shear strains are not directly calculated in FLAC but the shear strain increment (SSI) variable can be used as an analog to shear strain. SSI contour plots at the end of dynamic loading are shown on Figure 20. Vertical displacements at the crest and top of bedrock were tracked through the time history and are shown on Figure 28. An exaggerated deformed mesh is shown in Figure 29. 


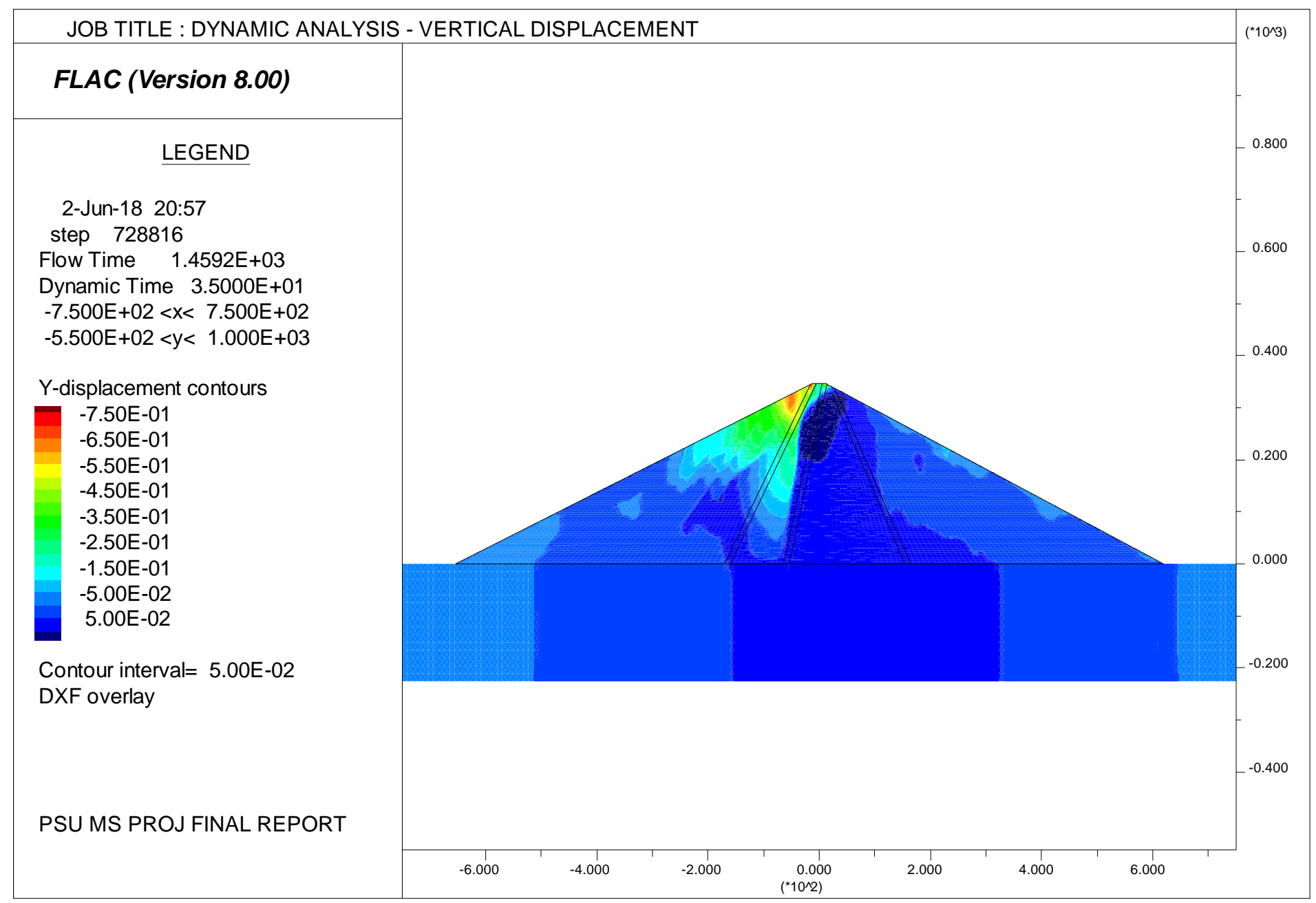

Figure 24: Dynamic Analysis - Vertical Displacement Contours (AKT023EW) 


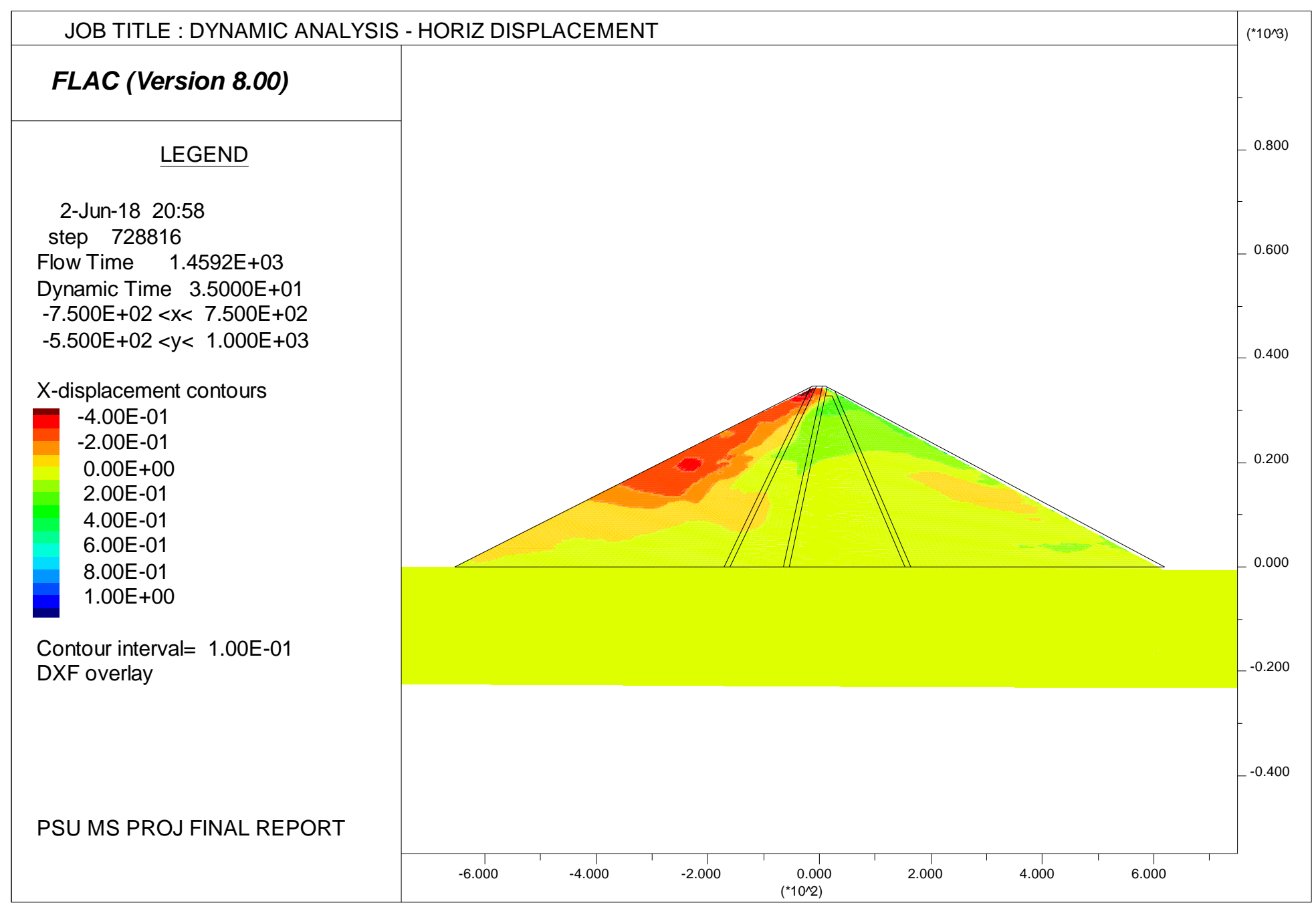

Figure 25: Dynamic Analysis - Horizontal Displacement Contours (AKT023EW) 


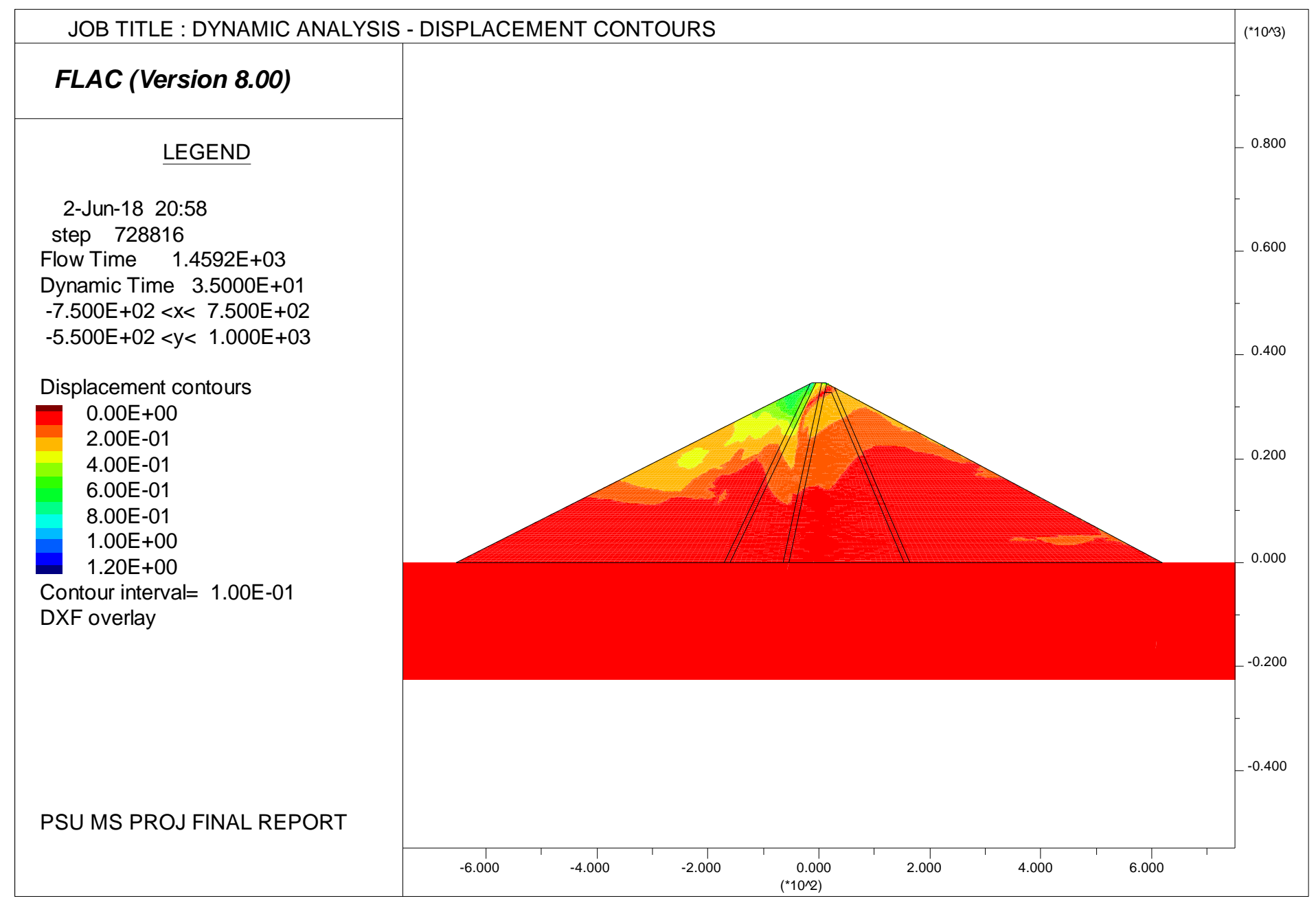

Figure 26: Dynamic Analysis - Displacement Contours (AKT023EW) 


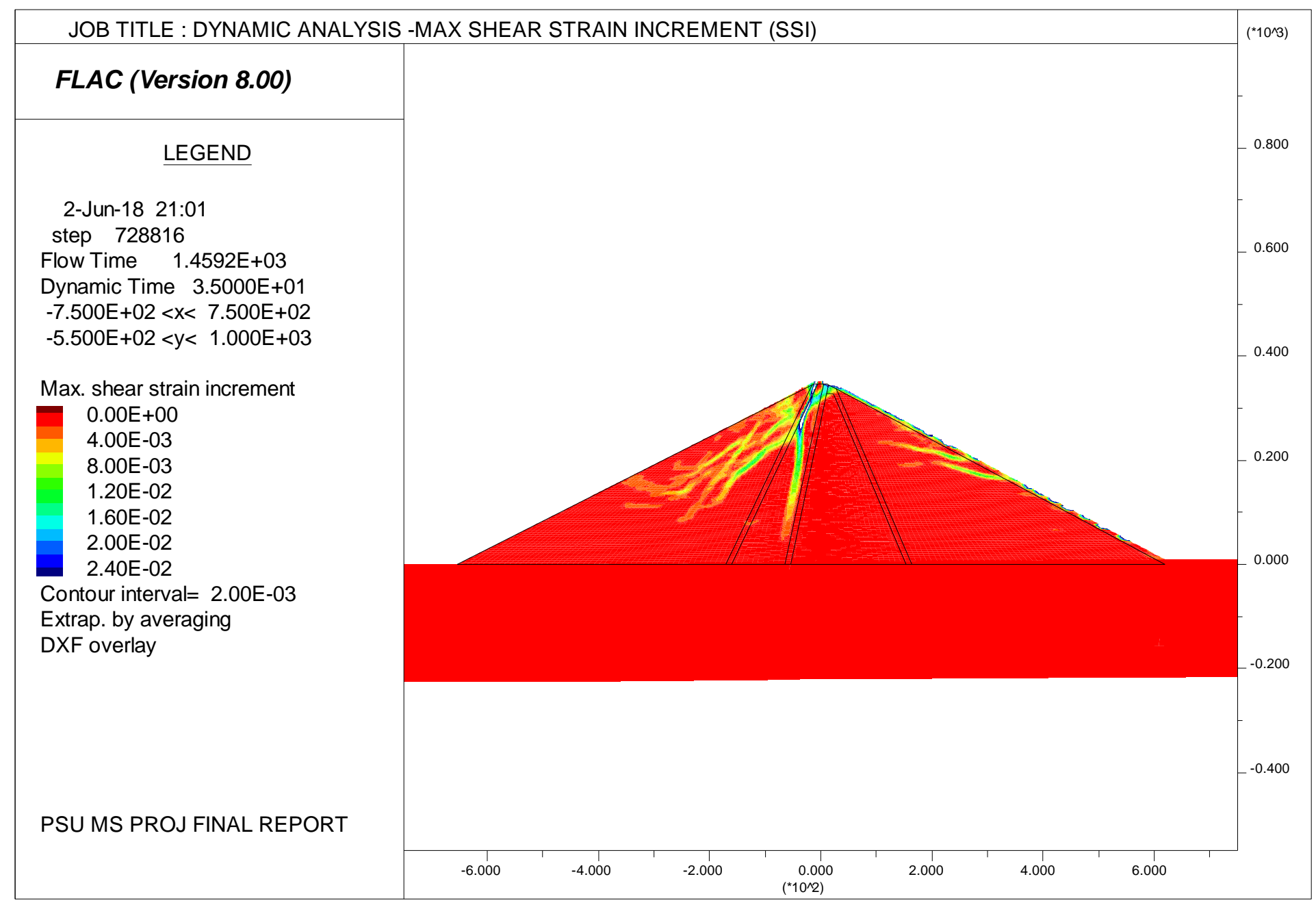

Figure 27: Dynamic Analysis - Maximum Shear Strain Increment at end of Dynamic Loading (SSI) (AKT023EW) 


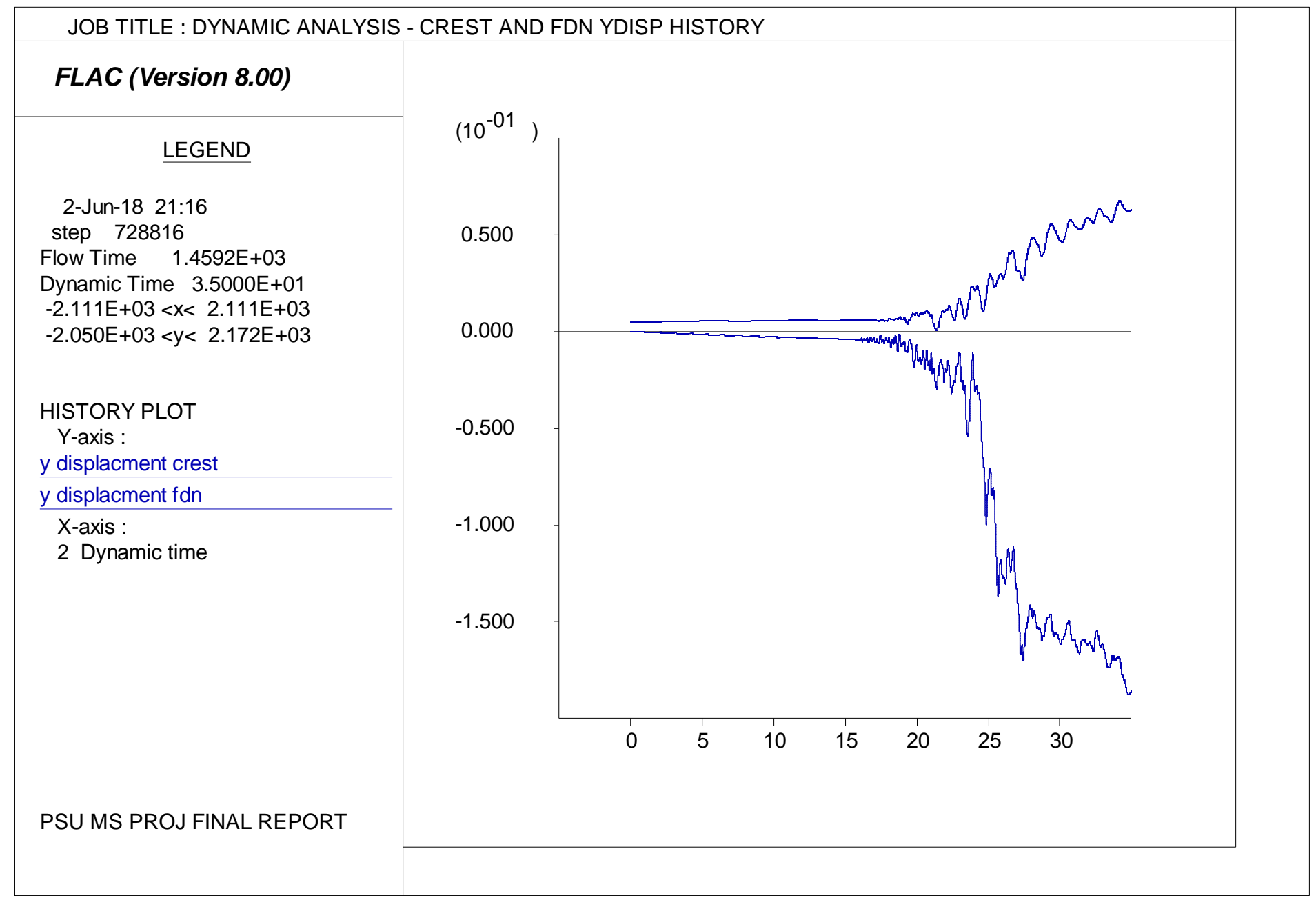

Figure 28: Dynamic Analysis - Crest and Top of Bedrock Vertical Displacement History (AKT023EW) 


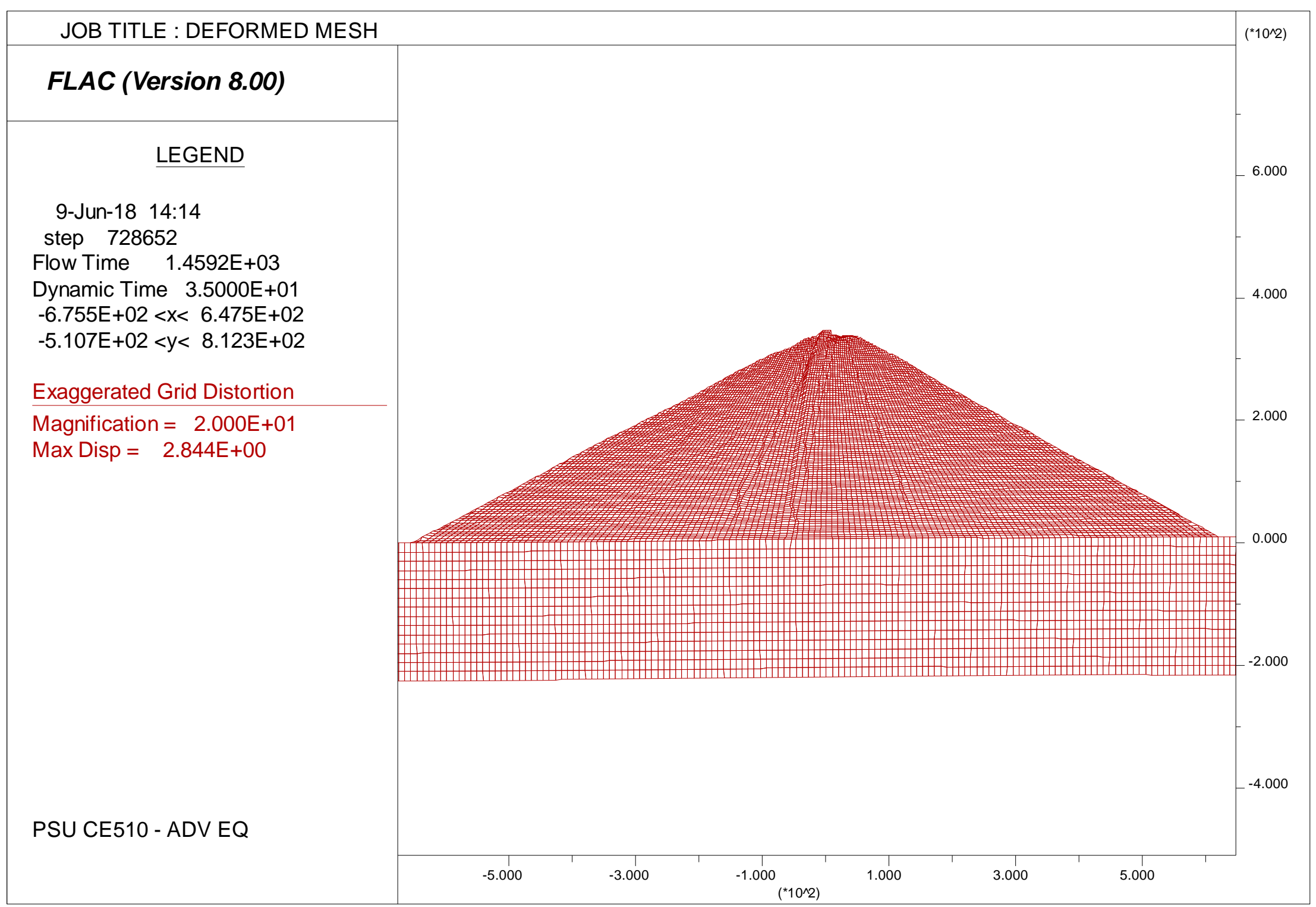

Figure 29: Dynamic Analysis - Exaggerated Deformed Mesh (AKT023EW) 


\subsection{Results}

The estimated maximum and permanent vertical and horizontal deformations for records AKT023ES and AKT023NS are shown in Table 9. Time history plots of the horizontal and vertical displacements are shown in Figure 30 and Figure 31. Results from the crustal sources were compared to the estimated deformation predicted by the Swaisgood (2014) regression equation. The regression equation relates crest deformation to earthquake magnitude, peak ground acceleration, and height of embankment and foundation for cases without significant liquefaction induced deformations. The equation was developed in 2003 and was updated in 2014 to include case histories data from the 2011 Tohoku (Mw 9) and 2010 Maule (Mw 8.8) subduction earthquakes. The median predicted deformation from the Swaisgood (2014) equation is $0.27 \mathrm{ft}$ which compares well to the permanent relative vertical deformation predicted by FLAC (Figure 32).

Table 9: Deformation Results

\begin{tabular}{|c|c|c|c|c|}
\hline Record & \multicolumn{2}{|c|}{$\begin{array}{c}\text { Permanent Crest } \\
\text { Deformations (ft) }\end{array}$} & \multicolumn{2}{c|}{$\begin{array}{c}\text { Maximum Crest } \\
\text { Deformations (ft) }\end{array}$} \\
\hline & Horizontal & Vertical & Horizontal & Vertical \\
\hline AKT023EW & -0.03 & -0.26 & -0.33 & -0.26 \\
\hline AKT023NS & -0.25 & -0.31 & -0.39 & -0.31 \\
\hline Mean & -0.14 & -0.29 & -0.36 & -0.29 \\
\hline
\end{tabular}


Relative Horizontal Crest Displacment (ft) vs Time (s)

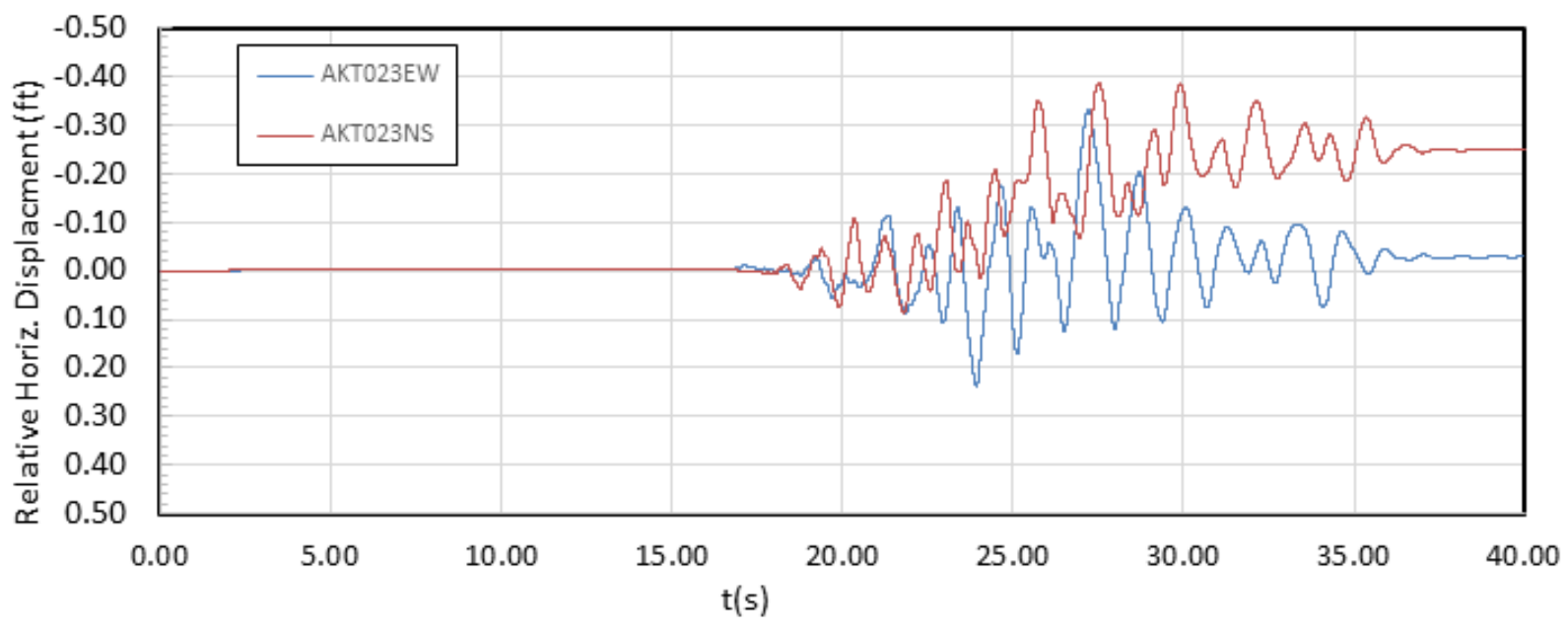

Figure 30: Relative Horizontal Crest Displacement (ft) versus Time (s) for AKT023EW and AKT023NS

Vertical Crest Displacment (ft) vs Time (s)

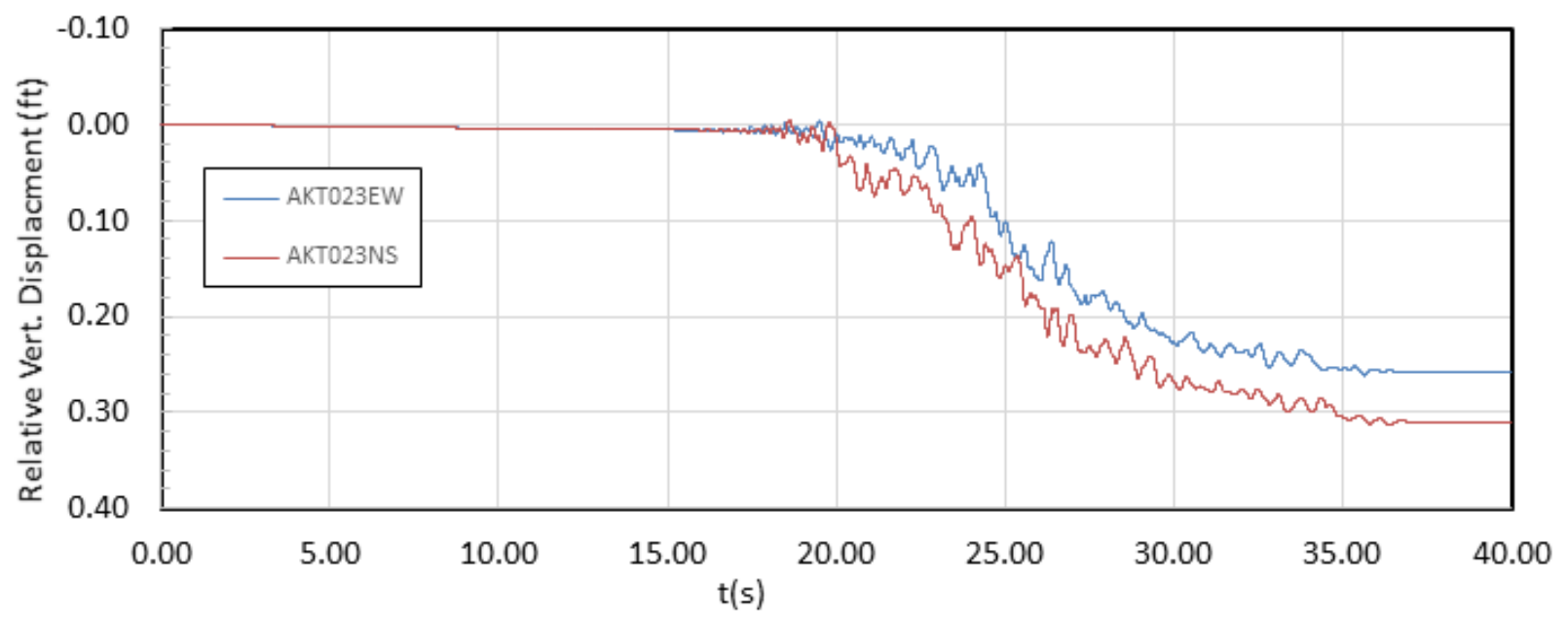

Figure 31: Vertical Crest Displacement (ft) versus Time (s) for AKT023EW and AKT023NS 


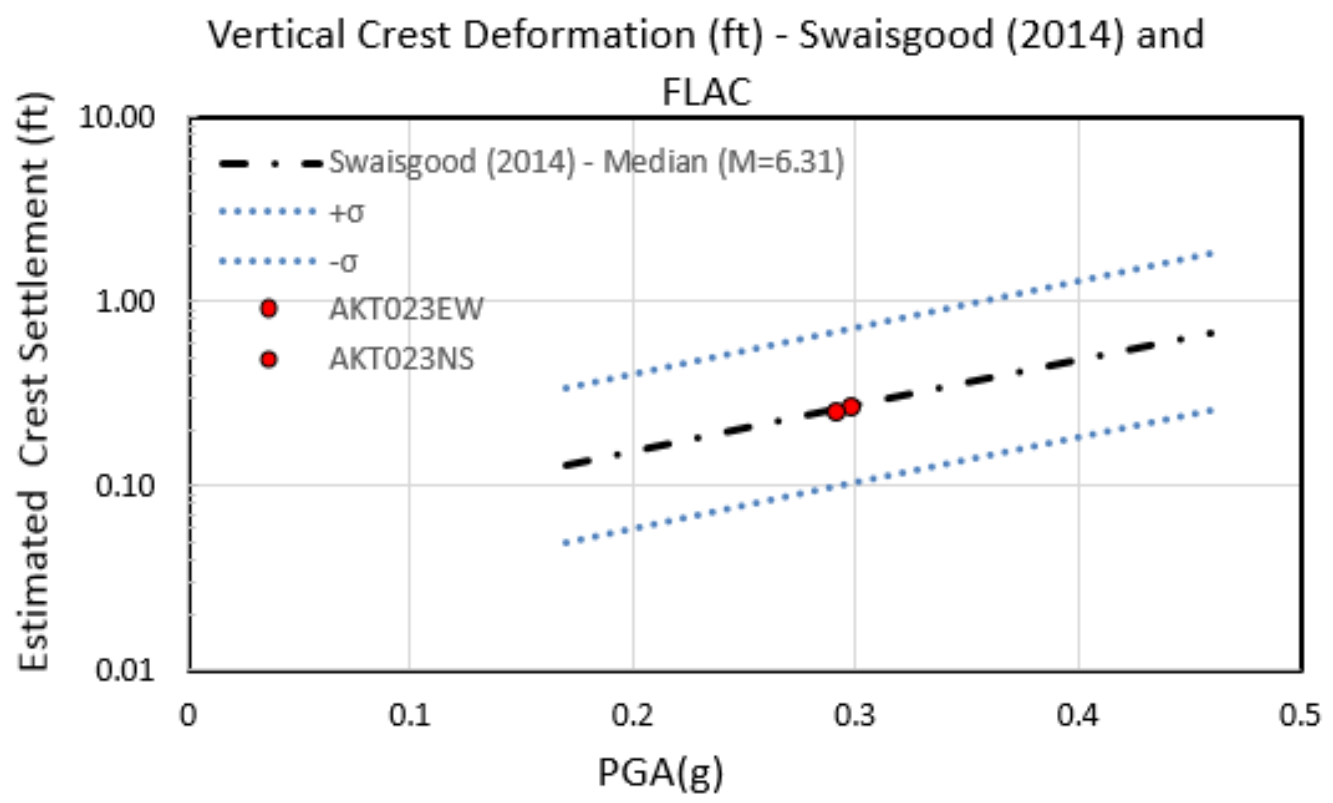

Figure 32: Vertical Crest Deformation Comparison - Swaisgood (2014) and FLAC vs PGA (g)

Bedrock input PGA and the maximum PGA calculated at the crest are shown in Table 10 and

Figure 33. The amplification factors at PGA were compared to a relationship between the input and crest PGA established by Yu et al. (2012). The results are plotted on Figure 16 and the FLAC results compare well to the relationship and are considered reasonable. Amplifications at all periods are shown in Figure 35.

Table 10: Input and Crest PGAs, and Amplification Factors

\begin{tabular}{|c|c|c|c|}
\hline Record & $\begin{array}{c}\text { PGA } \\
\text { (Input) }\end{array}$ & $\begin{array}{c}\text { PGA } \\
\text { (Crest) }\end{array}$ & $\begin{array}{c}\text { PGA } \\
\text { Amplification } \\
\text { Factor }\end{array}$ \\
\hline AKT023EW & 0.298 & 0.662 & 2.221 \\
\hline AKT023NS & 0.292 & 0.415 & 1.421 \\
\hline
\end{tabular}




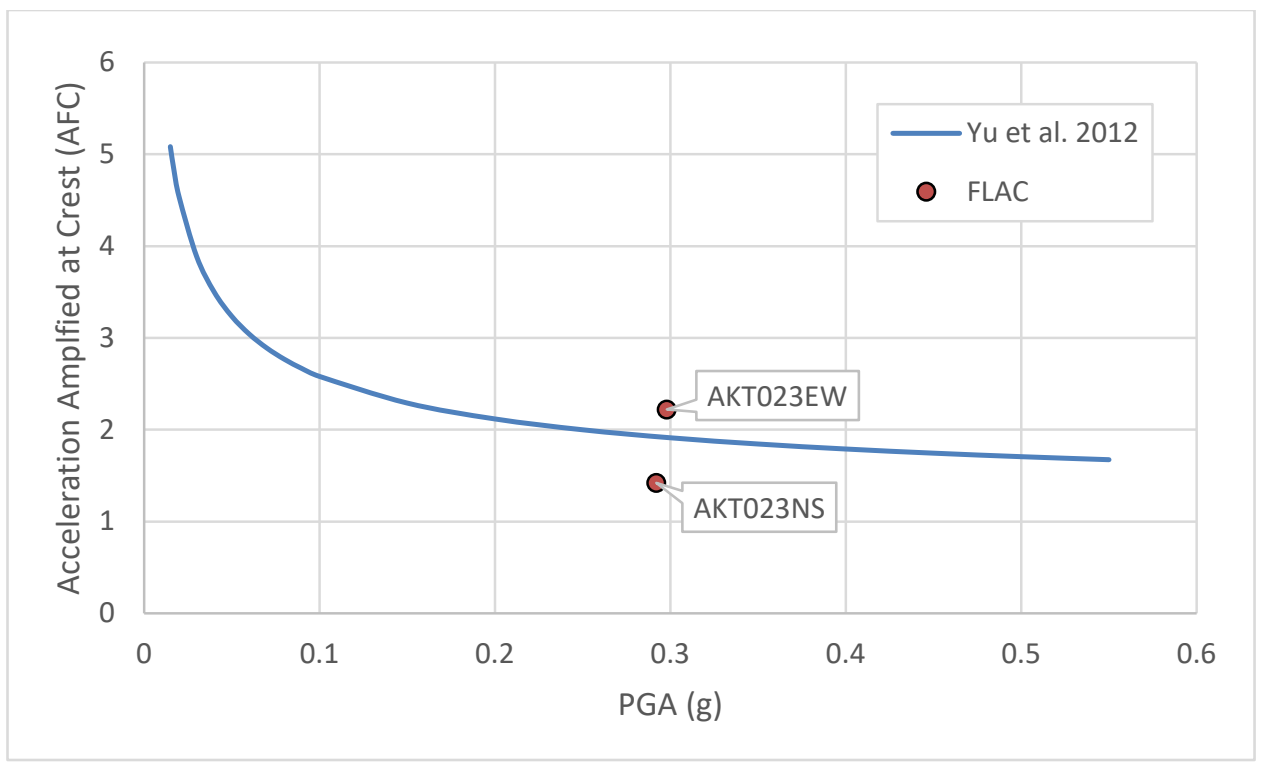

Figure 33: PGA vs Amplification Factor at Crest - Yu et al. 2012 and FLAC results

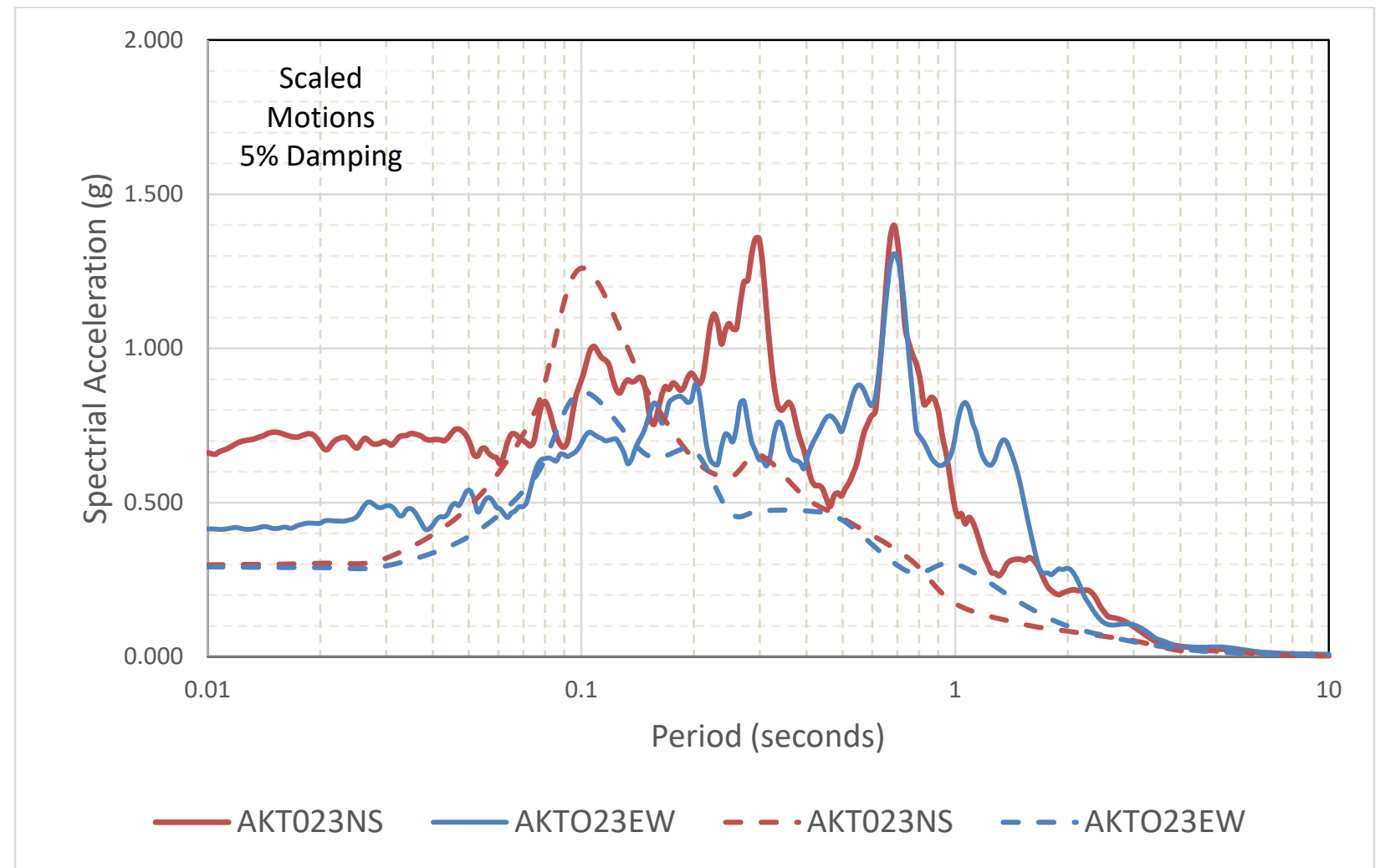

Figure 34: Crustal Source Response Spectra - Input Outcrop Motion (dashed) and Top of Crest (solid) 


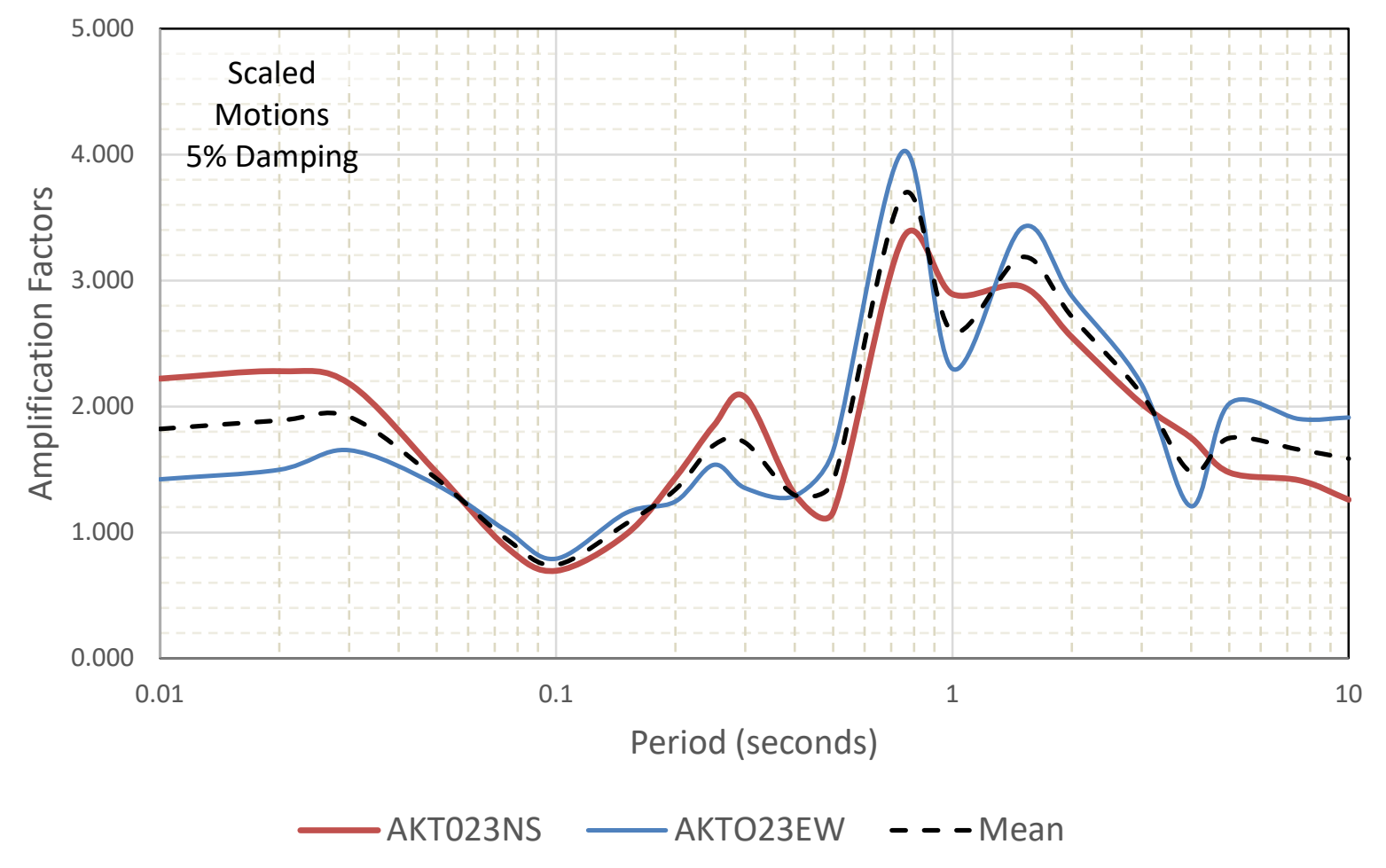

Figure 35: Crustal Source Amplification Factors - Input Outcrop Motion relative to Top of Crest 


\subsection{CONCLUSIONS AND OBSERVATIONS}

This objective of this study was to conduct a non-linear deformation analysis (NDA) of an embankment dam subject to seismic loading using the NDA program FLAC. The results from the crustal ground motion records indicate that the permanent vertical crest deformation compares well to the estimated deformation from Swaisgood (2014) and the bedrock to crest PGA amplifications factors appear to be reasonable when compared to published relationships. The shear strain patterns in the model indicate that failure surfaces are developing down through the core, extending laterally through the upstream shell but that fully formed failure surfaces have not developed

The following are observations of the analysis process that would be beneficial to consider in future analyses:

Modeling: The crustal sources used in this project had relatively short durations (35s) compared to the subduction zone sources (150-300s). The longer duration time histories will require significantly more computational time. In order to speed computational time and allow for the usage extra variables to be calculated while the model is solving, the size of the model should be reduced to as small as is reasonable to maintain computational accuracy and to best approximate the geometry of key embankment features.

Parametric Studies: The model developed represents an idealized representation of the embankment. Selected embankment material parameters were assumed from design parameters. These parameters would likely vary throughout the embankment which may change the predicted response of the embankment. Therefore it is important to conduct parametric studies in order to capture the range of predicted embankment response to seismic loading.

Initial Stress State: The goal of conducting the initial static stress analysis was to establish a reasonable initial stress distribution that conformed to the expected behavior of the embankment dam. FLAC has the capability to perform a transient seepage analysis that can be used to estimate the pore pressure distribution throughout the model. However, convergence issues occurred when attempting to model the pore pressure distribution in this manner. Therefore, for simplicity, a phreatic surface was assumed. The phreatic surface assumed or modeled should ideally be calibrated to observed 
measurements. Additionally, it would be beneficial to calibrate the initial stress model to observed historical deformation.

Constitutive Model: The constitutive model used in the analysis was a simple Mohr-Coulomb model with sigmoidal 3 function used to approximate the G/Gmax curves. It is a simple model, suitable to this level of analysis but it has some drawbacks. It is not capable of pore pressure generation, stress dependence is not built into the model (but could be implemented), and dilation angle was not included. Future modeling efforts should consider using other constitutive models in addition to the Mohr-Coulomb model in order to better understand the range of embankment response. 


\subsection{REFERENCES}

Addo, K., N. Abrahamson, and R. Youngs. Probabilistic Seismic Hazard Analysis (PSHA) Model. Volume 3: Ground Motion Characterization (GMC) Model. Report No. E658-Vol.3, BC Hydro, 2012.

Atkinson, G.M, and D.M. Boore. Empirical Ground-Motion Relations for Subduction-Zone Earthquakes and Their Application to Cascadia and Other Regions. Bulletin of the Seismological Society of America, Vol. 93, No. 4, 2003, pp. 1703-1729.

Atkinson, G.M., and M. Macias. Predicted Ground Motions for Great Interface Earthquakes in the Cascadia Subduction Zone. Bulletin of the Seismological Society of America, Vol. 3, No. 99, 2009, pp. 1552-1578.

Bray, J. and Travasarou, T (2007). Simplified Procedure for Estimating Earthquake-Induced Deviatoric Slope Displacements, Journal of Geotechnical and Geoenvironmental Engineering, ASCE, 133(4), pp 381-392.

Bray, J.D., Macedo, J., and Travasarou, T. (2018). Simplified Procedure for Estimating Seismic Slope Displacement for Subduction Zone Earthqaukes, ASCE, 144(3).

Cakir, Recep, and Walsh, Timothy J., Shallow Seismic Site Characterization at 25 ANSS/PNSN Station and Compilation of Site-Specific Data for the Entire Strongmotion Network in Washing and Oregon, Final Technical Report submitted to the U.S. Geological Survey, March 2012.

Center for Engineering Strong Motion Data (CESMD), Strong Motion Virtual Data Center (VDC), http://strongmotioncenter.org/, 2012.

EPRI (1993). Guidelines for determining design basis ground motions, Electric Power Research Institute, Vol. 1-5, EPRI TR-102293.

Foster, M. A., Fell, R., Spannagle, M. (2000). "The statistics of embankment dam failures and accidents," Canadian Geotechnical Journal, National Research Council Canada, 37(5), 1000-1024.

Gazetas, G. and Dakoulas, P. (1991). Seismic Analysis and Design of Rockfill Dams: State-of-the-art, Soil Dynamics and Earthquake Engineering, 11, pp 27-61, 1992.

Hynes-Griffin, M.E., and Franklin, A.G. (1984). Rationalizing the seismic coefficient method: MP GL-84-14, USACE.

Itasca, 2016. "Fast Lagrangian Analysis of Continua, Version 8." Itasca Consulting Group. http://www.itascacg.com/flac/index.php

KiK-Net, Japanese National Research Institute for Earth Science and Disaster Resilience, http://www.kyoshin.bosai.go.jp/.

Kramer, S.L. (1996). Geotechnical Earthquake Engineering. Prentice Hall, Upper Saddle River, NJ.

Makdisi, F., and Seed, H. B. (1978). Simplified procedure for estimating dam and embankment earthquake-induced deformations." J. Geotech. Eng., 104(7), 849-867

Matsumoto, N., Sasaki, T., and Ohmachi, T. (2011). "The 2011 Tohoku earthquake and dams," ICOLD 89th Annual Meeting in Lucerne, June 1, 2011. 
McCrory, Patricia A., Blair, J. Luke, Waldauser, Felix, and Oppenheimer, David H., Juan de Fuca slab geometry and its relation to Wadati-Benioff zone seismicity, Journal of Geophysical Research, Vol. 117, B09306, 2012.

Newmark, N.M., (1965). "Effects of Earthquakes on Dams and Embankments," Geotechnique, 15(2), pp 139-160.

Pacific Earthquake Engineering Research Center (PEER), Ground Motion Database - NGA-West2 Shallow Crustal Earthquakes in Active Tectonic Regimes, http://ngawest2.berkeley.edul, 2013

Pacific Earthquake Engineering Research Center (PEER), NGA-West2 GMPEs Excel File, http://peer.berkeley.edu/ngawest2/databases/, 2015.

Pells, S. and Fell., R. (2003). "Damage and cracking of embankment dams by earthquake and the implications for internal erosion and piping," Proc., 21 ${ }^{\text {st }}$ Int. Congress on Large Dams, Montreal, ICOLD.

Swaisgood, J.P., (2003). "Embankment Dam Deformations Caused by Earthquakes," Proc., 2003 Pacific Conference on Earthquake Engineering, Christchurch, New Zealand

Swaisgood, J.P., (2014). "Behavior of Embankment Dams During," The Journal of Dam Safety, ASDSO, 12(2), pp. 35-44.

USACE, ER 1110-2-1806, 31 May 2016 - Earthquake Design and Evaluation for Civil Works Projects Seismic evaluation for existing projects

USACE, ECB-2015-XX (Draft), Selection of Design Earthquakes and Associated Ground Motions, 7 December 2015.

Vucetic, M. and Dobry, R. (1991). Effect of Soil Plasticity on Cyclic Response. Journal of Geotechnical Engineering, ASCE, 117(1), pp. 89-107.

Yu, L., Kong, X., and Xu, B. (2012). Seismic Response Characteristics of Earth and Rockfill Dams, 15th WCEE, Lisbon, Portugal, Paper No.2563, Sept, 2012.

Zhao, J., J. Zhang, A. Asano, Y. Ohno, T. Oouchi, T. Takahashi, H. Ogawa, K. Irikura, H.K. Thio, P.G. Somerville, Y. Fukushima, Y. Fukushima. Attenuation Relations of Strong Ground Motion in Japan Using Site Classification Based on Predominant Period. Bulletin of the Seismological Society of America, Vol. 96, No. 3, 2006, pp. 898-913. 
7.0 APPENDIX - FLAC CODE 
Project Record Tree export

; File:E: \PSU \Final Project\Production Runs \MS PROJ DAM X CODE.dat

;Units: Imperial: foot-slug-second; Date: Jun 11, 2018 4:11:34 PM

; Title: PSU MS PROJ

;Branch 1:GEO.sav

; Silas T. Sanderson, PSU MS Project

; Original Date: 14 May 18

; Model: Dam X

; Purpose: conifigure geometry, load dynamically, assess total vert deformation and embankment response

; Units: ft, s, slugs

config ats gwflow dynamic extra 20 ; configures model for seepage flow, dynamic analysis, and 20 extra variables

set flow off dyn off; set seepage (flow) and dyanmic loading off for intial static analysis

set grav $=32.2$; gravity $32.2 \mathrm{ft} / \mathrm{s} / \mathrm{s}$

water bulk $=0.0$; use 0.0 for initial drained static analysis

water dens $=1.9379 \quad$; water density in slugs/ft3

$----------------------------------------------------------$

; STEP 1 - IMPORT GEOMETRY

--------------

grid 400,110 . define grid for entire

def model_props ; useful routine to quickly calli,j limits

\$JGPMAX = jgp ; 111

\$IGPMAX $=$ igp; 401

\$IGPMIN $=1$

\$JZMAX = jzones $; 110$

\$IZMAX = 1 ;

end

model_props

gen $-1900.0,0.0-400.0,347.0400 .0,347.01900 .0,0.0$ i=1,401 j=16,111; generate embankment elements as a rectangle - element height $=347 \mathrm{ft} / 110=3.15 \mathrm{ft}$

gen $-1900.0,-225.0-1900.0,0.01900 .0,0.01900 .0,-225.0 \mathrm{i}=1,401$ j=1, 16 ; generate bedrock as a rectangle - element height $=225 \mathrm{ft} / 15=15 \mathrm{ft}$

$\mathrm{m}$ mohr

table $1-1900.0,0-653.95,0-12,34712,347619.25,01900.0,0$; top ground surface of embankment

gen table 1 ; mark top of ground surface

m null region 1,50 300,50 ; null region above marked ground surface - this will create triangular elements along the face of the embankment

table $2-162,0-5,3475,347-64.8,0-162,0$; core

table $5-54.8,010.98,32822.2,328153,0-54.8,0$; pit run gravel

gen table 2 ; mark core outline

gen line $-172,0-15.97,344.85 ; \mathrm{u} / \mathrm{s}$ edge of u/s gravel

gen table 5 ; mark pit run gravel outline

; geometry adjustments

gen line $10.98,32814.69,345.46$

ini $x-4.2931657$ y 343.79724 i 199 j 110

ini $x-5.0$ y 347.0 i 198 j 111

ini x 5.0 y 347.0 i 203 j 111

ini $x$ 14.865353 y 345.30142 i 208 j 110

ini $x 10.966295$ y 327.9948 i 205 j 106

ini $x-16.360458$ y 344.58615 i 193 j 110

; assign groups to elements

group 'Gravel' ; assign all to gravel first and then reassign to groups that are better defined

group 'Rockfill' region 143,68 231,68

group 'Core' region 189,65

group 'Pit Run' region 200,70

group 'Foundation' $j=1,15$

group 'Gravel' $i=183 j=16,30$

group 'Gravel' $i=184 j=37,49$

group 'Gravel' $i=185 j=60,63$

group 'Gravel' $i=194 j=16,24$

group 'Gravel' $i=195 j=30,47$

group 'Gravel' $i=196 j=58,62$

group 'Gravel' $i=197 \quad j=110$ 
toading on nodes

ni $x-34.170113$ y 335.0 i 186 j 108

ini x 575.7984 y 24.6 i 265 j 22

save GEO.sav

; Branch 2:STATIC.sav

; Define Boundary Conditions and Initialize Stresses

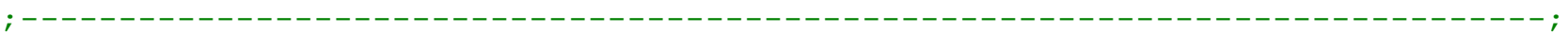

fix $x i=1$; fix the edge of the model in the $x$ dir

fix $x, y=1$; fix the base of hte model in $x$ and $y$ directions

fix $x$ i=\$IGPMAX; fix the other edge of the model in the $x$ dir

history 9999 unbalanced; assign history 9999 to track unbalanced force in model tracking equil

model elastic group 'Foundation' ; make foundation bedrock elastic

call groupPropsGrav.fis ; assign material properties

; Define histories for tracking static analysis

his 1 srat; track solve ratio

; Solve for static stresses

; Divide embankment into 10 equal increments by j zones

ij 16 to 11095 zones - 10 zones in each increment

; 1st lift j 1626

model null i 1 ,\$IGPMAX j 26 , \$JGPMAX

solve elastic

save STATIC.sav

; Branch 3:LIFT_2.sav

; -----------------------

; 2 nd lift j 2636

; ----------------------

m mohr j 26,36

ini ydis $=0.0 \mathrm{xdis}=0.0 \mathrm{xvel}=0.0 \mathrm{yvel}=0.0$

model null region 1,26 400,26

call groupPropsGrav.fis

solve

;----------------------

; 3rd lift j 3646

m mohr j 36,46

ini ydis $=0.0$ xdis $=0.0 \mathrm{xvel}=0.0$ yvel $=0.0$

model null region $1,36400,36$

call groupPropsGrav.fis

solve

;----------------------

; 4 th lift j 4656

;----------------------

$m$ mohr j 46,56

ini ydis $=0.0 \mathrm{xdis}=0.0 \mathrm{xvel}=0.0 \mathrm{yvel}=0.0$

model null region $1,46400,46$

call groupPropsGrav. fis

solve

;----------------------

; 5 th lift j 5666

; ----------------------

$m$ mohr j 56,66

ini ydis $=0.0$ xdis $=0.0 \mathrm{xvel}=0.0$ yvel $=0.0$

model null region $1,56400,56$

call groupPropsGrav.fis

solve

;----------------------

; 6 th lift j 6676

;----------------------

m mohr j 66,76

ini ydis $=0.0$ xdis $=0.0 \mathrm{xvel}=0.0$ yvel $=0.0$

model null region $1,66400,66$

call groupPropsGrav.fis

solve

;-----------------------

; 7 th lift j 7686 
m mohr j 76,86

ini ydis $=0.0$ xdis $=0.0 \mathrm{xvel}=0.0 \mathrm{yvel}=0.0$

model null region $1,76400,76$

call groupPropsGrav.fis

solve

; --------------------

; 8 th lift j 8696

; ---------------------

m mohr j 86,96

ini ydis $=0.0$ xdis $=0.0 \mathrm{xvel}=0.0$ yvel $=0.0$

model null region $1,86400,86$

call groupPropsGrav.fis

solve

; - - -------------------

;9th lift j 96106

; ----------------------

m mohr j 96,106

ini ydis $=0.0 \mathrm{xdis}=0.0 \mathrm{xvel}=0.0 \mathrm{yvel}=0.0$

model null region $1,96400,96$

call groupPropsGrav.fis

solve

; ---------------------

;10th lift j 106116

; --------------------

m mohr j 106,116

ini ydis $=0.0 \mathrm{xdis}=0.0 \mathrm{xvel}=0.0 \mathrm{yvel}=0.0$

model null region $1,106400,106$

model mohr i 191,192 j 109

call groupPropsGrav.fis

solve

save LIFT_2.sav

; Branch 4:RES_1.sav

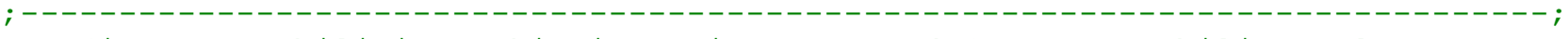

; Define permeabilities, this input is generated from permeabilites.xls

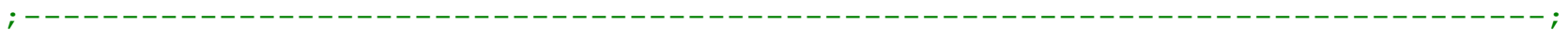

prop k11 2.63E-8 k22 5.26E-8 group 'Core'

prop k11 5.26E-07 k22 $5.26 \mathrm{E}-7$ group 'Gravel'

prop k11 2.63E-05 k22 5.26E-06 group 'Pit Run'

prop k11 2.63E-05 k22 5.26E-06 group 'Rockfill'

prop k11 8.94E-08 k22 8.94E-08 group 'Foundation'

; histories of u/s shell element

his 12 pp $i=168 \quad j=18$

; histories of core element

his $13 \mathrm{pp} \quad i=188 \quad j=16$

his $14 \mathrm{pp} \quad i=190 \quad j=51$

his $15 \mathrm{pp} \quad i=194 j=85$

ihistoires of $\mathrm{d} / \mathrm{s}$ pit run

his $16 \mathrm{pp} \quad i=205 j=16$

his $17 \mathrm{pp} \quad i=205 \quad j=51$

his $18 \mathrm{pp} \quad i=205 j=85$

water bulk = 4200 ; bulk modulus of water (note: can use reduced modulus to speed flow).

Table $10-1900,335-34.2,335-25.0,200.050 .0,24.6619 .25,01900,24.6$; assumed phreatic surface

water table 10 ; apply water table

set funsat on

set flow on; turn seepage flow on

set steps 100000000000

set sratio $=1 e-6$

cycle 1000 ; cycle model to smooth assumed phreatic

save RES_1.sav

; Branch 5:MECH.sav

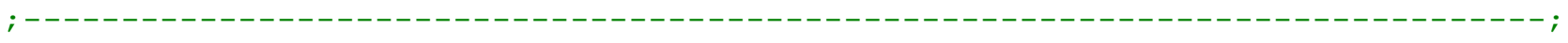

; Apply mechanical force of water

ini xdis 0.0 ydis 0.0 
; Apply reservoir to elevation 1870 (335 FT) down to base of foundation El 1485 (-50) ; d/s groundwater at ground surface el 1535 ( $0 \mathrm{ft})=\mathrm{tw}$ apply pres 24024 var 0,-24024 from 1,16 to 186,$108 ;(1870-1485) * 62.4=24024$ psf Reservoir Loading

set mech on ; turn mechanical on

set flow off; turn seepage off

water bulk 0.0

set step 1000000

solve; solve model

save MECH.sav

;Branch 6:PRE_DY.sav

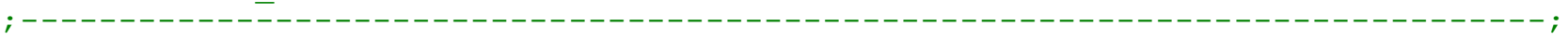

; final dynamic properties

call groupPropsDyn.fis

groupPropsDyn ; update embankment materials for mean eff stress dependence solve

step 1000

ini $x$ disp $=0.0$ ydisp $=0.0$

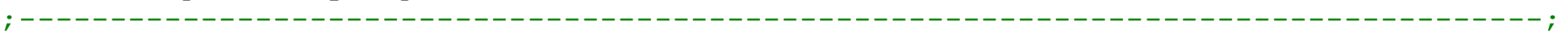

; Prepare for Cycling (Bring to Equilibrium with Final Boundary Conditions)

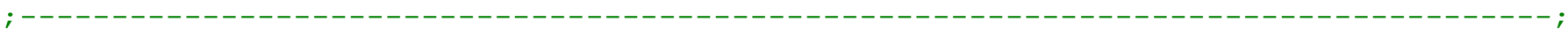

set dyn=on

; Initialize Damping

set dy_damp= combined

; Define Itasca hysteretic damping

call hysdamping.dat; call sig3 damping functions

; Bring to Equilibrium with final fluid modulus

water bulk $=4100000$; increase bulk modulus of water

; call solvefmod5.dat; REQUIRES FMOD5.FIS - NEED TO ADJUST UNITS FOR PSF?

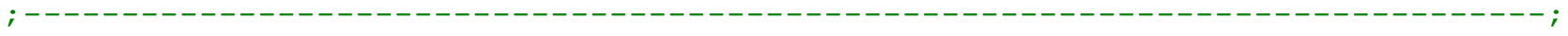

; Apply Free Field and Rigid Boundary Conditions Before Cycling

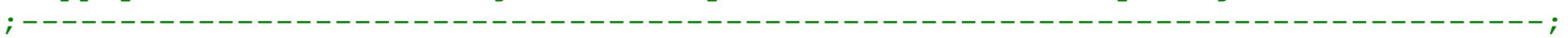

free $\mathrm{x}$

fix $j=1$

apply ff

fix $x$ y $j=1$

solve ; bring to equilibrium

step 1000

initial values of $\mathrm{x}$ - and $\mathrm{y}$-displacements/velocities

ini $x d i s p=0.0$ ydisp $=0.0$

ini $x v e l=0.0$ yvel $=0.0$

solve

ini $x$ disp $=0.0$ ydisp $=0.0$

; Define Time Histories for dynamic analysis

his 2 dytime

his 10 xdis $i=200 \quad j=110$

his 12 xdis $i=200 \quad j=16$

his 11 ydis $i=200 \quad j=110$

his 30 xacc $i=200 \quad j=110$

his 31 xacc $i=188 \quad j=16$

his 33 ydis $i=189 \quad j=16$

his 34 ydis $i=189 j=1$

save PRE_DY.sav

; Branch 7:PRE_CY.sav

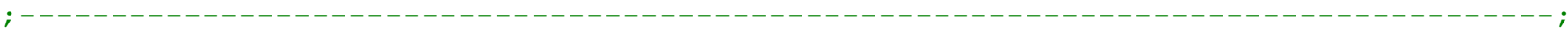

; State 5: Prepare for cycling - Read Earthquake Load

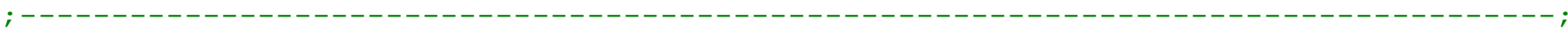

; Prepare to cycle

ini $\mathrm{xdisp}=0.0$ ydisp $=0.0$

ini $x$ vel $=0.0$ yvel $=0.0$

set flow=on mech=on; turn mech and flow on

set dytime $=0.0$; set dytime to 0 = start of record

set large

set step 1000000000

; Set Damping 
set dy_damp=rayleigh $0.01 \quad 1.0$; apply a small amount of damping at the estimated natural frequency to reduce numerical "noise" 


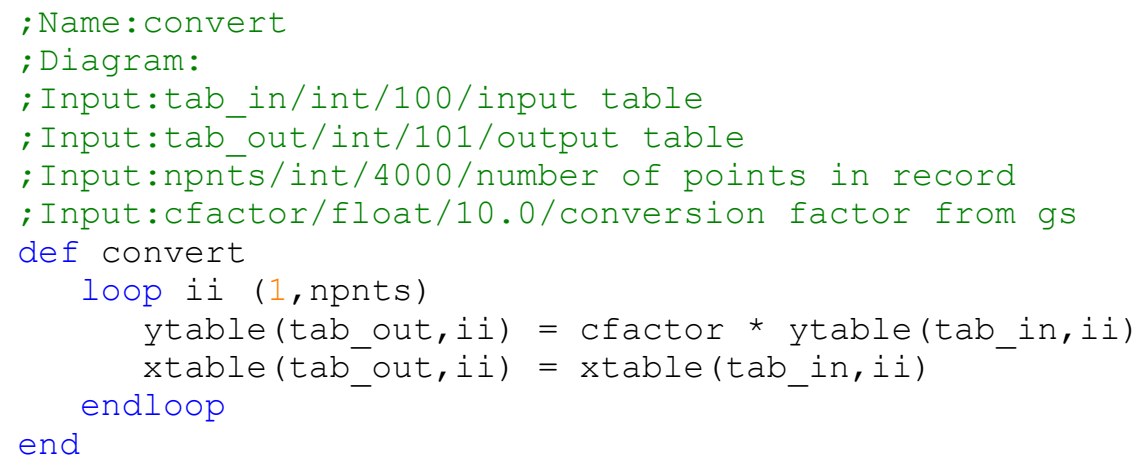


; there are no unit conversions for properties so all units should

; be input to be consistent with input units: ft, s, slugs

; prop dens 3.820 shear=3.61e6 bulk=1.68e7 friction=13.5 cohesion=600 notnull group

'Core'

;prop dens 4.565 shear=1.32e7

iprop dens 4.379 shear $=1.32 \mathrm{e} 7$

iprop dens 4.752 shear $=1.32 \mathrm{e} 7$

$\mathrm{bulk}=2.85 \mathrm{e} 7$

friction $=42.5$

notnull group 'Gravel'

bulk $=2.85$ e 7 friction $=42.5$

notnull group 'Pit Run'

bulk $=2.85 e 7$ friction $=45$

notnull group 'Rockfill'

iprop dens 4.379

shear $=2.72 e 7$

bulk $=3.63 e 7$ notnull group 'Foundation'

set echo off

; function to define properties per group

def grouppropsDyn

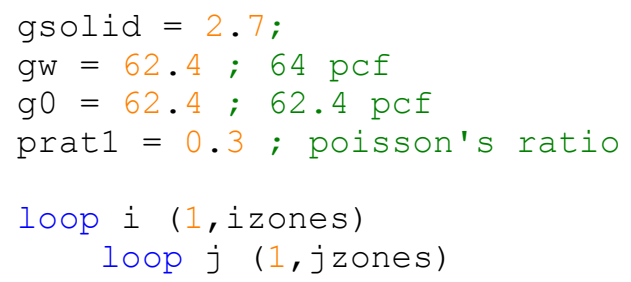

if z_group $(i, j)=$ 'Foundation' then ; 

end if

endif unit weight pof

cohesion $(i, j)=5000$

friction $(i, j)=50$.

; calculate density, moduli, porosity

vratio= (uw/g0-gsolid)/(gw/g0-uw/g0);

porosity $(i, j)=\operatorname{vratio/}(1+\operatorname{vratio})$;

dryden=gsolid*g0/(1+vratio) ;

density $(i, j)=\operatorname{dryden} / 32 \cdot 2$;

dum $=u w / 32.2$;

shear $\bmod (i, j)=\operatorname{vs}^{\wedge} 2 \star d u m ;$

bulk_mod $(i, j)=\operatorname{shear} \bmod (i, j) *(2 \cdot *(1 \cdot+$ prat $)) /(3 \cdot *(1 \cdot-2 \cdot *$ prat $))$; end_loop

end end_loop

groupProps Dyn

set echo on 


\section{; input units: ft, s, slugs}

; parameters needed: dry density, shear modulus, bulk modulus, friction angle, cohesion ; Core: sat UW $=123$ pcf, dry UW $=95$ pcf, Gmax $=600$ Su, Poisson's ratio =

$0.4, \mathrm{Su}=600$ psf, phi $=13.5$

0.3 , phi= 42.5 deg

; Bedro

0.2 , elastic model

friction $=42.5$

friction $=42.5$

friction $=45$ friction=13.5 cohesion=600 notnull group

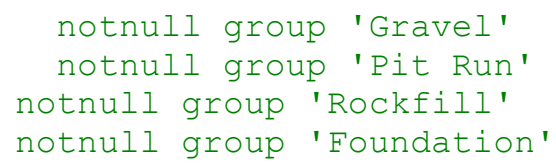

; function to define properties per group

def groupPropsGrav

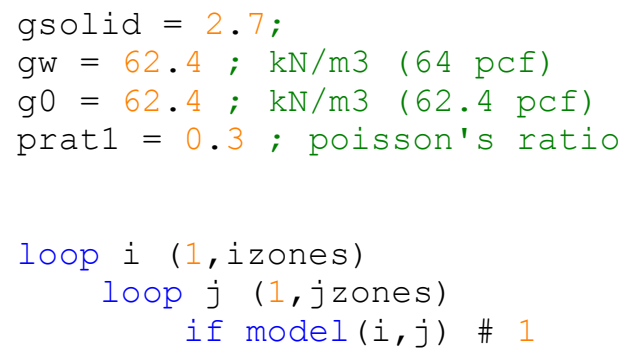




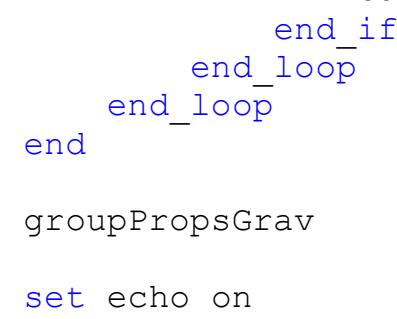


; hysdamping · dat

ini dy_damp hyst sig3 $1.02-0.60-1.80$ group 'Rockfill' ; from fitting Gazetas (1992) rockfilil curve

ini dy_damp hyst sig3 1.014-0.4792 -1.15 group 'Pit Run' ; from fitting EPRI 50-120 ft ini dy_damp hyst sig3 1.014-0.4792-1.15 group 'Gravel' ; from fitting EPRI 50-120 ft ini dy_damp hyst sig3 1.014-0.52 -1.22 group 'Gravel' ; from fitting Vucetic-Dobry (1991) $\mathrm{PI}=15$ 


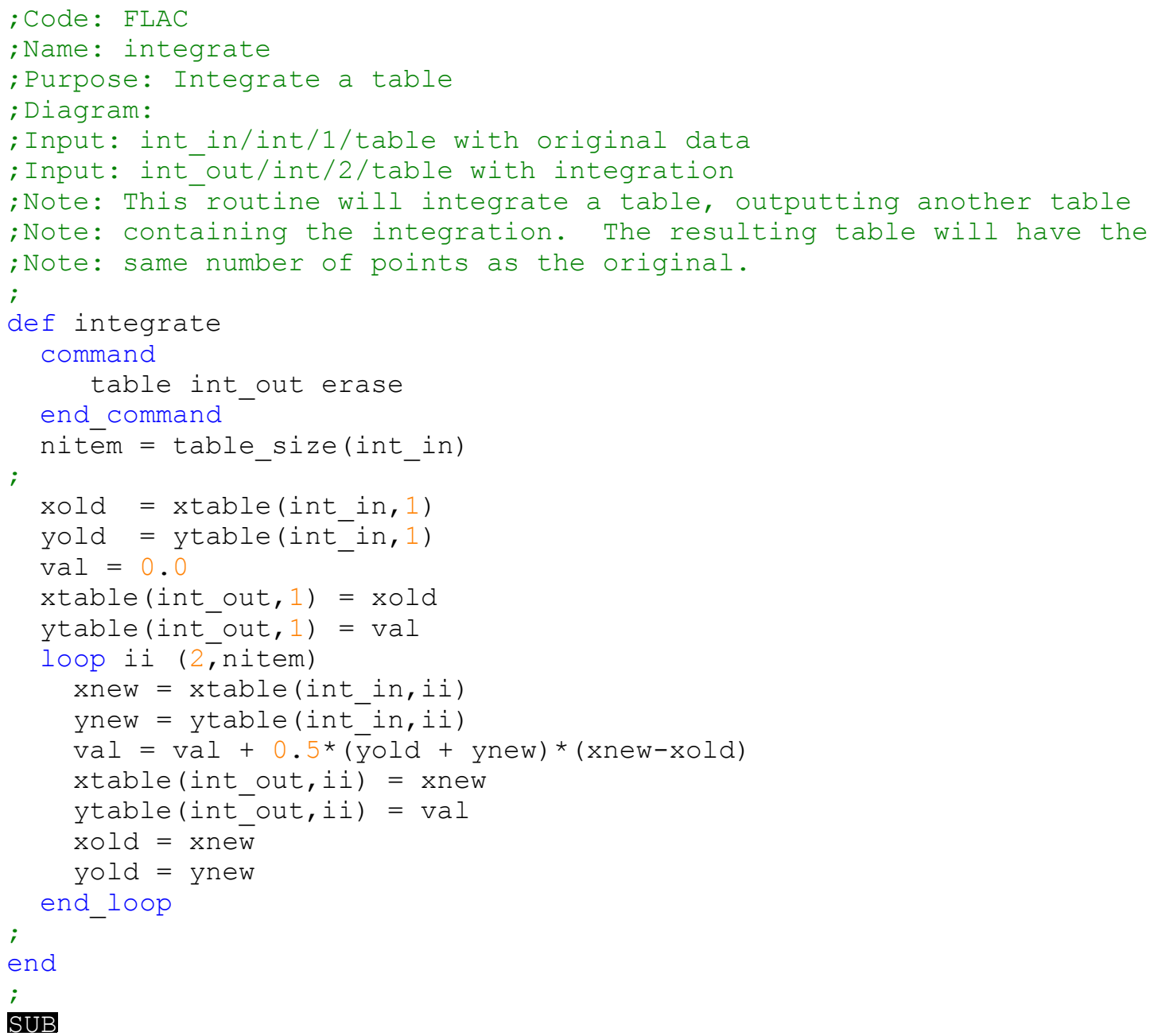

